Portland State University

PDXScholar

3-29-1990

\title{
The Effect of Hot Dense Hydrogen and Argon in a Ballistic Compressor on the Structure and Composition of Pure Iron
}

David Samuel Silver

Portland State University

Follow this and additional works at: https://pdxscholar.library.pdx.edu/open_access_etds

Part of the Physics Commons

Let us know how access to this document benefits you.

\section{Recommended Citation}

Silver, David Samuel, "The Effect of Hot Dense Hydrogen and Argon in a Ballistic Compressor on the Structure and Composition of Pure Iron" (1990). Dissertations and Theses. Paper 4139.

https://doi.org/10.15760/etd.6022

This Thesis is brought to you for free and open access. It has been accepted for inclusion in Dissertations and Theses by an authorized administrator of PDXScholar. Please contact us if we can make this document more accessible: pdxscholar@pdx.edu. 
AN ABSTRACT OF THE THESIS OF David Samuel Silver for the Master of Science in Physics presented March 29, 1990.

Title: The Effect of Hot Dense Hydrogen and Argon in a Ballistic Compressor on the Structure and Composition of Pure Iron.

APPROVED BY THE MEMBERS OF THE THESIS COMITTEE:
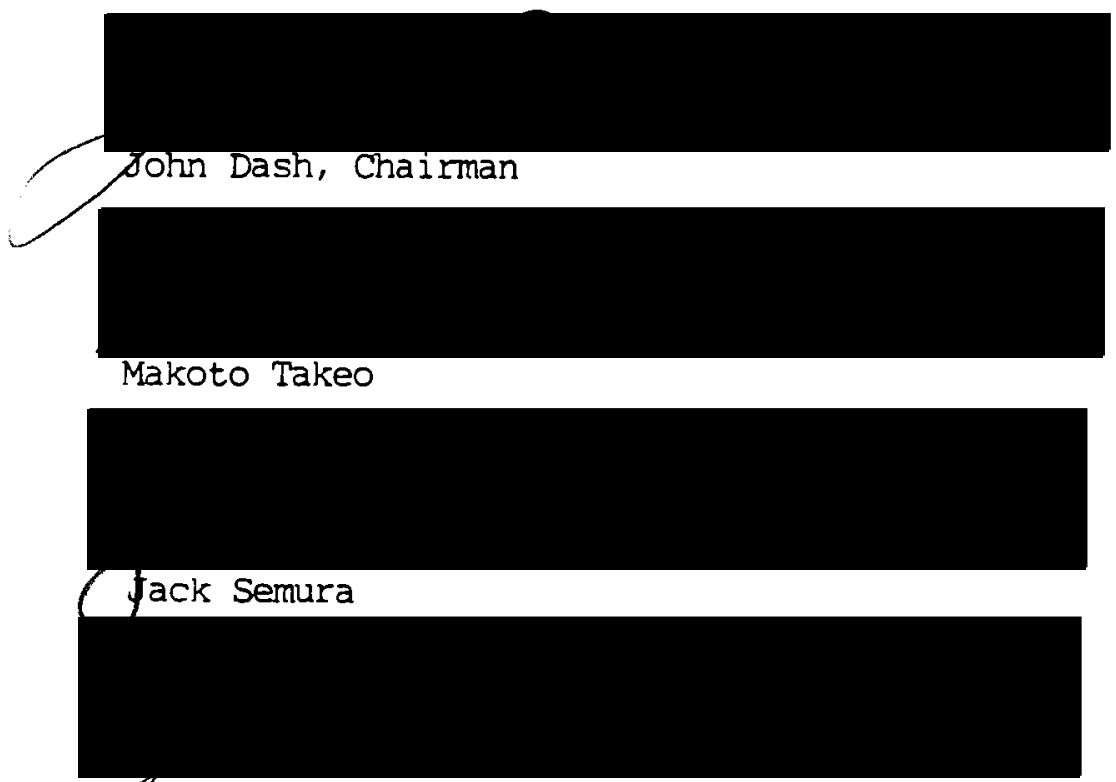

Marvin Beeson

An experimental study of pure iron foil exposed to a hot, dense hydrogen and argon gas mixture in a ballistic compressor yielded evidence of structural and compositional changes of the metal due to the presence of the hydrogen gas. Three iron foils have been compared, one of unexposed pure iron, another of pure iron exposed to a mixture of 
hydrogen and argon gas, and the third of pure iron exposed to argon alone. Exposure to these high temperature, high pressure gases took place in a ballistic compressor.

Line formations were found on the surface of the iron foil exposed to both hydrogen and argon. These appeared as ' $V$ '- or ' $W$ '-shaped configurations, giving the appearance of a serrated edge. Such lines were not found for the other two iron foils. Characteristic peaks of energy dispersive $x$-ray spectra yield different surface concentrations of oxygen when each iron foil sample is compared. This concentration is much less for iron foil exposed to both hydrogen and argon gases than for the other two samples. Also a larger carbon peak was found for the former sample, when compared to the latter two. A shift in the $200 \mathrm{x}$-ray diffraction peak by one degree $2 \theta$ was observed for the sample exposed to hydrogen and argon, and a 'triple' peak was observed for the 310 plane for the same iron sample. 
THE EFFECT OF HOT DENSE HYDROGEN

AND ARGON IN A BALLISTIC COMPRESSOR

ON THE STRUCTURE AND COMPOSITION OF PURE IRON

by

DAVID SAMUEL SILVER

A thesis submitted in partial fulfillment of the requirements for the degree of

MASTER OF SCIENCE

in

PHYSICS

Portland State University

1990 
TO THE OFFICE OF GRADUATE STUDIES:

The members of the Committee approve the dissertation of David Samuel Silver presented March 29, 1990.
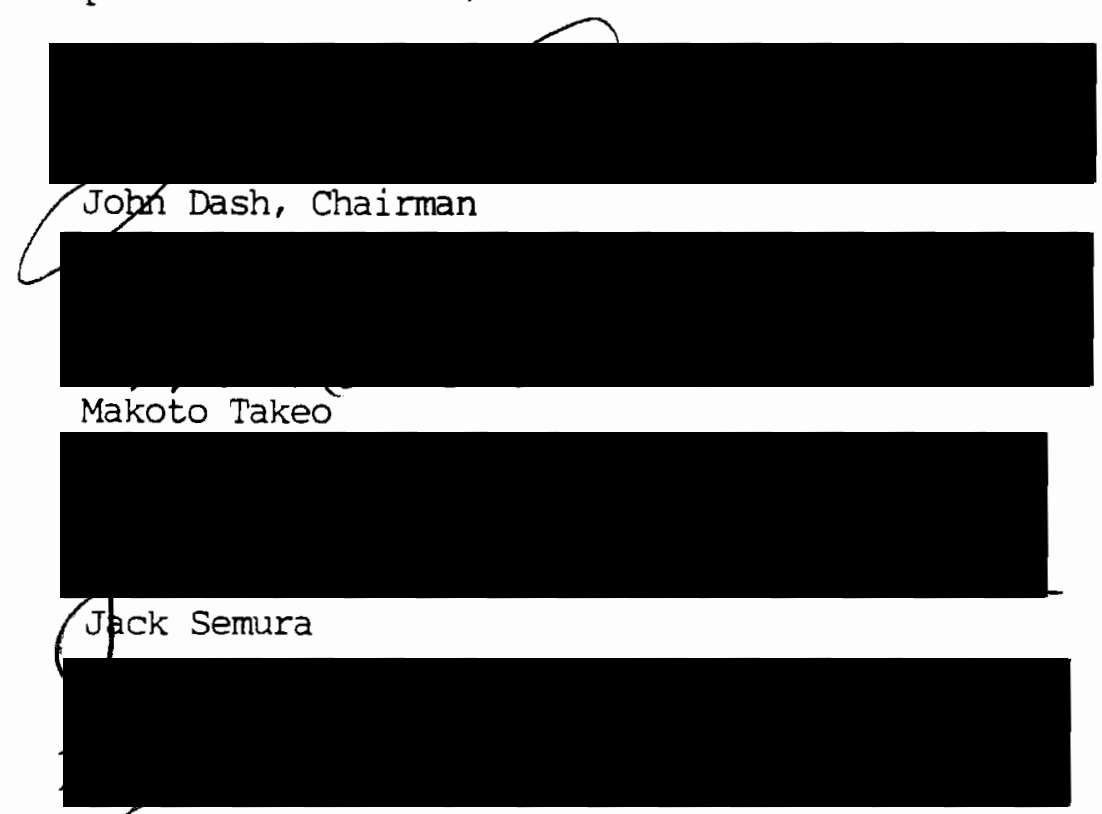

Marvin Beeson

APPROVED:

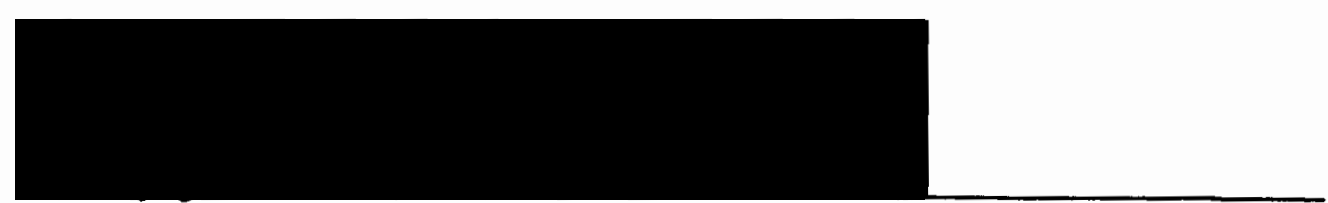

Makoto Takeo, Chair, Department of Physics

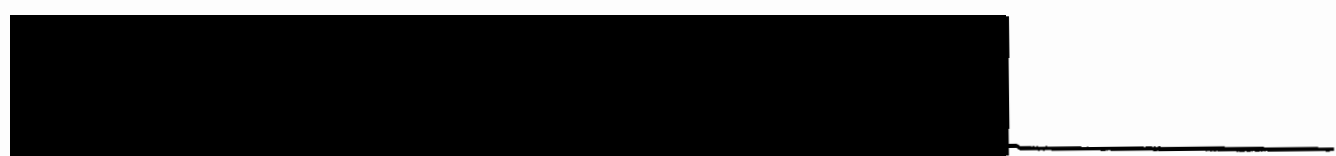

C. William Savery, Interim 7 ce Provost for Graduate Studies and Research 


\section{ACKNOWLEDGEMENTS}

I express gratitude towards Dr. John Dash for his support and his patience during the completion of this work. Through his direction I was able to maintain a proper perspective of, and a sense of scientific involvement with, my subject at hand. I also appreciate his support when outside influences often constrained my time.

I also give thanks to Dr. M. Takeo for aiding me with the creation of my new samples using the ballistic compressor. 
TABLE OF CONTENTS

PAGE

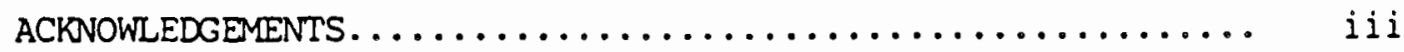

LIST OF TABLES $\ldots \ldots \ldots \ldots \ldots \ldots \ldots \ldots \ldots \ldots \ldots \ldots \ldots \ldots \ldots \ldots \ldots$

LIST OF FIGURES $\ldots \ldots \ldots \ldots \ldots \ldots \ldots \ldots \ldots \ldots \ldots \ldots \ldots \ldots \ldots \ldots \ldots \ldots$

INTRODUCTION..................................

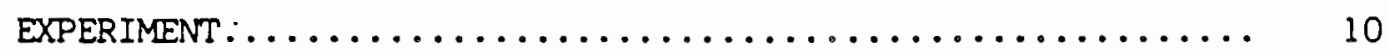

RESULTS AND DISCUSSION........................ 23

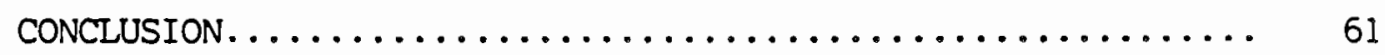

SELECTED BIBLIOGRAPHY.......................... 63 APPENDICES

A ELECTRON DIFFRACTION...................... 65

B THIN IRON FILM SAMPLE FRAMES............... 68 


\section{LIST OF TABLES}

TABLE

PAGE

I Accepted Values of BCC Iron................ 29

II Iron Unexposed...................... 32

II Iron Exposed to Argon Alone (Reverse Side)....... 33

IV Iron Exposed to Hydrogen and Argon............ 34

$\mathrm{V}$ Iron Exposed to Hydrogen and Argon (Reverse Side, Repositioned)........................... 35

VI Comparison of $2 \theta$ and $I / I_{1}$ values............ 36 


\section{LIST OF FIGURES}

FIGURE

PAGE

1. BCC Structure (left) and FCC Structure (right).......6

2. An Alloy of Iron and Titanium................ 8

3. Hydrogen Solubility in Iron as a Function of Temperature. 9

4. Diagram of the Ballistic Compressor.............. 13

5. Magnet System and Water Pump Used to Thin Iron

Iron Specimens...................... 16

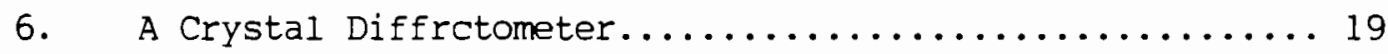

7. Diffraction Pattern of Unexposed Iron.............. 24

8. Ribbon-1ike Microstructure of Unexposed Iron.......... 25

9. Deformation and Ribbon-like Cells............... 26

10. Zone-refined Iron Specimen after Grain Growth.......... 26

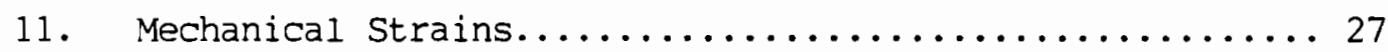

12. A Triple Peak and a Double Peak................. 31

13. Three Diffraction Charts Made From the X-ray

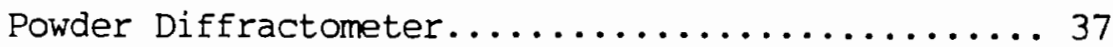

14. Iron Not Exposed........................ 39

15. Iron Not Exposed................................

16. Siip-bands........................... 40

17. Broadened slip-bands...................... 40

18. Neumann's Bands.......................... 42

19. Photograph of Neumann's Band................... 42

20. Iron Exposed to Hydrogen and Argon...............43 
21. Iron Exposed to Hydrogen and Argon..............43

22. Iron Exposed to Hydrogen and Argon............. 45

23. Iron Exposed to Hydrogen and Argon............. 45

24. Iron Exposed to Hydrogen and Argon..............49

25. Iron Exposed to Hydrogen and Argon.............49

26. Iron Exposed to Hydrogen and Argon............ 50

27. Iron Exposed to Hydrogen and Argon.............. 50

28. Iron Exposed to Argon Alone................. 51

29. Iron Exposed to Argon Alone................. 51

30. Iron Exposed to Argon Alone................ 52

31. Iron Exposed to Argon Alone................. 52

32. Spectrum of Iron Unexposed................. 54

33. Spectrum of Iron Unexposed................ 56

34. Spectrum of Iron Unexposed................ 56

35. Spectrum of Iron Exposed to Hydrogen and Argon...... 57

36. Spectrum of Iron Exposed to Hydrogen and Argon...... 57

37. Spectrum of Iron Exposed to Hydrogen and Argon...... 58

38. Spectrum of Iron Exposed to Hydrogen and Argon...... 58

39. Spectrum of Iron Exposed to Hydrogen and Argon...... 58

40. Spectrum of Iron Exposed to Argon Alone........... 59

41. Characteristic Peak Counts................. 60

42. Scattered Beam From Atomic Planes to Target........66 66 


\section{INTRODUCTION}

Hydrogen is the most abundant element in the universe. There is hope that hydrogen might be able to replace petroleum as an economic fuel source one day. Hydrogen, colorless and flammable, occurs first on the periodic table and has an atomic number of one, and an atomic weight of 1.00797 . Its melting point is $-259.14^{\circ} \mathrm{C}$, and its boiling point is $-252.5^{\circ} \mathrm{C}$. Natural hydrogen occurs as a mixture of two isotopes: light hydrogen, and deuterium (heavy hydrogen), the latter containing a neutron within its nucleus. The two isotopes exist together with a ratio of 5000:1. A third isotope, tritium, occurs in small amounts and is radioactive with a half life of about 12.5 years. Hydrogen is used in petroleum refining, and in rockets as a fuel agent.

To serve the industrial and consumer needs of the world, hydrogen must be separated from other elements that almost always occur with it. The industrialized world is strongly motivated to make hydrogen a fuel source because it has the highest density of energy per unit weight of any chemical fuel. It is also a nonpollutant.

Some pure metals, such as magnesium and vanadium, can form metal hydrides, typically represented as

$$
\mathrm{M}+\mathrm{H}_{2} \rightleftharpoons \mathrm{MH}_{2} \text {, where } \mathrm{M} \text { is a metal. }
$$

Reilly and Sandrock (1) report that the above reaction is reversible, that at a certain level of pressure of hydrogen gas, the reaction proceeds forward, forming a metal hydride. If the pressure of hydrogen gas is taken below this level, then the metal hydride decomposes into 
the metal and hydrogen gas. This level is termed the equilibrium pressure. Reilly and Sandrock indicate that the stability of a hydride depends upon the ease or difficulty of taking hydrogen out of the compound. A property that exists for a metal hydride is its heat of formation, the heat given off when the hydride is actually being formed when hydrogen reacts with the metal. To decompose the hydride back into hydrogen gas and metal, the same amount of heat must be returned to the compound, this being its heat of decomposition. A stable hydride will have a high heat of decomposition (1).

At high pressures and temperatures, hydrogen molecules, $\mathrm{H}_{2}$, split up into atomic form, $\mathrm{H}$, and diffuse into interstitial sites nf the metal lattice. Hydrogen can therefore be stored in great amounts.

This report examines pure iron that has been subjected to hydrogen gas at high temperatures and pressures. M. Takeo and co-workers (2) have been investigating the possibility of producing iron hydride from the pure iron state. Their paper reports an observation of small, rhombic particles oriented in nearly the same direction, each about the size $500 \AA$ by $1000 \AA$, on transmission electron microscope micrographs. These particles were found in a thin iron sample sandwiched in a folding Mo grid after exposure in a ballistic compressor to a mixture of argon and hydrogen (about $16 \%$ by volume) at $118 \mathrm{~atm}$. and $1400^{\circ} \mathrm{C}$ for about a millisecond. The appearance of these particles suggested the presence of a second phase. The report explains that an energy dispersive $x$-ray spectrometer (EDS) with a thin film window indicates that these particles have the same composition as the background matrix, and since the spectrometer cannot detect hydrogen, but can detect elements down to atomic 6 , the presence of contamination or impurities is unlikely. 
Another observation on the possible presence of iron hydride crystals was made by V. E. Antonov and co-workers (3), who claim to have obtained iron hydride under a pressure of 64,000 atm. at a temperature of $250 \mathrm{C}$. They reported that the crystal lattice is hexagonal close-packed (hcp), but that all the hydrogen in the hydride escaped when the pressure was reduced to one atmosphere. The crystal structure then transformed itself back to its original lattice form, body-centered cubic (bcc). Takeo and co-workers apparently did not have this problem, possibly due to the difference in type of specimen.

Takeo et al. reported that the observed d-spacings and angles of the crystal structures of the particles yielded different values than those for the surrounding bcc structure. To show that hydrogen is present within these particles by experimental methods is difficult, however. The particles exist on a small scale.

These authors subseguently prepared five iron samples for further study. These were iron foils with dimensions of $20 \mathrm{~mm}$ by $35 \mathrm{~mm}$ with a thickness of 40 micrometers, after being cold-rolled from $100 \mathrm{~mm}$ thickness and annealed. Each of these specimens was spot welded to a stainless steel frame (about 0.15\% carbon, 11.5-13.5\% chromium, and the remaining, iron). In the ballistic compressor, the samples were attached, one by one, to the piston head with the sample face perpendicular to the front surface of the piston head. These were then fired in a gas mixture that contained $30-40 \%$ hydrogen, and the rest, argon, at $460 \pm 20$ atm. and 2000-2300 K. Afterwards, the hydrogen concentration of the samples was determined using a $7.5 \mathrm{MeV}$ beam of $15_{\mathrm{N}}$ ions over a $0.3 \mathrm{~cm}^{2}$ area of each (nuclear reaction between nitrogen nuclei and protons (2)). The 
data recorded (using a scintillation detector) for the first 60 seconds indicated that the hydrogen concentration was about $1.8 \times 10^{20} \mathrm{H}$ atoms per $\mathrm{cm}^{3}$ when averaging over all five samples. A control sample measured under the same conditions and at the same time gave an order of magnitude smaller concentration.

If iron and hydrogen were to form a compound, the hydrogen atoms would then be located within specific interstitial sites of the iron crystal structure. For the bec lattice, two types of interstitial sites are 1) tetrahedral site (T-site), and the 2) octahedral site (0-site). The T-site, surrounded by four atoms at equal distances, has a radius of $0.36 \AA$ for iron, while the O-sites, surrounded by six atoms, two being nearer than the other four, has a radius of $0.19 \AA$ for iron (2). Every simple bcc metal has 12 tetrahedral sites and six octahedral sites for each unit cell. The o-site tends to be favored over the T-site in metals for hydrogen occupancy (2). Takeo et al. report on a model for iron hydride based upon this assumption.

Iron infused with hydrogen in its 0 -sites is expected to expand or become distorted, at least along one of its crystal axes. Crystal anqle distortions are possible also.

F. Schreyer and co-workers (4) reported on the implantation of hydrogen into thin iron films at liquid nitrogen temperature, and that Mossbauer spectroscopy was used to study the implanted targets without any intermediate warming of the samples. They had used high doses of 18 and $24 \mathrm{keV} \mathrm{H} \mathrm{H}_{2}$ ions that were implanted into the alpha-iron films, and their experiments revealed the formation of a new component on these samples. The Mossbauer parameters suggested to them that part of their 
samples had been converted to the hydride that Antonov and co-workers had described. Liquid nitrogen temperature was used because Antonov and co-workers produced stable iron hydride at this temperature. At ambient laboratory temperature and one atmospheric pressure, the iron hydride reverted back to alpha-iron.

The primary purpose of the present study was to search for differences in morphology and structure between pure iron and iron exposed to a mixture of hot, dense argon and hydrogen gas, and for other possible indicators that lead to proof that iron hydride does, or does not, exist. This report presents possible evidence that favors its existence. Tools used for this study included a metallurgical microscope, a transmission electron microscope, an x-ray diffractometer, and a scanning electron microscope with an energy dispersive x-ray spectrometer attached.

Iron, a soft and malleable material, exists in three allotropic forms (four when beta-ferrite is included): 1) alpha-ferrite, or alphairon, which is stable at room temperature and has a bec structure up to $906^{\circ} \mathrm{C}$. Beta-ferrite exists at $769^{\circ} \mathrm{C}$ to $906^{\circ} \mathrm{C}$, and is often classified as a form by itself since at $769^{\circ} \mathrm{C}$, pure iron loses its ferromagnetic properties. Below this temperature iron is ferromagnetic. 2) Gamma-ferrite, or gamma-iron, which exists between $906^{\circ} \mathrm{C}$ and $1404^{\circ} \mathrm{C}$ and is fCC; 3) delta-ferrite, or delta-iron, which exists above $1404^{\circ} \mathrm{C}$ in the bcc structure (5). Delta-iron is stable up to the melting point of iron, which is $1535^{\circ} \mathrm{C}$.

The volume of iron undergoes critical changes as it makes its transition from bcc to fcc and back to bcc again. These changes are 
due to differences in atomic packing between the bcc and the fcc structure. The unit cell of the space lattice of alpha-iron and delta-iron consists of a total of 2 atoms, each corner atom equaling $1 / 8$ of an atom (a corner atom is shared by 8 other unit cells), and the center atom counts as one. The unit cell of the space lattice of gamma-iron consists of 4 atoms ( 6 face centers counts as $1 / 2$ an atom, and the other atoms in the unit cell are corner atoms). The size of each unit cell lattice at a particular temperature is given below (5):

$\begin{array}{llll}\text { Alpha-iron } & \text { BCC } & \text { Temp. }=16^{\circ} \mathrm{C} & \text { Side }=2.86 \dot{A} \\ \text { Beta-iron } & \text { BCC } & \text { Temp. }=800^{\circ} \mathrm{C} & \text { Side }=2.90 \dot{A} \\ \text { Gamma-iron } & \text { FCC } & \text { Temp. }=1000^{\circ} \mathrm{C} & \text { Side }=3.60 \dot{A} \\ \text { Delta-iron } & \text { BCC } & \text { Temp. }=1425^{\circ} \mathrm{C} & \text { Side }=2.93 \dot{A}\end{array}$

The lattice structure is shown in Figure 1. Two bcc unit cells makes one fcc unit cell during a phase transformation since the first unit cell consists of two atoms whereas the second unit consists of four. The volume of a beta-iron unit cell at $800^{\circ} \mathrm{C}$ is $(2.9 \dot{A})^{3}=24.39 \dot{A}^{3}$, and the volume of a garma-unit cell at $1000^{\circ} \mathrm{C}$ is $(3.6 \dot{A})^{3}=46.66 \dot{\mathrm{A}}^{3}$. Two beta-iron unit cell volumes are $48.78 \hat{A}^{3}$; therefore, upon heating iron from $800^{\circ} \mathrm{C}$ to $1000^{\circ} \mathrm{C}$, the volume decreases by about $4.3 \%$.
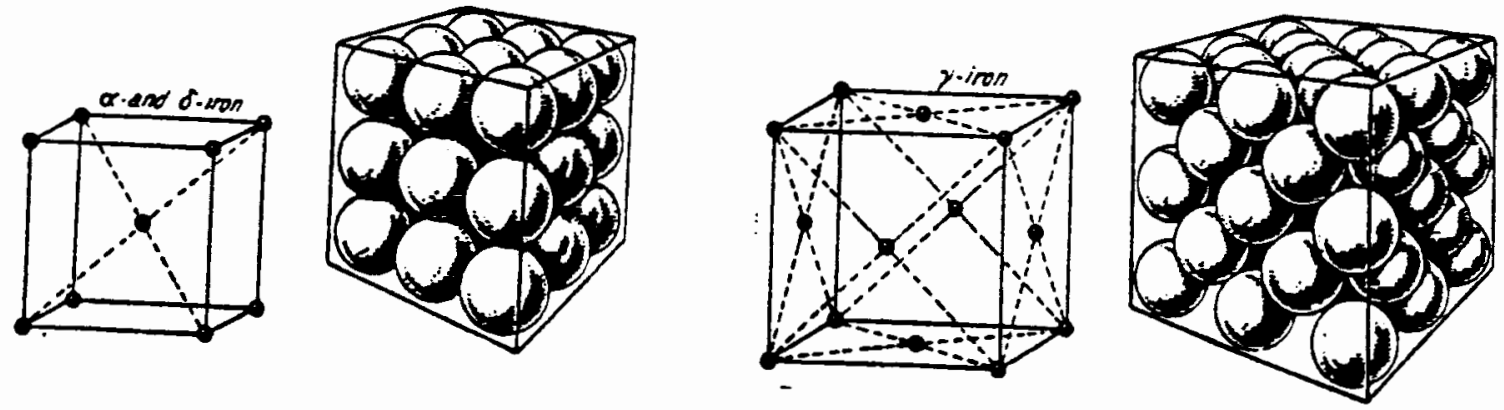

Figure 1. BCC structure (left) and FCC structure (right). 
The trapping of hydrogen may occur at trapping sites, such as, ivoids, boundaries, dislocations, impurity atoms, and possibly within microvoids that may be produced by annealing, as suggested by Kumnick and Johnson (6), particularly for thin iron foils. Impurities sojourn along grain boundaries, but whether hydrogen is trapped along here also is unclear.

Volume expansion and new surface exposure resulted in partially hydrided particles of an alloy of iron and titanium for Sandrock (1). Figure 2 illustrates this occurrence. According to Sandrock, hydriding pure iron-titanium for the first time is difficult because of the presence of a 'surface barrier'. This barrier is broken down when the alloy is heated in the presence of low-pressure hydrogen to about $400^{\circ} \mathrm{C}$ (other gases must be absent). Then after cooling it to room temperature, it will react with hydrogen easily. In the absence of air, hydrogen reacts with the alloy, even at ambient temperature, if the alloy contains 5 percent manganese. Hydriding reactions begin at the surface and penetrate it, developing cracks and exposing more surface area, thus creating more hydriding reaction upon repeated cycles of hydriding and dehydriding.

Data exists for the temperature variation of the solubility of hydrogen in iron in an equilibrium with $\mathrm{H}_{2}$ gas at atmospheric pressure. Measurements have been made for both single-crystal samples and polycrystalline samples. Data (Figure 3) plotted for solubility versus temperature (7) for well-annealed iron, by various investigators, are generally in good agreement with each other. A plot of $\theta$ versus $1 / T$ for bec iron, where $\theta$ is the atomic ratio of hydrogen dissolved, shows 


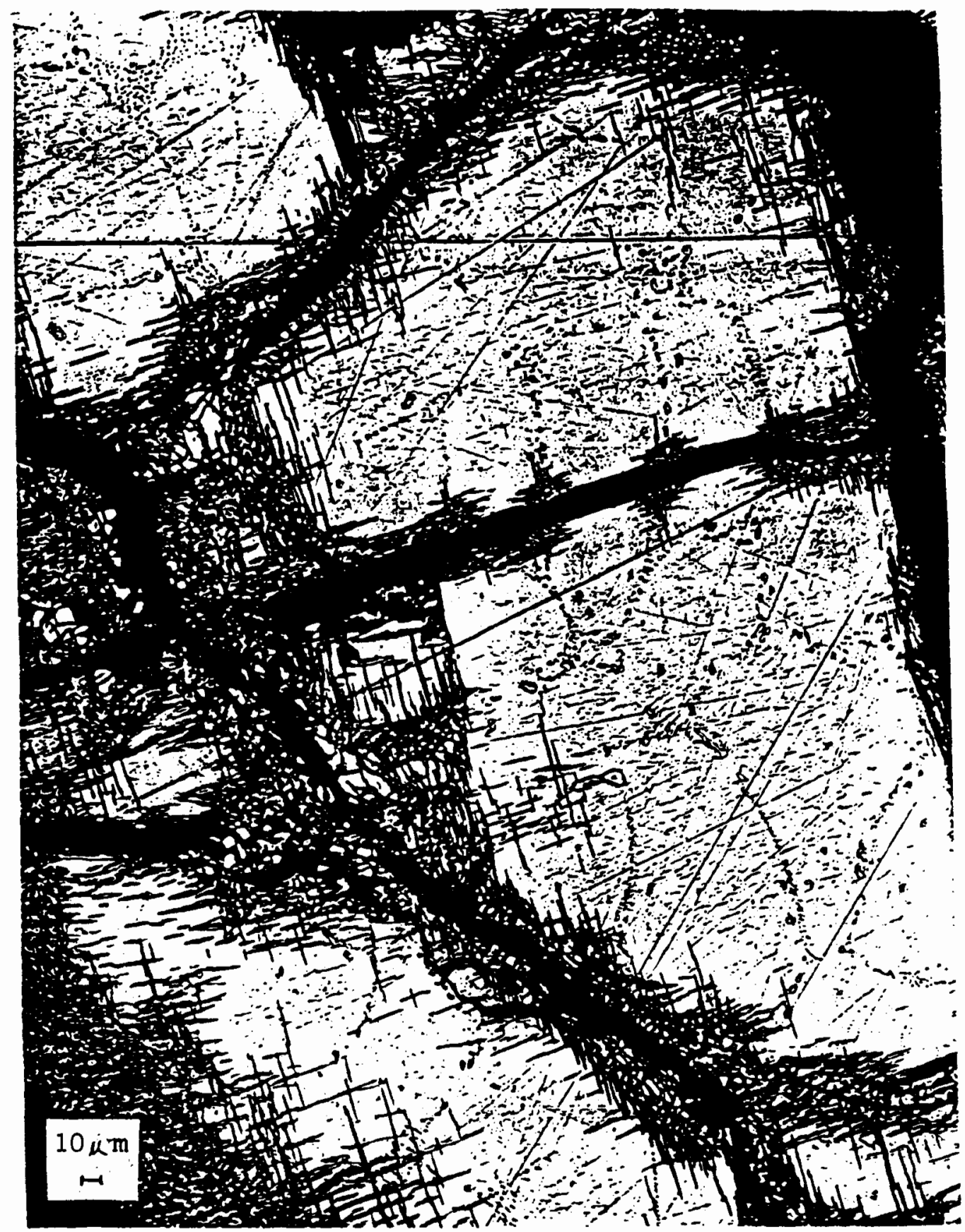

Figure 2. An alloy of Iron and Titanium. This alloy contains particles that are hydrides (both metals exist in equal amounts). This metallographic cross section illustrates particles that are cracked due to stresses caused by hydrogen infiltration into the metal, resulting in volume expansion. As more cracks develop, new surface areas are exposed. Magnification is roughly $300 \mathrm{X}$ (1). 
nonlinearity, and thus has created considerable confusion. The plot for hydrogen solubility depicts $\mathrm{H}$ solubility in the three allotropic forms of iron. The measurements of several investigators are combined in this plot to show the relative conformity with one another. DaSilva and coworkers (7) used iron samples in the form of cylinders and equilibrated them in a stream of pure hydrogen gas (99.9995\%). Three different samples were used to measure the H solubility; one was a single crystal, another was the same crystal treated to produce a polycrystalline sample, and a third was a very pure polycrystalline sample. These are marked as "our data" in the plot, and have the corresponding symbols: $\theta, 0, \theta$. According to DaSilva et al. the purity of the iron does not affect the $\mathrm{H}$ solubility of iron, at least from the alpha/garma transformation down to $350^{\circ} \mathrm{C}$. Their solubility data obtained for single and polycrystalline samples are in good agreement. Grain boundaries appear to have little influence on the $\mathrm{H}$ solubility of iron.

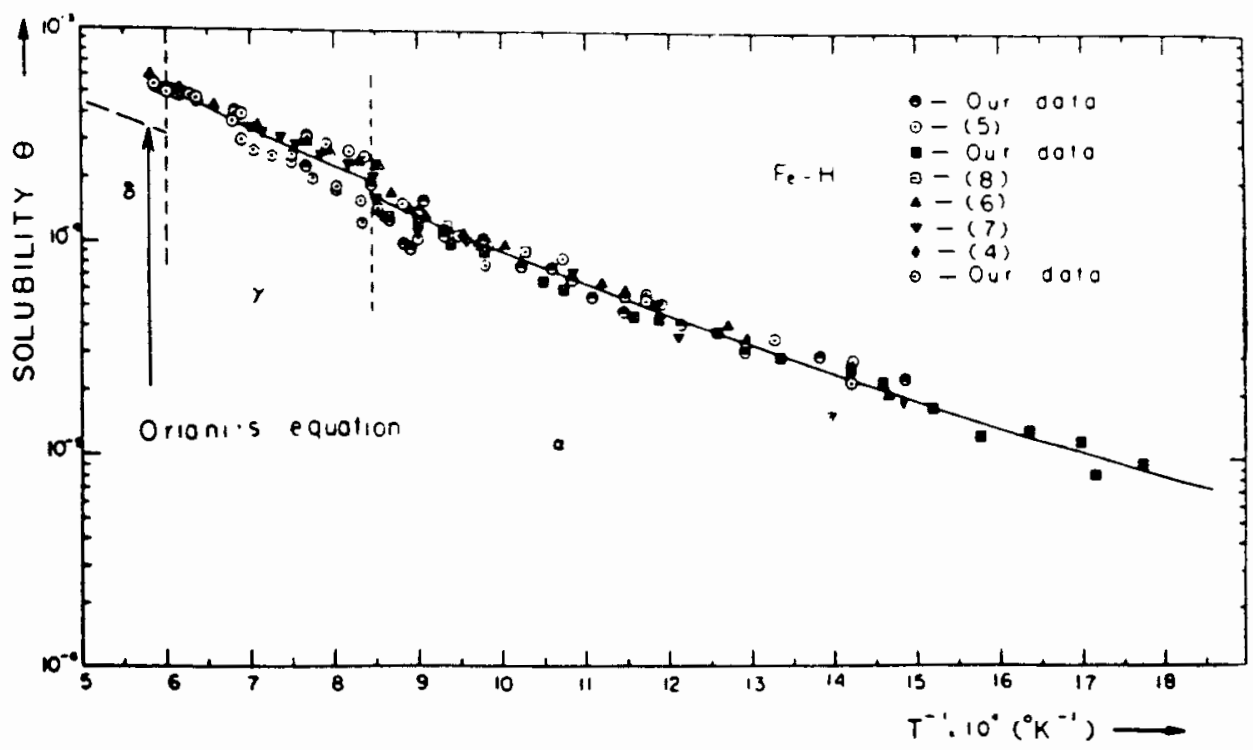

Figure 3. Hydrogen solubility in iron as a function of temperature. $\theta$ is the atomic ratio of hydrogen dissolved, and it is dimensionless. 


\section{EXPERIMENT}

This research was wholly dependent upon a ballistic compressor, which was used to create a hot, dense gas that could react with iron samples. The iron samples were mounted on a piston head within the ballistic compressor and were subjected to either a mixture of hydrogen and argon gases or just argon alone at high temperatures and pressures. The gas was compressed for no more than a millisecond with a cooling rate of about $10^{5} \mathrm{~K} / \mathrm{sec}$.

Analyses of exposed iron samples began with M. Takeo's already prepared five samples, which were called $1,2,3,4$, and 5 dots. These samples were thinned to less than $40 \mu \mathrm{m}$ by alternately coldrolling and annealing at $700^{\circ} \mathrm{C}$ in a vacuum, followed by cooling in a vacuum, which measured to be about $1.3 \times 10^{-6}$ to $1.3 \times 10^{-7} \mathrm{~atm}$, according to M. Takeo. These samples, spot welded on stainless steel frames, were exposed to hydrogen concentrations of 30 to $40 \%$, and the remainder, argon, an inert gas. They were subjected to about $460 \pm 20$ atm. pressure at about $2000 \pm 100^{\circ} \mathrm{C}$.

Upon visual eye examination of these samples, a 'wax-like' film was found spread over each, and when placing one of them, 5 dots, under a metallurgical microscope, details, such as crystal boundaries, were missing due to this 'wax-like' substance. Visualization of the iron surface using the SEM was difficult at best; there was a build up of charge over this wax-like substance and over particles scattered about. 
The energy dispersive $x$-ray spectrometer indicated that these particles were composed of silicon. M. Takeo stated that at the time of firing these samples, a small window had broken due to the high pressures created by the compression within the ballistic compressor, that the chamber of the compressor had become 'dirty' with foreign materials. Also he mentioned a copper wire that may have been vaporized within the chamber. This probably was the source of copper peaks on EDS charts.

At this point studies of these iron samples were discontinued and new iron foil samples were prepared in the ballistic compressor, after cleaning the chamber of foreign materials.

The overall plan was to investigate three different types of samples and make comparisons. These samples were:

1) Sample one: iron exposed to hydrogen and argon

2) Sample Two: iron exposed to argon alone

3) Sample three: iron unexposed

With these three samples, investigation could determine whether hydrogen affects the iron foils uniquely. Details for preparation of samples are:

IRON EXPOSED TO HYDROGEN AND ARGON:

$\begin{array}{ll}\text { Time of Firing: } & 11: 55 \text { AM, 26 January } 1989 \\ \text { Percent Hydrogen: } & 38.4 \% \\ \text { Temperature: } & 2300 \mathrm{~K} \\ \text { Pressure: } & 466 \text { atmospheres } \\ \text { Dimensions: } & 10 \mathrm{~mm} \text { by } 10 \mathrm{~mm} \text { iron foil }\end{array}$

IRON EXPOSED TO ARGON ALONE:

$\begin{array}{ll}\text { Time of firing: } & 11: 50 \mathrm{AM}, 31 \text { January } 1989 \\ \text { Percent Argon: } & 100 \% \mathrm{~K} \text { (desired: } 2300 \mathrm{~K} \text { also) } \\ \text { Temperature: } & 3000 \mathrm{~K} \text { (despheres } \\ \text { Pressure: } & 387 \text { atmosph } \\ \text { Dimensions: } & 10 \mathrm{~mm} \text { by } 10 \mathrm{~mm} \text { iron foil }\end{array}$

IRON UNEXPOSED:

Dimensions:

$10 \mathrm{~mm}$ by $10 \mathrm{~mm}$ iron foil $(99.997 \% \mathrm{Fe})$ 
Each sample was spot welded on a $2 \mathrm{~mm}$ stainless steel frame with a composition similar to each of those made for samples 1 through 5 dots.

The ballistic compressor was allowed to cool for several days after each firing. The pressure of the compressed gas was read from the output of a transducer, and the temperature was determined by a computer (8) Figure 4 illustrates the arrangement of the ballistic compressor.

Next, the specimens were examined with a metallurgical microscope. The specimen, placed perpendicular to the optical axis, is illuminated through the objective lens by light from a light source. A condenser focuses the light into a beam and a half silvered mirror makes it nearly parallel to the optical axis. The light then reflects from the specimen into the objective lens in such a way that only rays from features that are normal or nearly normal to the optical axis make their way through this objective lens, and those parts of the specimen that reflect light at an angle greater than the aperture angle miss the objective. Therefore, many characteristics of the specimen that are inclined to the optical axis appear dark. Such features include grain boundaries and other important features.

The metallurgical microscope was equipped with a photographic camera (PSU 56235) for Polaroid film. Photographs were made using Polaroid type $55 \mathrm{film}$, black and white, which gave both a positive and a negative print $(P-N)$. Photographs for this report were taken with an objective lens of $11 X$ magnification and a projector lens of $8 X$. This yielded a magnification of $150 \mathrm{X}$. Also a $40 \mathrm{X}$ objective lens was used, and with an $8 \mathrm{x}$ projector lens, sample areas were enlarged $460 \mathrm{x}$. The lens to film distance was $34.3 \mathrm{~cm}$. Features are presented in the photographs that are 'mirrored' in the same location but on opposite sides of the sample 

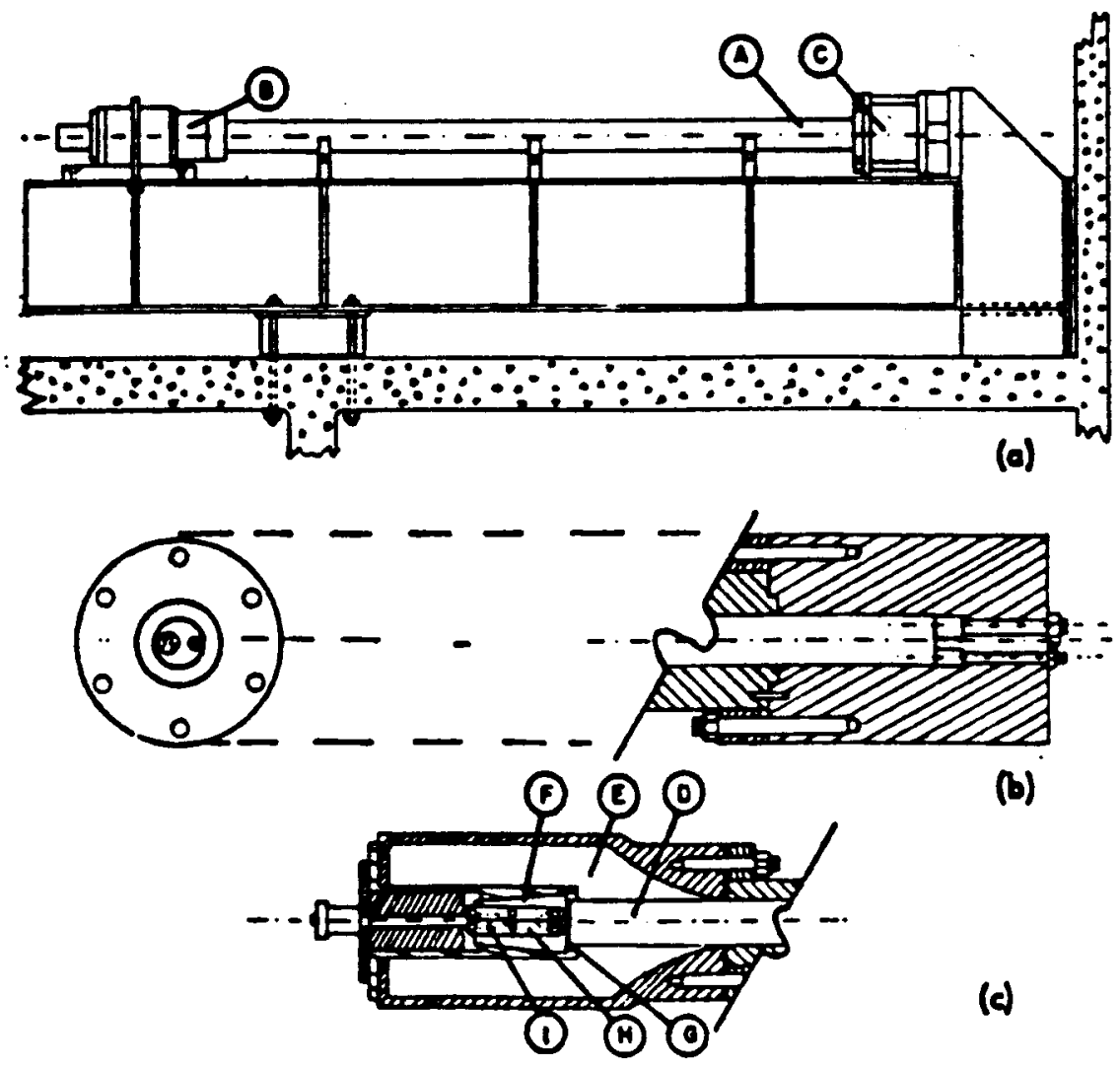

Fiqure 4. Diagram of the Ballistic Compressor. Originally placed at the University of Oregon, it is now located at Portland State University. (a) A side view of the compressor. (b) A piezoelectric pressure gauge and a sapphire window are contained within the end wall of the high pressure head. (c) The driving gas reservoir contains the piston holding and release mechanism ( 8 ).

(A) Horizontal tube, $2.90 \mathrm{~m}$ long, $5.715 \mathrm{~cm}$ in diameter.

(B) Driving-gas reservoir

(C) High-pressure head

(D) Tail of the piston

(E) Driving-gas reservoir (9.30 liters in volume)

(F) Evacuated chamber

(G) O-ring seal; isolates rear of piston from the driving gas pressure

(H) Spring-loaded jaws; latched around a nub, attached to the rear of piston

(I) Plunger; operation is to open spring-loaded jaws and to push piston out of evacuated chamber. 
exposed to hydrogen and argon, and of the sample exposed to argon alone. Positive prints that matched crystal boundaries on each side are oriented in the same direction for easy viewing.

The light microscope offered only a limited view of the structure of each sample. The transmission electron microscope and the scanning electron microscope produced greater magnifications and greater resolutions by the use of electromagnetic lenses and high speed electrons. The transmission electron microscope (TEM) allowed specimens to be seen internally, as long as they were 'thin' enough. The scanning electron microscope allowed surface features of bulk materials to be visualized. Initial TEM work is presented in this report on iron thinning techniques and on pure iron diffraction patterns.

The iron foil strips received from M. Takeo (99.997\% Fe) needed thinning for TEM study. This preparation included thinning a portion of iron foil so that a beam of electrons could penetrate it, and cutting the foil to a small enough size to sandwich inside a Mo grid. The thinness of the foil to less than 0.1 micrometers was achieved by chemical polishing.

Two chemical solutions had been employed for the thinning process, one yielding better results than the other. The first solution, listed by Tegart ( 9 ) and used by a previous student, polishes iron metals, but with the effect of leaving behind a brown viscous layer on the surface. The ingredients of this solution is:
a) $3 \mathrm{ml}$ nitric acid
b) $7 \mathrm{ml}$ hydrofluoric acid
c) $30 \mathrm{ml}$ water (pure)

This solution must remain within a temperature range of 60 to $70^{\circ} \mathrm{C}$ for 
the duration of the thinning process.

In order to maintain this temperature, a 'water circuit' was created, using a double glass layer that allowed the water to circulate inside these layers, while at the same time, the solution was held in a separate container inside the beaker. A plastic vial contained the solution since hydroflouric acid reacts with glass. The beaker contained two separate hose fitting outlets (Figure 5) to which tubing was attached. A water pump circulated the heated water from a 'heat reservoir' through the beaker and back again to this reservoir. A $1500 \mathrm{ml}$ pyrex container of pure water placed over a hot plate acted as the heat reservoir. The thinning process for each sample usually lasted under two minutes when using this solution.

Once the solution in its plastic container was placed inside the beaker, the beaker was placed into a magnetic field with a strength of about 7600 gauss (measured from a Gaussmeter - Bell 620). The magnetic field appeared to provide a more uniform surface to the metal as it thinned. This seems likely since the acid solution would react with the iron along the interface, forming $\mathrm{Fe}^{2+}$ and $\mathrm{Fe}^{3+}$ ions, which are charged particles, and when these particles have a velocity while in the magnetic field, a force perpendicular to the direction of their motion and to that of the magnetic field acts upon them, carrying them away from the interface.

Iron foils to be thinned were cut into strips with dimensions of $1 \mathrm{~cm}$ by $2 \mathrm{~cm}$ each. The edges of each foil were framed with a chemical resistant tape, otherwise they thinned away too quickly before the surfaces reached sufficient thinness. Small holes toward the center each thinned foil were desired so that the edges of these holes could be cut away for TEM observations. However, the brown layer persisted to deposit over the 


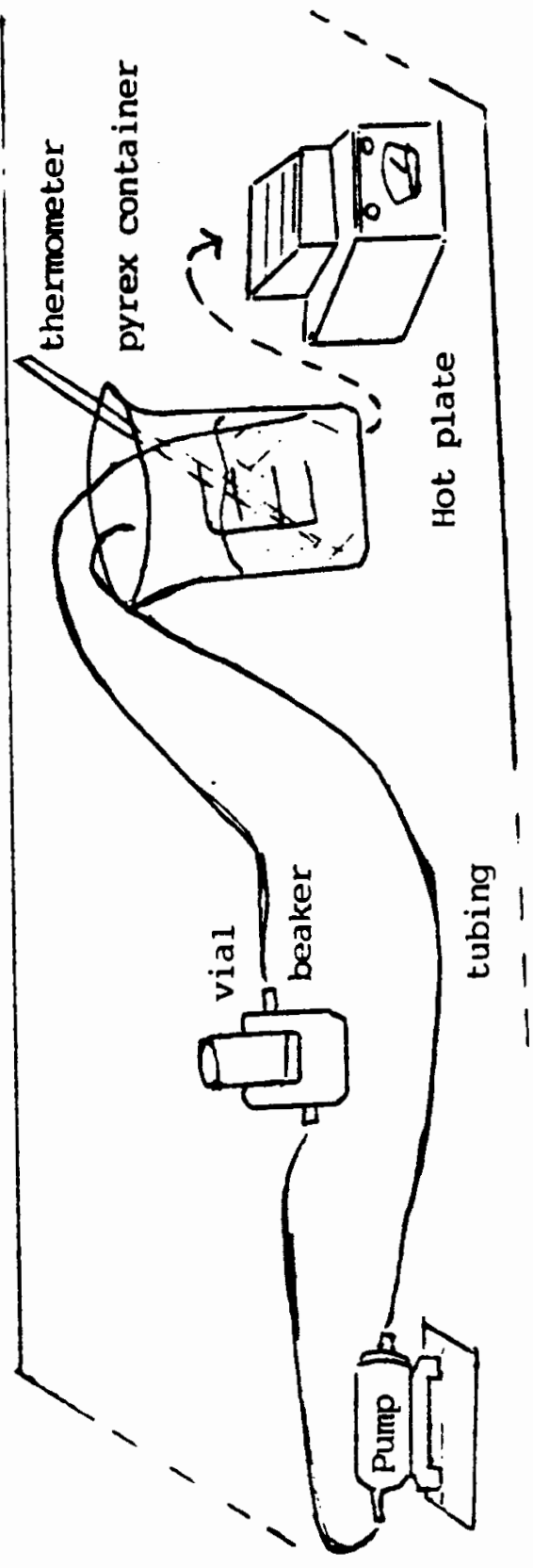

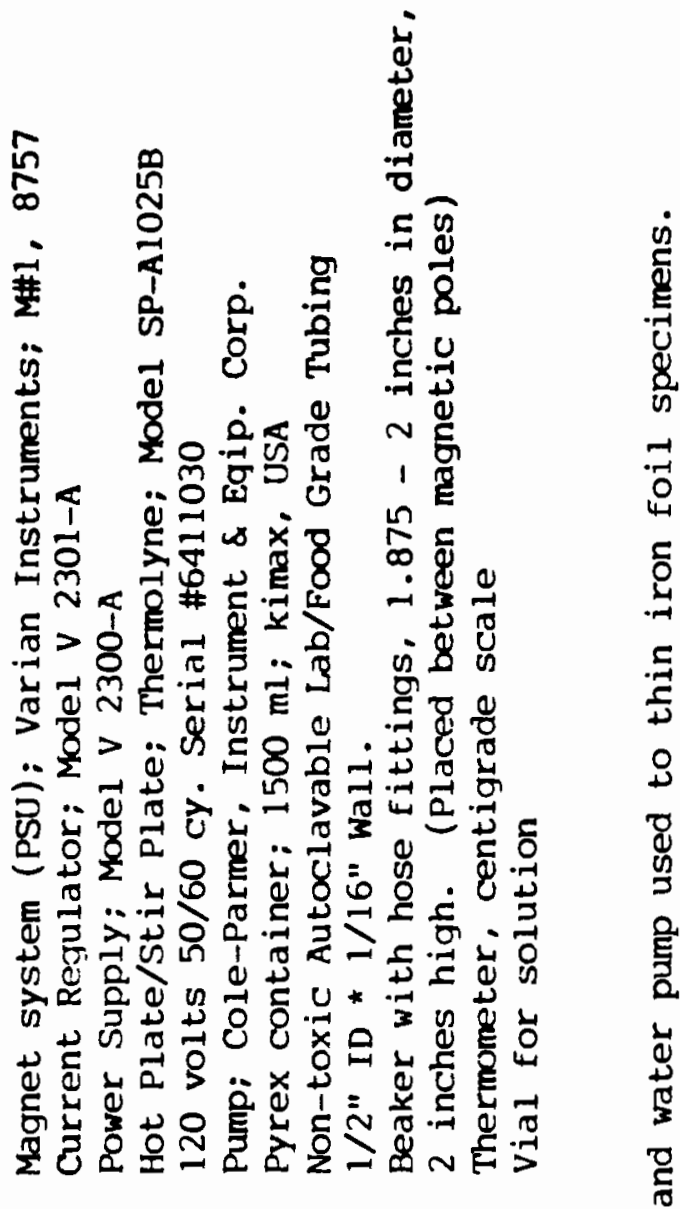

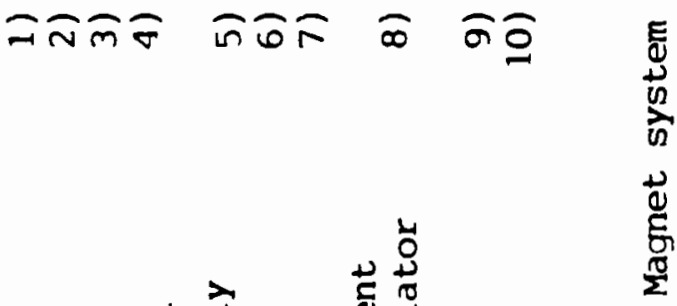

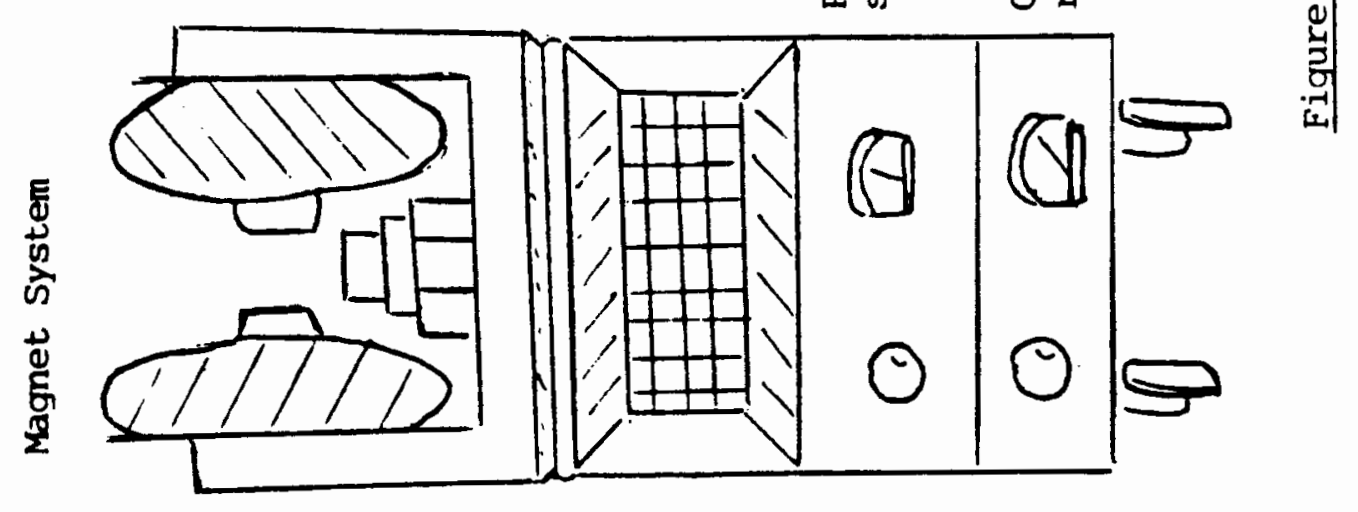


surfaces of the first 30 samples thinned by this solution.

Mechanical abrasives failed to remove the brown layer, so a second solution was considered. An answer to this problem was achieved by using an organic solution. The solution contained oxalic acid, and had to be made on a daily basis. Although the time required for keeping the foil submerged within the solution lasted from 30 to 45 minutes, the surfaces were virtually free of the brown layer. Normally, the ingredients for this solution, taken from Tegart (9), are:
a) $80 \mathrm{ml}$ distilled water
b) $28 \mathrm{ml}$ of oxalic acid (100 g/l)
c) $4 \mathrm{ml}$ hydrogen peroxide (30 percent)

The solution must remain at a constant temperature of about $35 \mathrm{c}$. The plastic vial was replaced by a glass container since no reaction with glass was expected. The procedure for the thinning process with these two solutions is summarized below:

1) Cut and frame each iron foil so that they fit inside plastic vial (thinning must be one at a time).

2) Heat water reservoir to desired temperature that is necessary for solution to work (in this case about $61^{\circ} \mathrm{C}$ ).

3) Prepare the solution and place it inside vial and then into the beaker.

4) Check and maintain desired temperature using temperature gauge (wrap the base in plastic for hydroflouric acid solution).

5) Turn on water pump for the 'water circuit'.

6) Place beaker between poles of magnet system (make sure magnet system is cooled by circulating water).

7) Turn on magnetic field (strength, about 7600 gauss; mag. cur.. 4 amps).

8) Dip prepared iron foil into solution using clamps or tweezers to hold it steady.

9) After foil is thinned (small, holes developed at its center), pull out of solution, quickly dip into methanol, then into pure water, and afterwards, dry with a hair dryer as quickly as possible.

10) When no viscous brown film is present (should be very shiny), then foil specimen is ready for TEM observation

11) Cut from thinnest portion possible, using the aid of a traveling light microscope, and place cut portion inside folding grid.

12) Place grid with its specimen inside TEM specimen holder. 
Instead of mixing 100 grams of oxalic acid into one liter of water and mixing a proper proportion of this into the solution, the oxalic acid was directly added in solid form to the solution. The proportions used were 3.5 grams of oxalic acid, $10 \mathrm{ml}$ of distilled water, and $0.5 \mathrm{ml}$ of hydrogen peroxide. All samples using this technique came out clean and shiny. A magnetic field was also employed for thinning in this solution. One sample thinned within the magnetic field was compared to a sample thinned with the magnetic field absent. There were fewer 'thin' areas for electron transmission by the TEM for the latter sample.

Portions of the thinned specimen needed to be 'locked' within the folding grid to keep it from 'jiggling'. A TEM photograph of a specimen along with a diffraction pattern is presented in this report (TEM used: Hitachi Hu $125 \mathrm{C})$.

The next aspect of research included the use of an $x$-ray powder diffractometer. The diffractometer was a General Electric XRD-5 D/F $x$-ray unit. The function of the diffractometer is to obtain $x$-ray intensities through various angles between the incident beam and the diffracted beam. Intensities became great when angles satisfy the Bragg condition, forming peaks above the background spectrum (10). Though often used to measure reflections from powder samples, the diffractometer was used to measure reflections of $x$-rays from polycrystalline iron foil samples.

The source of $x$-rays was a copper anode, which emitted Cuka $x$-rays, a monochromatic beam with a wavelength of about $1.542 \AA$ when the CuKa, and the CuK $\alpha_{2}$ doublet is averaged together. The copper $x$-rays was passed through a nickel foil so that the CuK $\beta$ (1.39 $\AA$ wavelength) was filtered out. This was possible since the absorption edge of nickel was $1.487 \AA$. 
The diffractometer consisted of a turntable and a Geiger counter that moved around it (Figure 6). When the sample was placed at the center of the turntable, it rotated, therefore changing the angle of the incident beam and the reflected beam. The detector rotated around the table in such a way that it turned $2 \theta$ for every $\theta$ the sample moved. The detector was always in position to receive the reflected rays. Charts were always scaled for $2 \theta$ with a linear trace, and the peaks were measured above the background radiation. The peaks were then tabulated as relative to one another with the highest being 100 .

a)

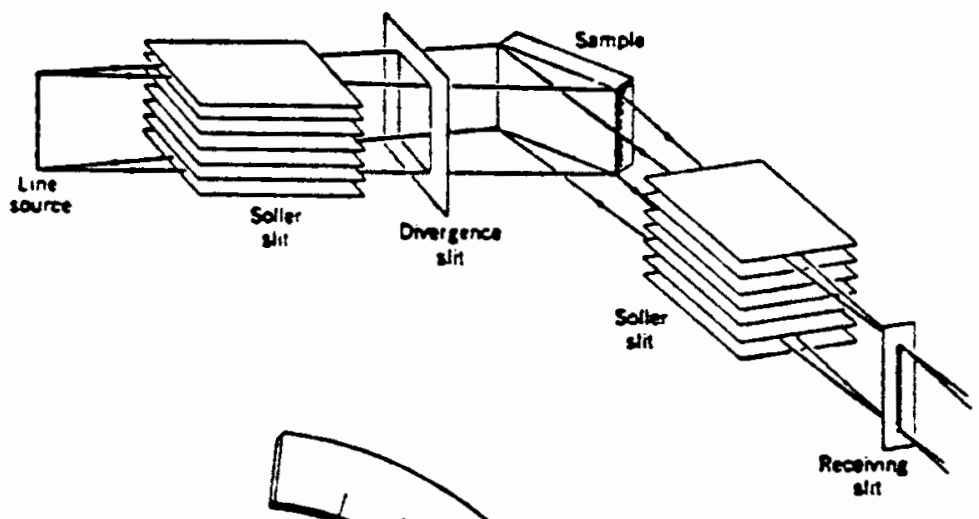

b)

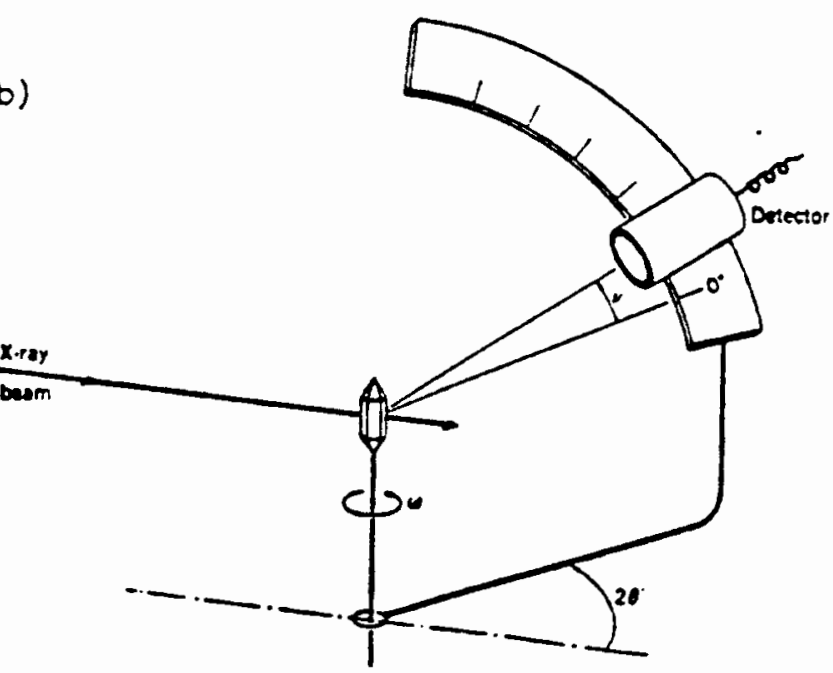

Figure 6. A crystal diffractometer. a) An illustration of an $x$-ray system for a powder diffractometer. b) The single crystal diffractometer arrangement. The nickel filter is inserted in front of the x-ray beam (10). 
Peak heights were measured in $\mathrm{mm}$ and peak widths were measured

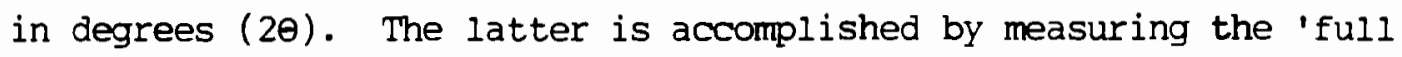
width at half maximum' (FWHM). The center of each peak was chosen to

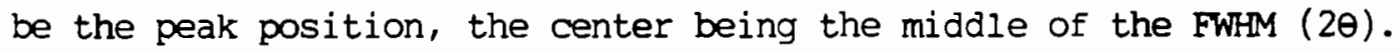

The scanning electron microscope (ISI - SS40, International Scientific Instruments Inc.), along with the metallurgical (light) microscope, provided fundamental visual data for the experiments. The scanning electron microscope provided a finely focused electron beam on the specimen, from which secondary and backscattered electrons produced a current that is collected and amplified. A cathode ray tube is synchronized with the electron probe that moves across the specimen, so that topographical features are seen on the tube screen. The magnification is the ratio of the screen display width to the specimen width being probed by the electron beam.

The photographic films produced using the SEM are in similar 10cations as those produced using the light microscope. The photographic images made from the SEM were created with the intent of obtaining greater resolution and higher magnification than those created from the light microscope.

Six SEM photographs represent surface features of the iron samples, one of iron unexposed, another of iron exposed to argon alone, and the other four of iron exposed to hydrogen and argon. All SEM photographs are taken at magnifications of 3000x, except for two, which are of iron exposed to hydrogen and argon, which have been magnified 690x for one, and $2000 x$ for the other. The working distance was set for $12.5 \mathrm{~mm}$ with the sample tilted 45 degrees. These settings provided the best conditions that could be found for the surface image. 
A high spot size (nearly maximum on the SEM) and a low brightness scale best revealed the surface features of each sample. The high spot size made lines visible by what appeared to be charging them with electrons, making them a bright white against the background image. Lines and boundaries were nearly invisible with a low or medium spot size. The accelerating voltage was kept at $10 \mathrm{kV}$.

An energy dispersive $x$-ray spectrometer (supplied by Link Systems) provided the compositional analysis of each sample. The composition of lines and chosen areas were recorded on EDS charts as well as relative heights of characteristic peaks for the elements displayed. A semiconductor detector, a single crystal wafer of silicon treated with lithium, about 3 to $5 \mathrm{~mm}$ in thickness, converts the $\mathrm{x}$-rays coming from the specimen into current that is proportional to the $\mathrm{x}$-ray photon energy. The current is transmitted in pulses and stored into a memory of a computer according to pulse strength. The results are displayed on a screen monitor. With the beryllium window removed from the detector, light elements such as carbon and oxygen can be detected, whereas before, with the window in place, the EDS can detect elements down only to atomic number 11 . The window, therefore, was removed, because both carbon and oxygen were desired peaks on the energy spectra.

Areas of concentration on each EDS chart were below $1.28 \mathrm{keV}$, where Fel, oxygen, and carbon peaks occur. The counts of each peak fall within the 'full scale' count of each display, the full scale count being the highest point at which a peak remains fully visible before being cut off by the chart boundary. The 'dead time' indicated at the top of each chart is the time that the detector does not accept pulses; the detector accepts only one pulse at a time before new ones are read, and therefore, a 
proportion of pulses is not detected. A dark, vertical line at the bottom center of each spectrum, which records the height of the radiation count at that point, acts as a reference for the energy display, the energy being printed at the bottom of the chart for this line. The characteristic peaks and the Bremsstrahlung or 'white radiation' occur together, therefore, the second is subtracted from the first in order to obtain roughly proper heights for each characteristic peak. This procedure was also employed for the $\mathrm{x}$-ray powder diffractometer charts. The slope of the background radiation increases for most of each EDS display as the energy (keV) decreases. This is due to the efficiency of the counter; the background transmission begins to fall off at about $2.5 \mathrm{keV}$ fairly rapidly for decreasing energy. 


\section{RESULTS AND DISCUSSION}

The water solution used with the water circuit shown in Figure 5 consistently thinned and polished each sample of iron, leaving behind no visible traces of a viscous, brown film on the surfaces. The polished iron specimen was thin enough in a few places for TEM study.

After surgically cutting away a small portion of polished iron from the thinned specimen, it was placed into a folding grid and mounted into the specimen holder of the TEM (Hitachi Hu 125 Microscope). Once the diffraction pattern was obtained and developed, measurements were recorded directly from the negative (measurements from a positive print increases the chances of 'measurement error' from magnification changes or print distortions). Most areas of the thinned iron specimen were still too thick for an electron beam to penetrate, so careful consideration of this problem is applied when cutting the sample from the thinned iron foil. Holes within the matrix usually provided projecting 'leaves' or 'slivers' that extend outwards and trail off, and therefore become thin enough for the electron beam to penetrate. One of these 'projections was used for this purpose.

The relationship $r d=\lambda I$ is used to determine lattice spacings (Appendix A). When the camera constant is unknown, $\lambda 1$, the relationship $r_{1} d_{1}=r_{2} d_{2}=r_{3} d_{3}$ can determine the relative positions of spots with one another so that crystal orientation is found. This relationship showed that the sample was indeed of the bcc structure. The d-spacings 
of iron are known, and $r_{1} / r_{2}=d_{1} / d_{2}$ was verified, where $r_{1}$ and $r_{2}$ are the radial distances from the center of two distinct spots from the diffraction pattern. Once two or three spots are found in this manner, the other spots are calculated by vector addition. The diffraction pattern for the iron flake is shown in Figure 7 (photograph \#1) and has the indices of the zone axis $\overline{11}$, which corresponds to one given by Andrews et al. (11). The accelerating voltage for this pattern was $75 \mathrm{kV}$. All the spots in Figure $7 \mathrm{fit}$ the iron structure, and several have been labeled.

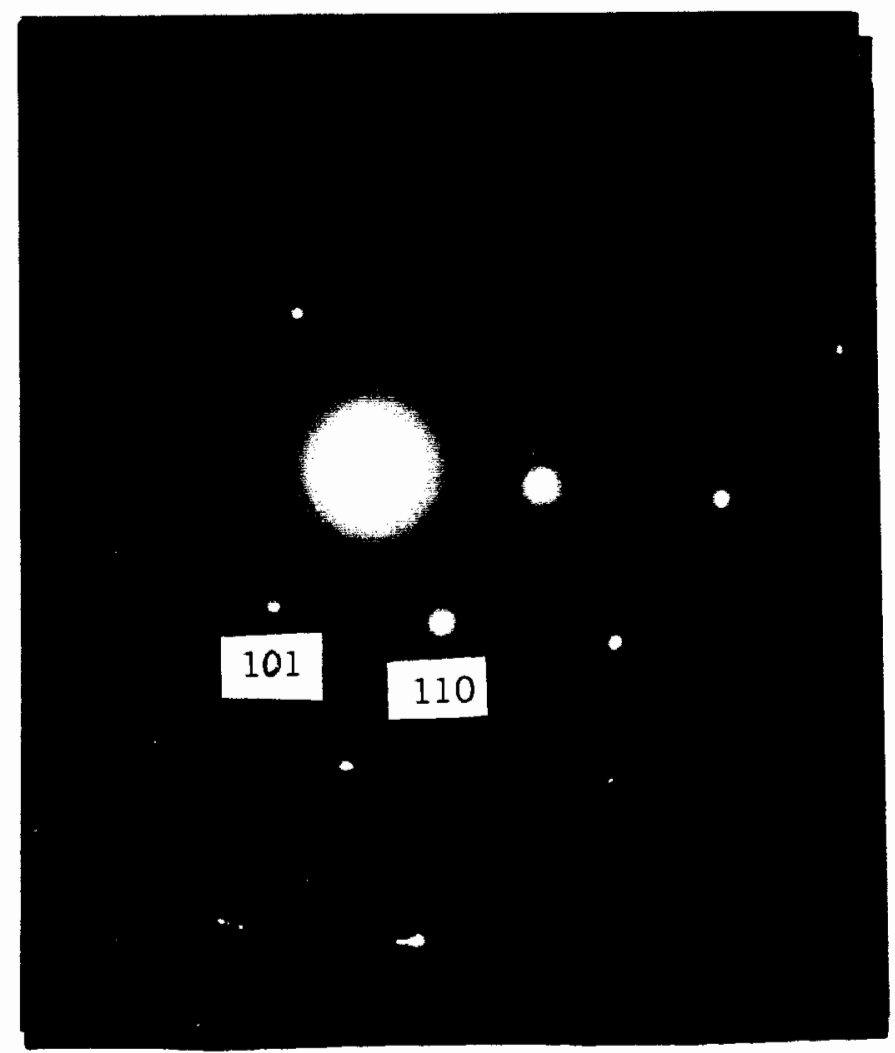

Figure 7. Diffraction pattern of unexposed iron. This photograph was produced using a transmission electron microscope (TEM). The diffraction pattern reveals the structure of iron (photograph \#1). 
Figure 8 (photograph \#2) illustrates a ribbon-like microstructure. A small fraction of this area was used for the diffraction pattern, and the magnification is 47,900X. Hsun Hu (12) published a TEM photograph of a microstructure produced by plastic deformation. According to him, during the process of cold-rolling, mechanical energy becomes stored within the specimen structure. Point defects, dislocations, and other structural faults occur. Being in a state of higher energy, the specimen becomes unstable in structure. This stored energy is not released until the annealing process begins, which thermally activates it, and microstructural changes occur.

Upon annealing the cold-worked metal begins undergoing change, or 'recovery', where dislocations are rearranged and the process of poly-

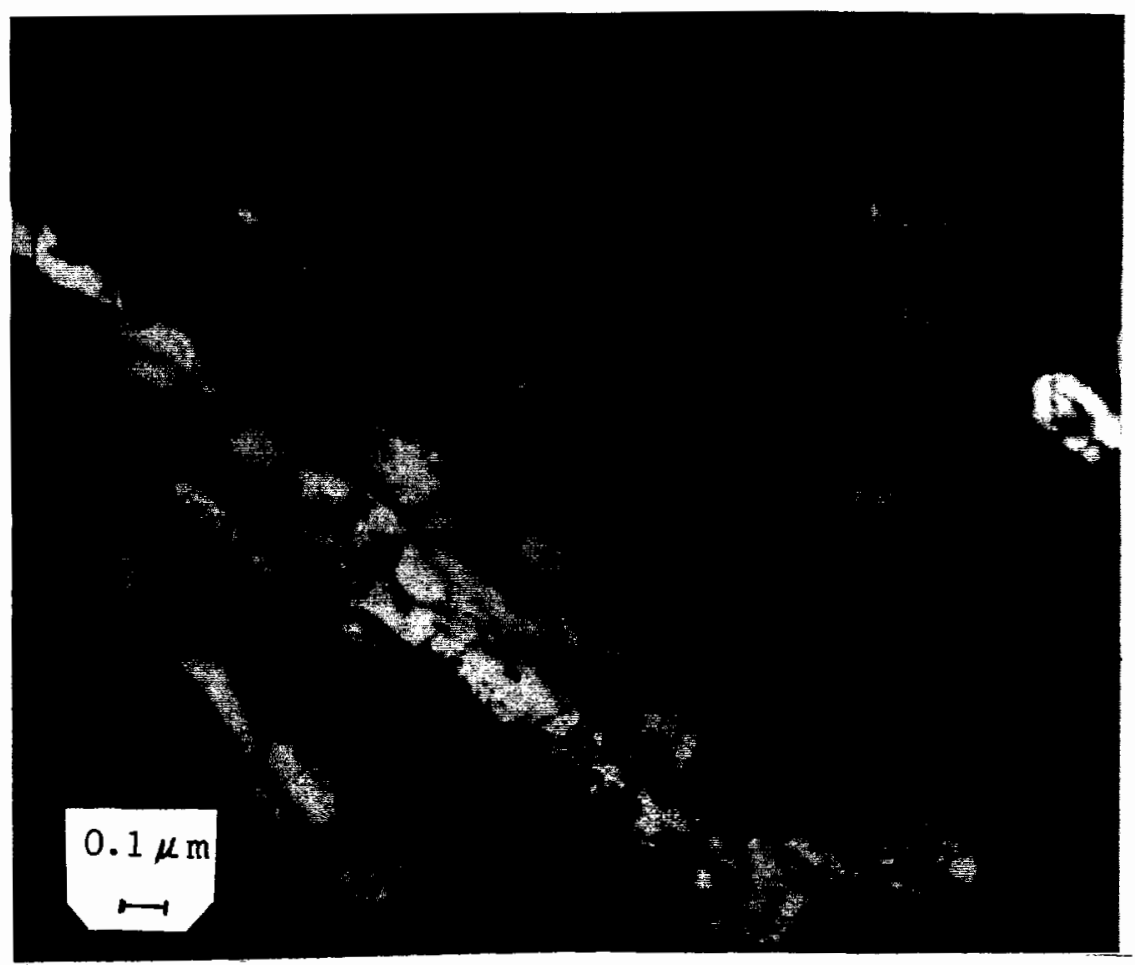

Figure 8. Ribbon-like microstructure of unexposed iron. This TEM photograph represents the area from which the diffraction pattern was created (photograph \#2). 
gonization is implemented. The iron foils of this report were 'as received' from the manufacturer, cold-rolled and annealed at $700 \mathrm{C}$. Ribbon-1ike cells appear in photograph \#2, similar to those of Fig. $9 \mathrm{~b}$. Recrystallization occurs when new grains nucleate and grow after the process of recovery. The grains become strain-free and fuse together, forming high angle boundaries. The fusion of these 'subgrains' occur along regions of small volume but where the lattice is highly distorted (12). Further annealing increases the grain sizes (Figure 10).
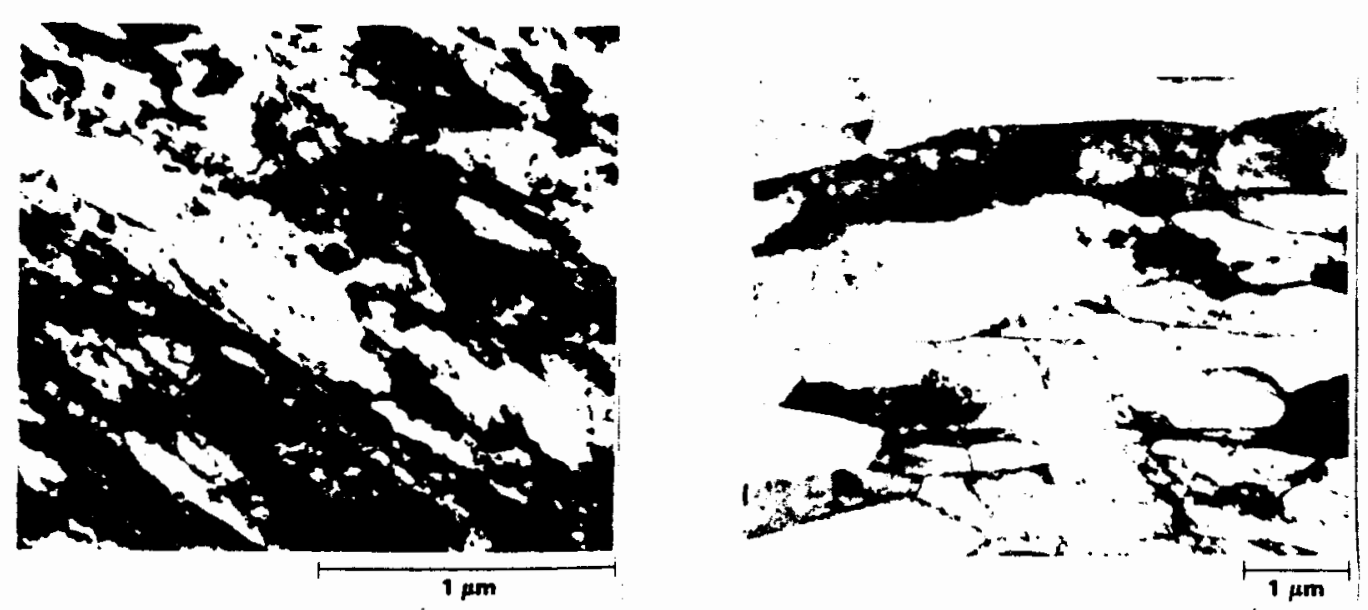

Figure 9. Deformation and ribbon-like cells. a) Left picture represents deformation cells in iron, magnified $30,000 x$. b) Right picture represents ribbon-like cells in iron just after annealing, magnified 11,000X (annealed at $550 \mathrm{C}$ for 20 minutes) (12).

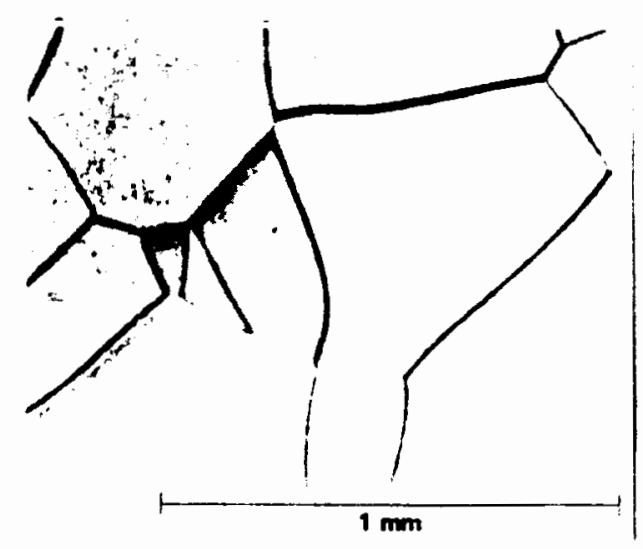

Figure 10. Zone-refined iron specimen after grain growth. Growth occurred at $800 \mathrm{C}$ for 12 minutes. Mag. is $45 \mathrm{X}$ (12). 
The $\mathrm{x}$-ray powder diffractometer illustrated the slight variations of d-spacings among the iron foil samples investigated. This machine operated with a copper anode that acts as a source of $\mathrm{x}$-rays. The $\mathrm{x}$-ray beam was monochromatic with a known wavelength, cuKa. CuKe was absorbed by a nickel filter. At slower goniometer settings, say at $0.4(2 \theta) / \mathrm{min}$., the Cuka peaks became resolved into doublets, such as the one indicated for the 211 plane in Table V. At higher goniometer settings, say at $2(2 \theta) / \mathrm{min}$. or $4(2 \theta) / \mathrm{min}$., the peaks were single for each plane. The wavelengths of $\operatorname{CuK} \alpha_{1}$ and $\operatorname{CuK} \alpha_{2}$ are close, being $1.540 \AA$ and $1.544 \AA$ respectively.

A crystal is an atomic array of repeated congruent cells, and produces destructive interference for all directions of an incident beam except those that meet the Bragg condition, $2 d \sin \theta=n \lambda$. The condition of reinforcement establishes that waves be in phase by integral numbers. If an incoming wave is slightly out of phase with the one below it, then they combine to form a smaller amplitude upon reflection from successive planes than they would if they were perfectly in phase. But somewhere deeper within the crystal structure there is another wave that is out of phase with the first wave by half an integer, thereby cancelling it. If the crystal is small or not deep enough for a plane to exist that allows a wave to cancel another somewhere above it, then an "out of phase" toleration (13) exists. A characteristic peak, therefore, has width, and is not a vertical line. Generally, the width of a diffraction peak increases as the crystal itself decreases in thickness. Crystals are not perfectly formed such that atomic planes repeat 
in parallel succession from one end to the other uninterrupted. The lattice of a single crystal is likely to be broken up into pieces or 'blocks' which are slightly tilted in different directions with respect to one another. This can cause a small error in angles for which waves theoretically satisfy the Bragg condition.

Upon the completion of cold-rolling and annealing, an iron foil may possess 'residual' mechanical strains within the metal structure. Areas of uniform tension and compression (13) might exist for a sample, but might not exist for another part of the same sample. When uniform tensile strain occurs in a local region, than planes along the direction of strain will cause the characteristic peak to move towards a lower angle than normal since the d-spacings of those planes are enlarged. For the nonuniform case, the plane spacing exceeds its normal plane spacing in one place while in another it falls short of it, creating a broadened diffraction peak (Figure 11).

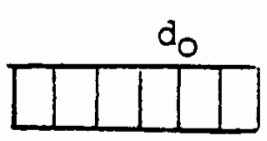

No Strain
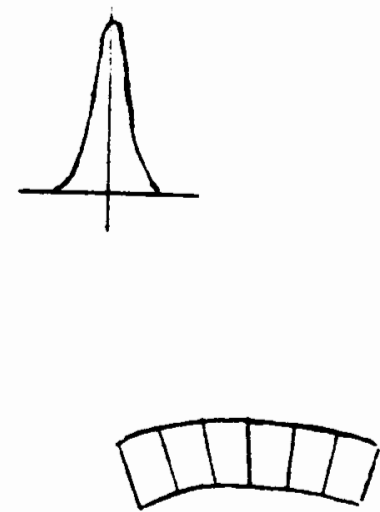

Nonuniform Strain

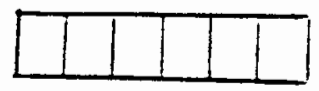

Uniform Strain
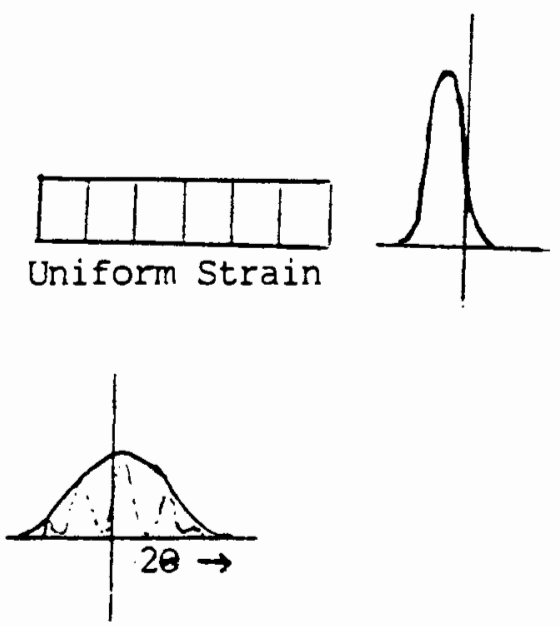

Figure 11. Mechanical strains. The possible strains in the iron foils that might affect the characteristic peaks from the diffractometer (13). 
Various parts of each iron sample were examined in the x-ray diffractometer in order to determine sample uniformity. The Miller indices indicate planes from which scattering occurred or should occur for theoretical values of angles which meet the Bragg condition for a given wavelength. Table I lists values for $\alpha$-iron obtained from the JCPDS diffraction data card, and the $\theta$ and $2 \theta$ values are calculated also. The wavelength of Cuko is used $(1.540 \mathrm{~A})$. Tables II, III, and IV indicate characteristic peak heights, peak positions, peak relative intensities, and peak widths.

\section{TABLE I}

ACCEPTED VALUES OF BCC IRON

\begin{tabular}{|c|c|c|c|r|}
\hline hKI & $d \dot{A}$ & $\theta$ & $2 \theta$ & $I / I_{1}$ \\
\hline 110 & 2.0268 & 22.3 & 44.6 & 100 \\
200 & 1.4332 & 32.5 & 65.0 & 19 \\
211 & 1.1702 & 41.2 & 82.4 & 30 \\
220 & 1.0134 & 49.0 & 98.0 & 9 \\
310 & 0.9064 & 58.2 & 116.4 & 12 \\
222 & 0.8275 & 68.5 & 137.0 & 6 \\
\hline
\end{tabular}

Notes: The angles are calculated from Bragg's condition, $2 d \sin \theta=n \lambda$, or $\theta=\sin ^{-1} \lambda / 2 \theta$

A space in Tables II, III, and IV separates the more standard peaks from the unusual peaks that are not necessarily associated with iron. Unusual peaks occurred at the beginning of most of the diffractometer charts at angles 16 and 23 for $2 \theta$ values. These peaks broadened into humps that were not always completely separated, but resembled the humps of a camel's back. The d-spacings that correspond to these angles are $5.53 \mathrm{~A}$ and $3.9 \mathrm{~A}$, respectively. The $3.89 \mathrm{~A}$ spacing normally occurs with iron oxide, $\mathrm{Fe}_{2} \mathrm{O}_{3}$ (File No. $19-615$; Fiche No. I-108-D 5), which is 
associated with $\theta=11.4$. The d-spacing for $5.98 \mathrm{~A}$ (File No. 21-920;

Fiche No. I-139-C 5), associates with $\theta=7.4$ and is also listed as $\mathrm{Fe}_{2} \mathrm{O}_{3}$. Also iron oxide corresponds to $d=5.46 \mathrm{~A}$ with $\theta=8.1$. Generally, the three forms of oxides; $\mathrm{FeO}, \mathrm{Fe}_{3} \mathrm{O}_{4}$, and $\mathrm{Fe}_{2} \mathrm{O}_{3} ;$ occur as giant molecular structures (14). The Tables for this report indicate that $\mathrm{Fe}_{2} \mathrm{O}_{3}$ is present.

No 110 characteristic peak appears for the iron sample that was not exposed to gases at high temperatures and pressures, probably because it did not have random structure. However, it did appear for the iron samples that were exposed to these gases within the ballistic compressor, probably because this recrystallized the iron foils and produced random structure.

An unusual characteristic peak in Table $V$ occurs as a triple projection, or a triple peak. The 310 peaks is from the iron sample exposed to hydrogen and argon, and is difficult to explain. If nonuniform distortion was present here, the triple peak would appear as one broad peak. The first and third peaks of the 310 plane are spaced far apart, with the second projecting in between them. The other iron foil samples did not show this characteristic (see Figure 12).

Table VI summarizes the peak positions and the peak relative intensities and compared to the accepted values of Swanson et al. (see Table VI). The iron used for the National Bureau of Standards (NBS) sample was a pure sheet of iron (better than $99.9987 \%$ ) prepared by G. A. Moore (15). This sample had been annealed at 1,100 C for 3 days in a hydrogen atmosphere, after which it had been cooled in one of helium. Hydrogen absorption, therefore, may have taken place within the iron foil of the NBS. 
Table V shows that the 200 plane of the iron sample exposed to hydrogen and argon is one degree in position different from that of the iron sample exposed to argon alone. The d-spacings that corresponds to these values are $1.4234 \AA$ and $1.4430 \AA$, respectively, and is a considerable difference. Figure 13 illustrates the diffraction spectra for all three samples taken under the same conditions. An unusual peak exists for the iron foil exposed to hydrogen and argon. This peak is a double projection at $2 \theta=142.5^{\circ}$ and $2 \theta=145.5^{\circ}$, and does not occur at a Bragg angle for iron.

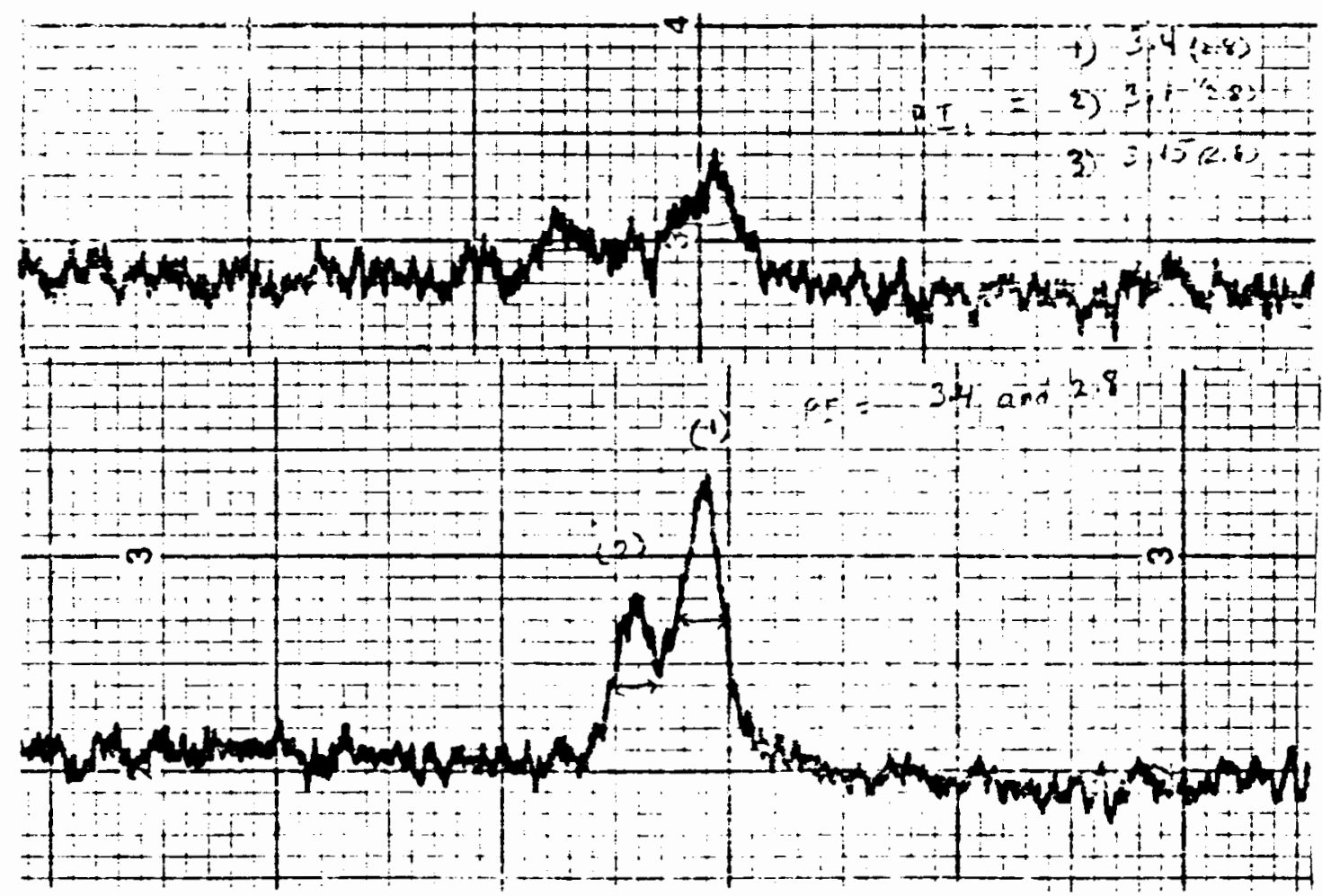

Figure 12. A triple peak and a double peak. a) The triple peak appears for the 310 plane in the iron exposed to hydrogen and argon gases. b) The double peak at the same area of this sample is for the 211 plane. 


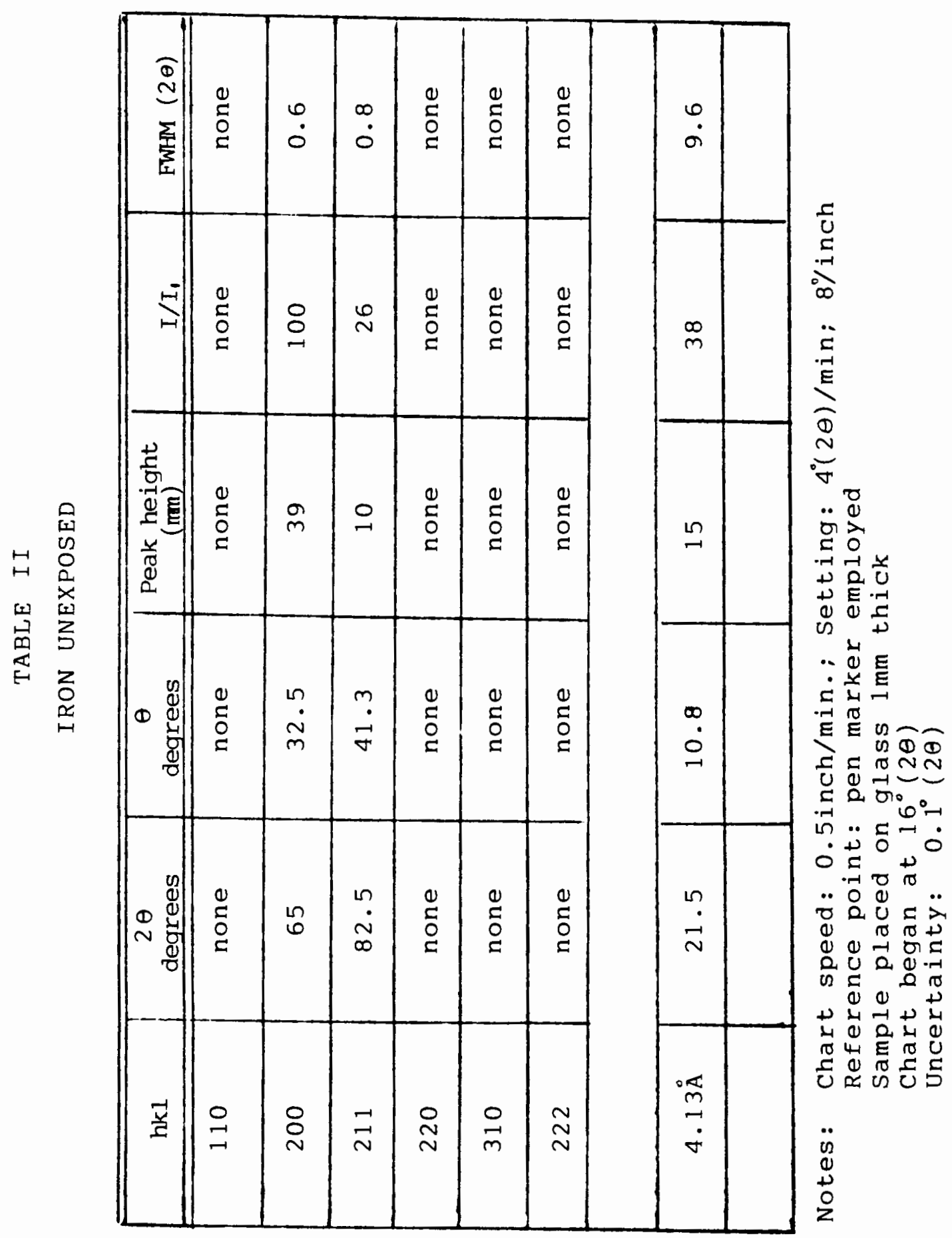




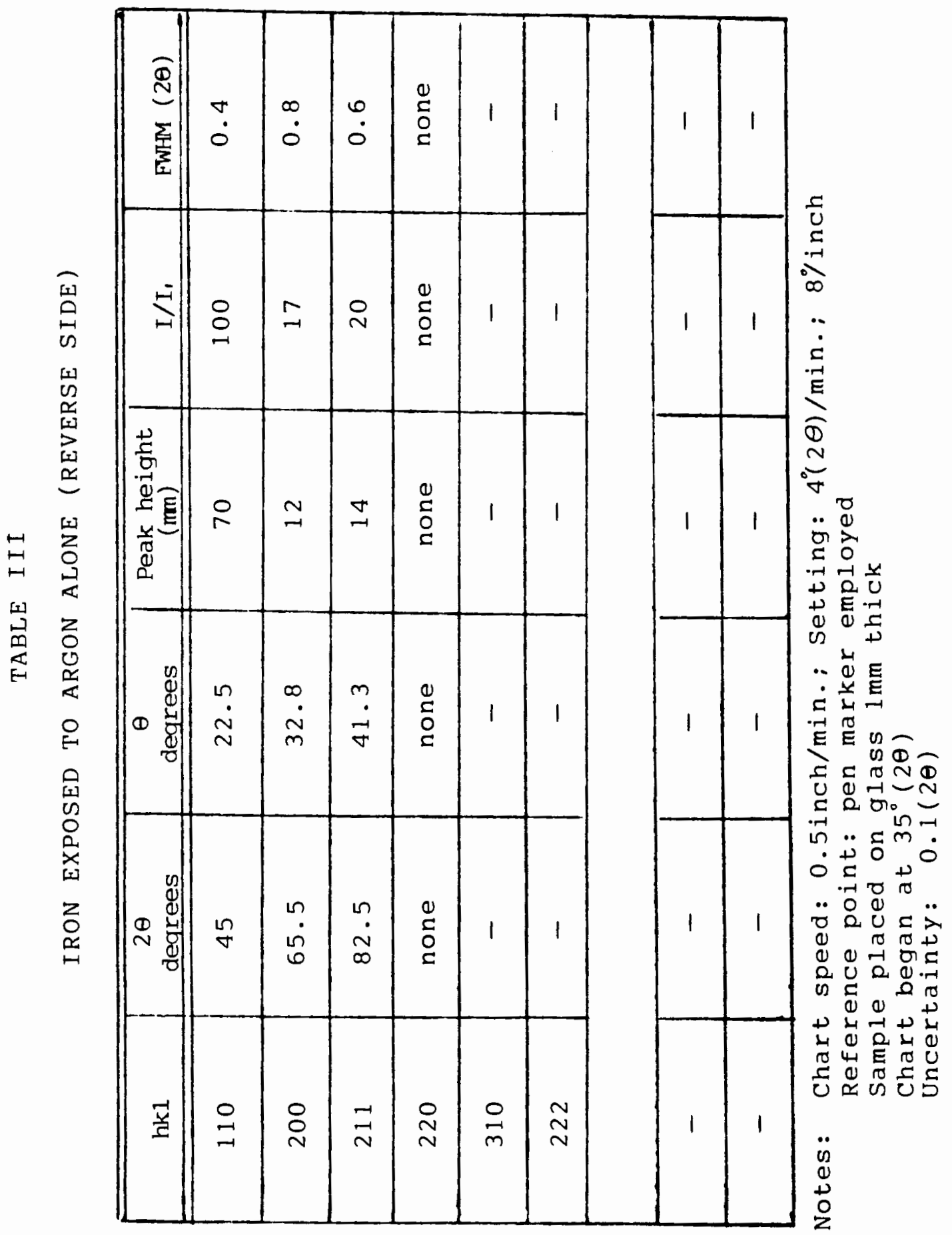




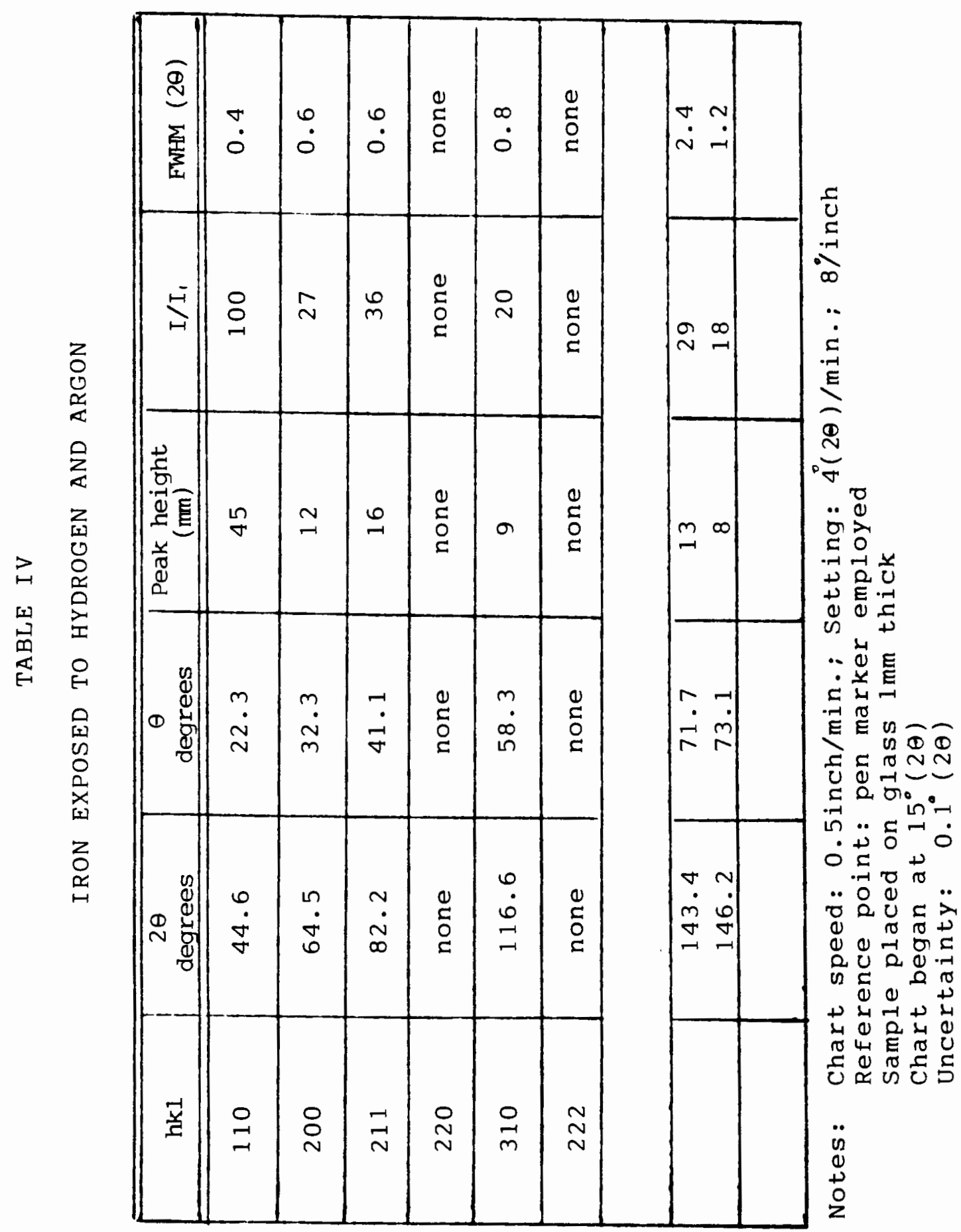




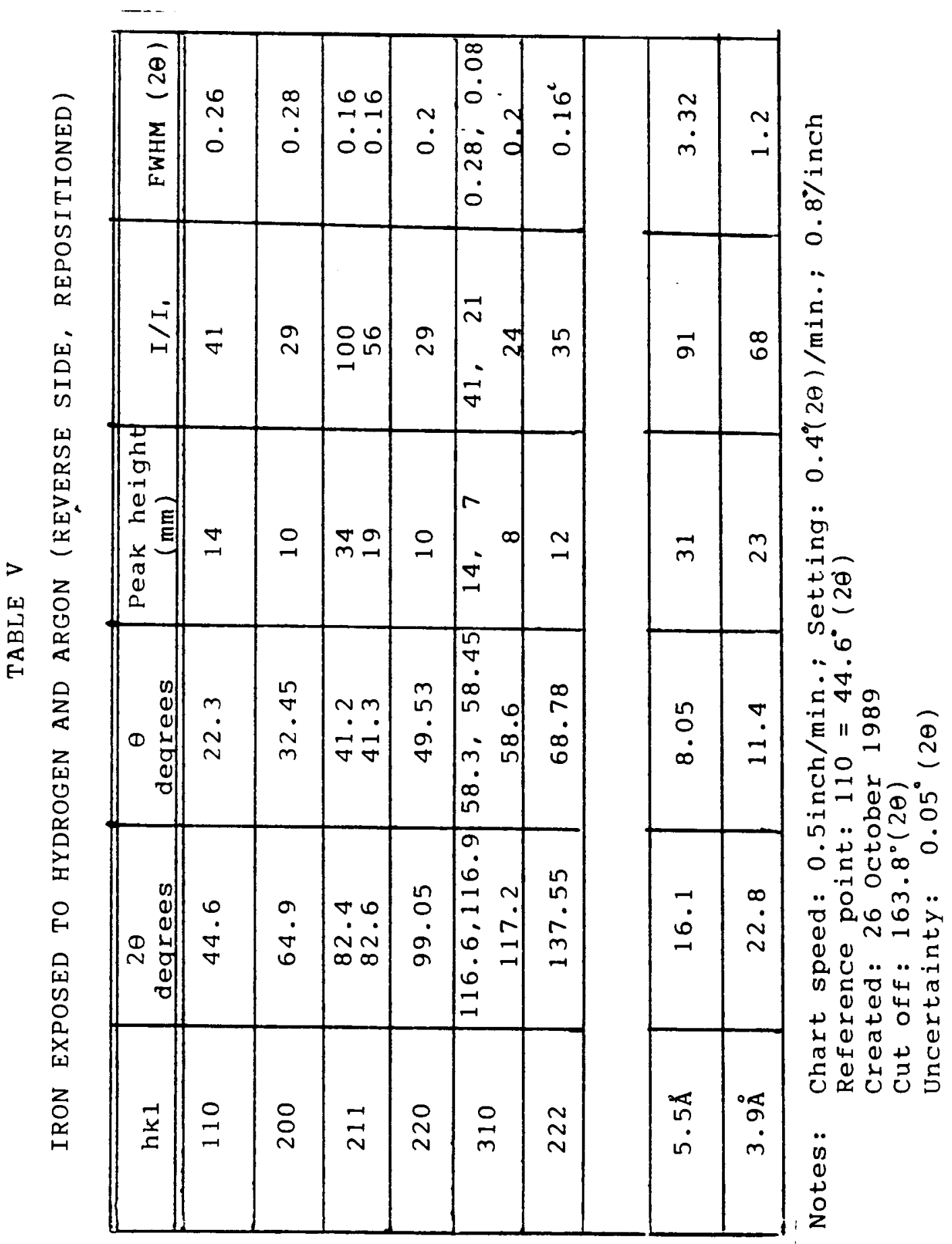




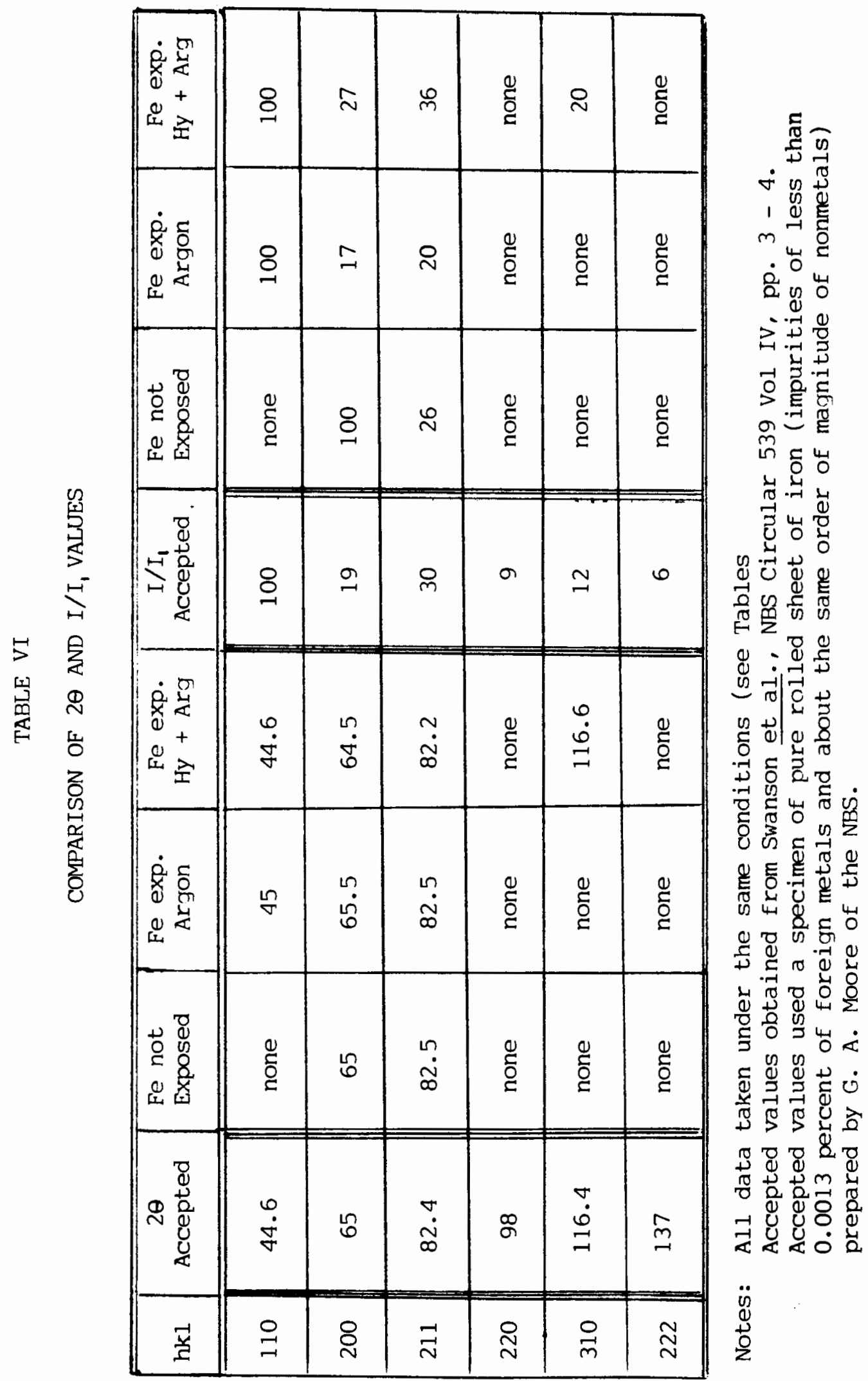




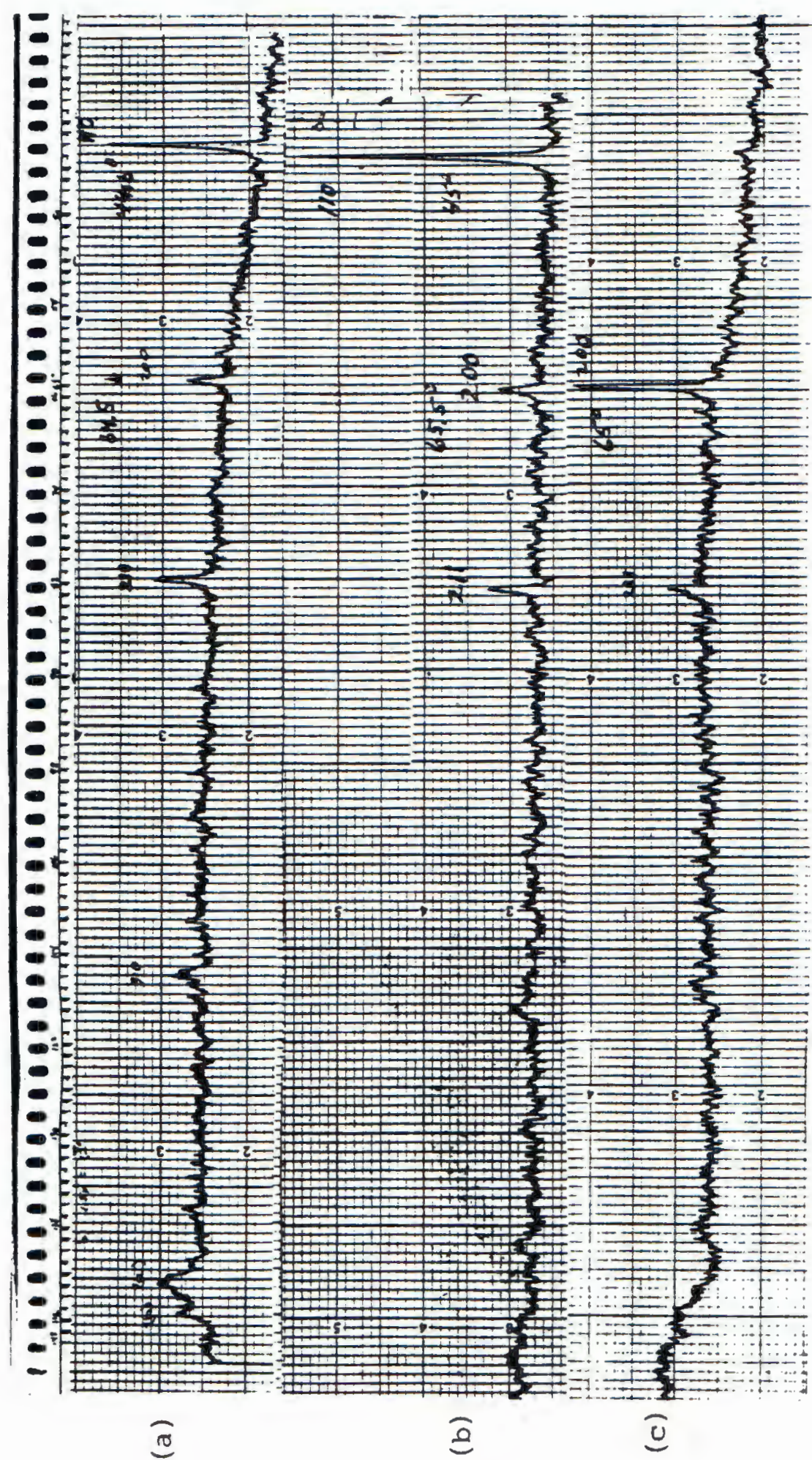

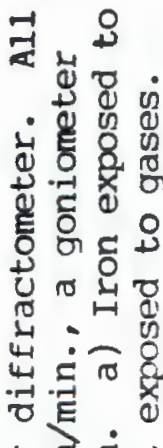

ᄂ $\geq \dot{2}+$

을

I.

8 n $\infty 5$

त 0 แ

누은

$x$.

(4)

$+\frac{1}{4} 0$

E

넝ㄷㄴ

$4 \pi$.

(4)

ه

娄 0

थ

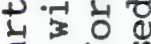

ర人

U

욜

-

U

0 (1)

4 (1)

4 낭

4

o ह

(4) $5 \leq$

녕

E क $\nabla$

ल내

-1:

(4)

ㄱ․네

여렁

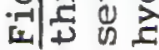

은 
The metallurgical microscope and the scanning electron microscope offer possible evidence of structural changes within the iron after exposure to hydrogen gas within the ballistic compressor. Figure 14 is a metallurgical microscope photograph of the iron surface that was not exposed to gases at high temperatures and pressures. The grain boundaries are clearly visible, as well as the 'brush-like' parallel lines that gloss over the surface which indicate the direction of cold-rolling. Photograph \#4, shown in Figure 15 is the surface of the same sample, but taken with the SEM for a magnification of $3000 \mathrm{X}$ (photograph \#3 is 200X). The line that is in the center is a crystal boundary, and the 'brushlike' lines that are barely visible on either side are the result of the cold-rolling action.

The left, bottom corner of photograph \#3 reveals dark patches, and a few are found at the extreme upper right hand corner also. The patches are most likely 'slip-bands', caused by the metal being strained past its yielding-point, or 'elastic limit' (16). Upon stretching, the metal collects black lines which increase and become patches, similar to that seen in Figure 16. These lines develop as the 'pull' increases past the metal's elastic limit. Polishing the surface can cause the dark lines to disappear, unless the deformation is severe. The slip-bands are not cracks or splits in the surface of the metal, but are instead slips along the cleavage planes of the crystal, forming small 'steps' or 'steplets' (16) which vary in angle from one grain to the next. Figure 17 shows that with increased stress, or with stress repeated many times, slip-bands can form into cracks just before the specimen breaks.

Another type of band that occurs on iron surfaces is the "Neumann's band". These bands are narrow and straight, without bending or angulation. 


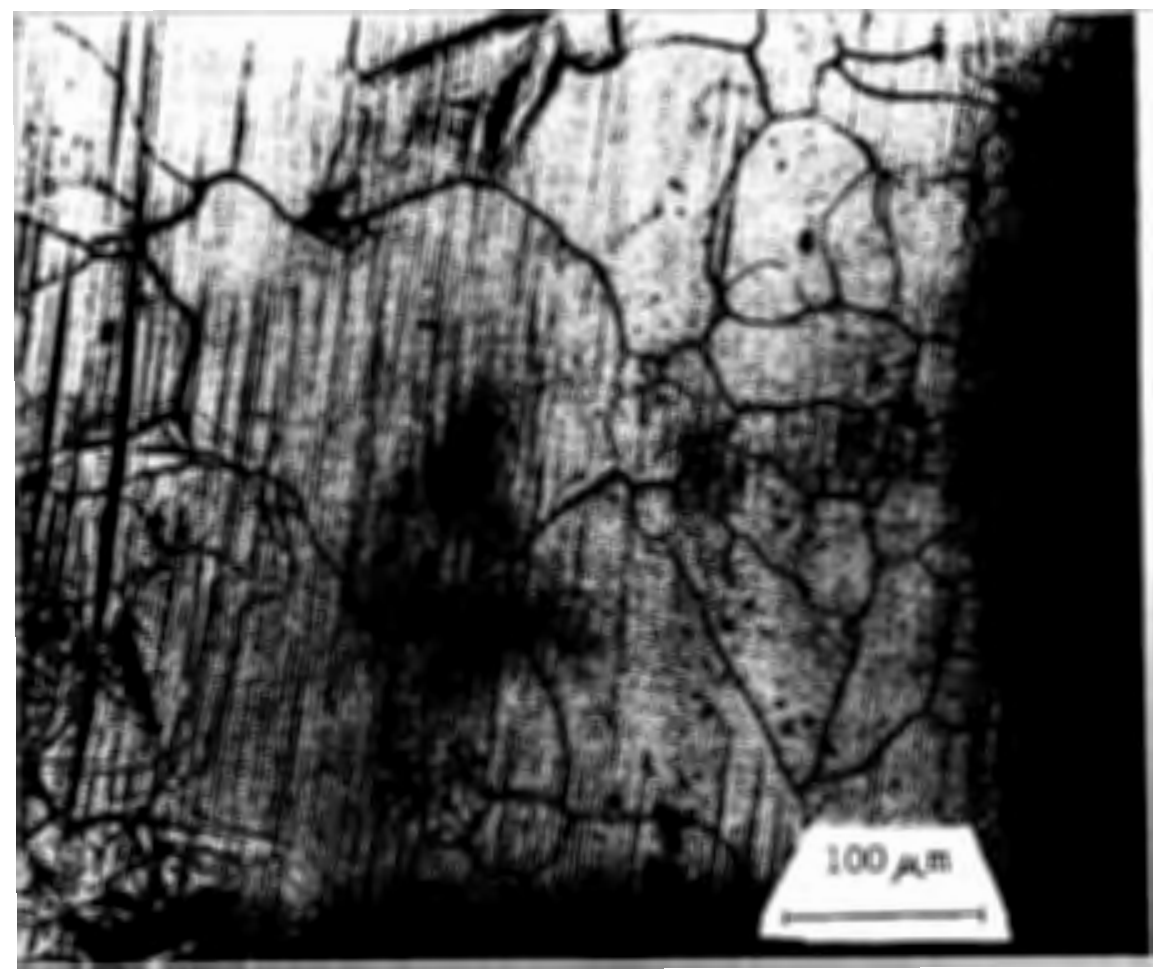

Figure 14. Iron not exposed. A metallurgical microscope reveals the crystal boundaries here. The iron had been cold-rolled and annealed to a thickness of less than 40 micrometers (photograph \#3).

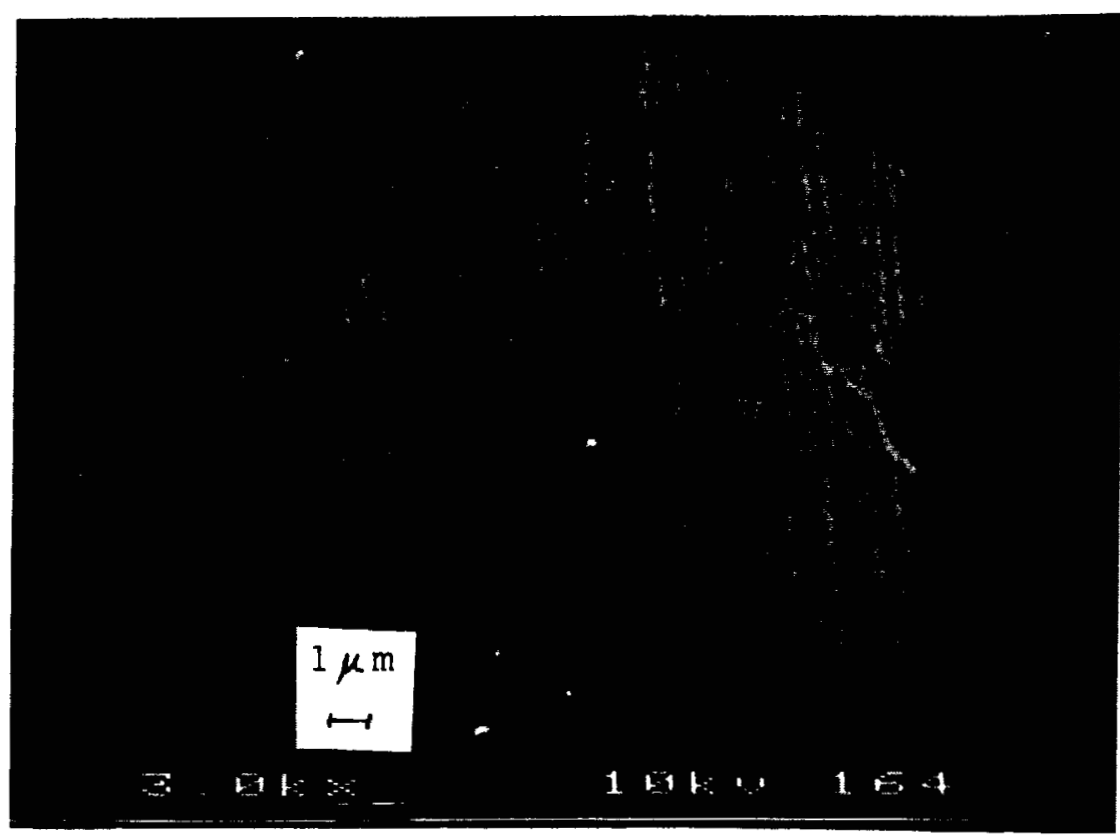

Figure 15. Iron not exposed. A scanning electron microscope reveals the iron surface at a magnification of $3000 \mathrm{x}$ (photograph \#4). 


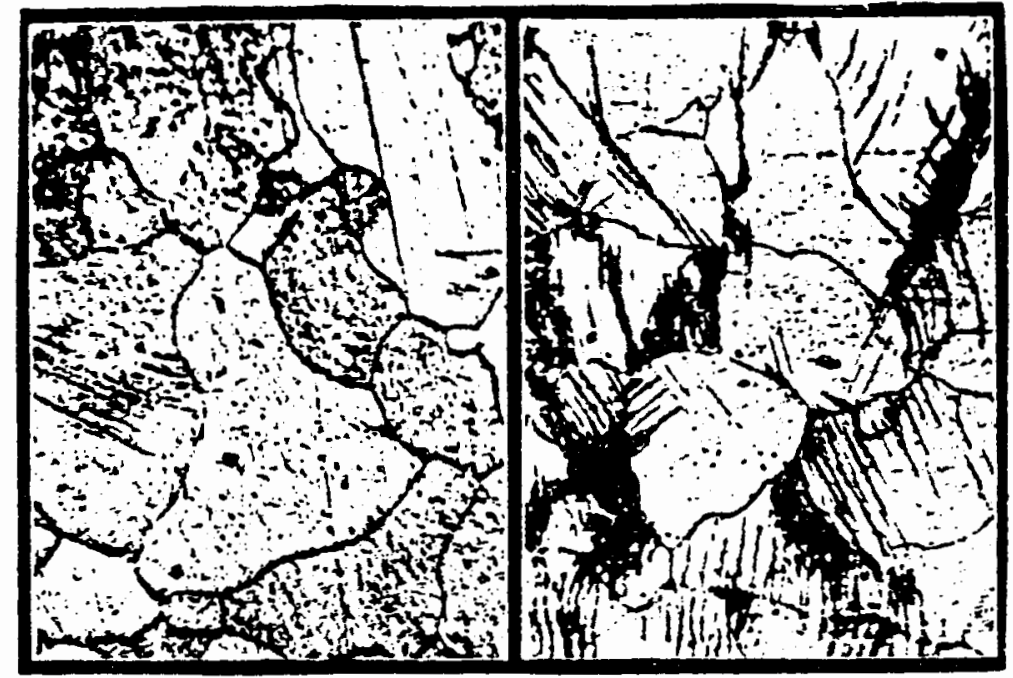

Figure 16. Slip-bands. Slip-bands appear (left side) as fine black lines when the metal has been strained. As the strain increases, so do these lines (right side) (16).

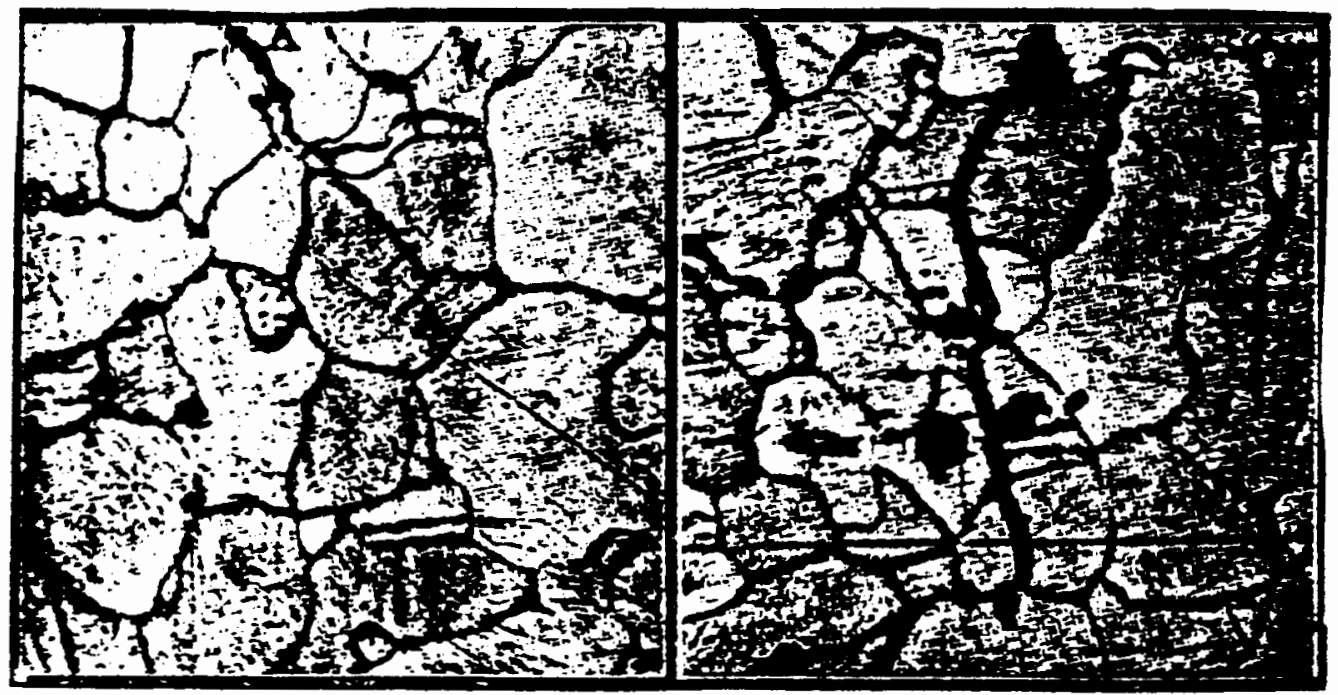

Fioure 17. Broadened slip-bands. Slip-bands broaden and develop into cracks (left side). Repeated stress causes a major crack (right side) to develop, which eventually breaks the specimen (16). 
Under a vertical illumination they appear dark, as seen in a metallurgical microscope. They are produced in iron by deformation, and by shock, such as by impact. The bands represent mechanically twinned strata or lamella (5), and are more easily formed by shock at ambient temperatures, rather than at high temperatures. Figure 19 illustrates several Neumann's bands. A photograph made with the metallurgical microscope appears to have captured a Neumann's band (Figure 19). This band emanates from a crystal boundary of the iron sample that was exposed to hydrogen and argon, and is the only one found among all three iron samples thus far.

Lines that do not appear to be 'slip-bands' or Neumanns' bands are illustrated in Figures 20 and 21 which are metallurgical microscope photographs with a magnification of about 190X. These line formations appear only for the iron foil exposed to hydrogen and argon gases, and portray line segments that are apparently 'bent', or that are combined, forming ' $V$ ' shaped vertices. Some vertices possess a rounded curve, while others possess the arrow shaped point. The ' $W$ ' shaped configurations seen in these photographs distinguish a serrated, or a mountainous, scenery, with some segments appearing thicker than others. The thick, dark line curved above the rest is a crystal boundary.

The Neumann's band of Figure 19 contains a barely visible line that parallels its thick, dark line just to its left. This could indicate that this particular band is a depression accompanied by a slight relief. The ' $V$ ' and ' $W$ ' shaped lines of Figures 20 and 21 do not contain this 'double-line' quality. Figure 22 contains a photograph that is magnified 460X, illustrating the serrated and angular nature of these lines. The lines might be caused by a volume expansion of the iron foil, resulting from the presence of hydrogen gas in the ballistic compressor. 


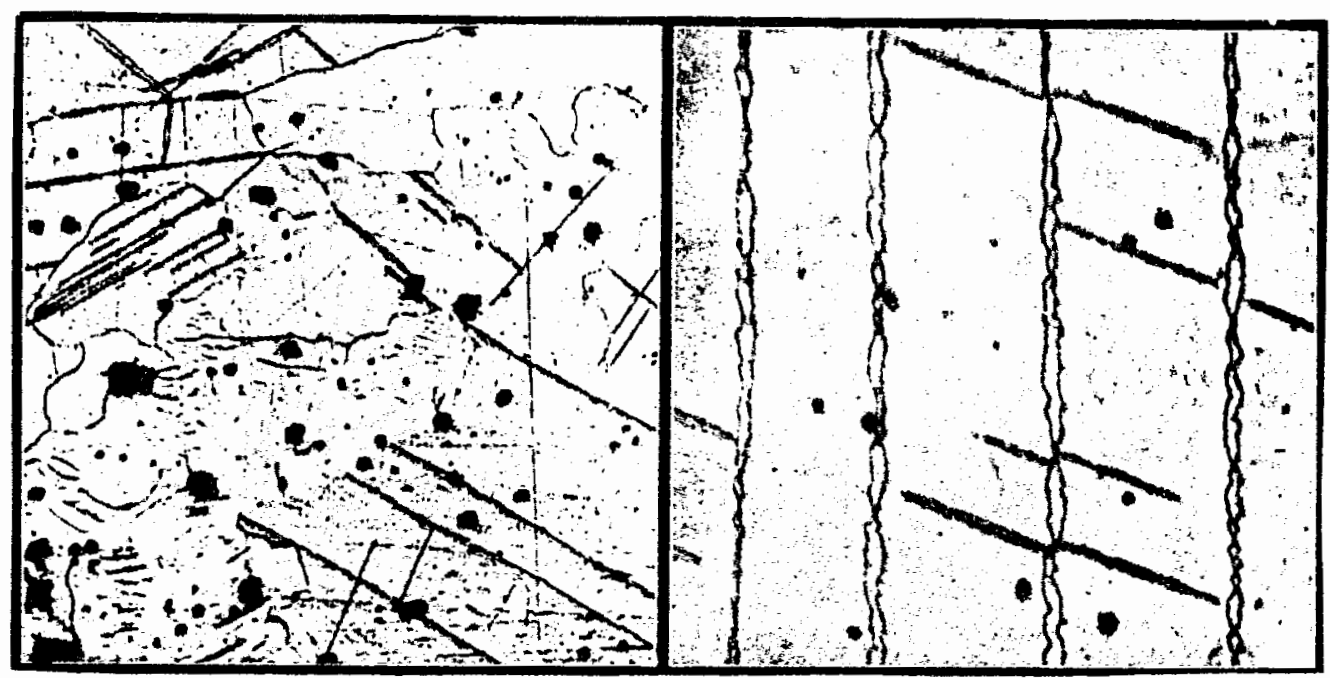

Figure 18. Neumann's bands. Neumann's bands appear on a sample of wrought iron (left side), magnified $150 \mathrm{x}$. Neumann's bands are seen indented (right side) with a magnification of $250 \mathrm{x}$ (16).

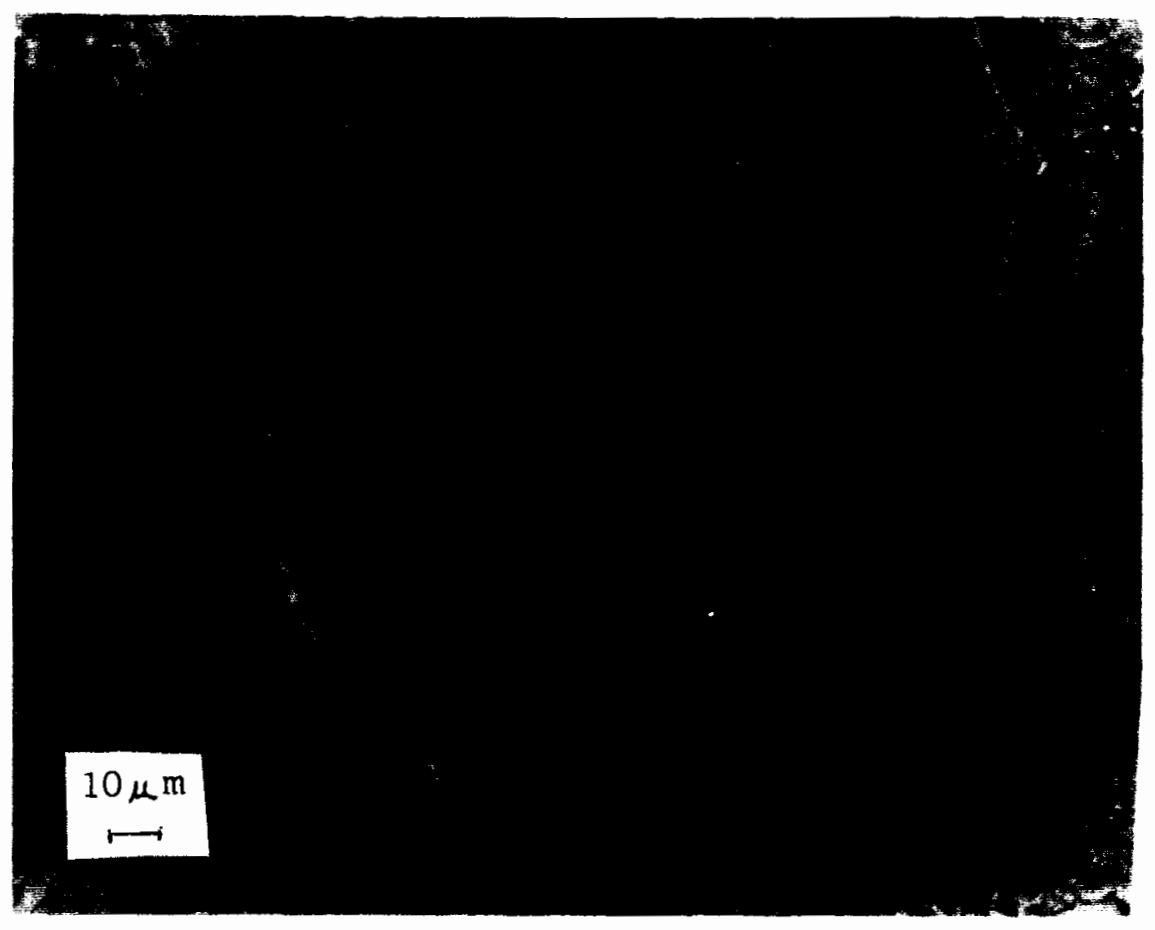

Figure 19. Photograph of Neumann's band. This meta1lurgical photograph of the surface of the iron sample exposed to hydrogen and argon contains a likely Neumann's band, magnified 600X (photograph \#5). 


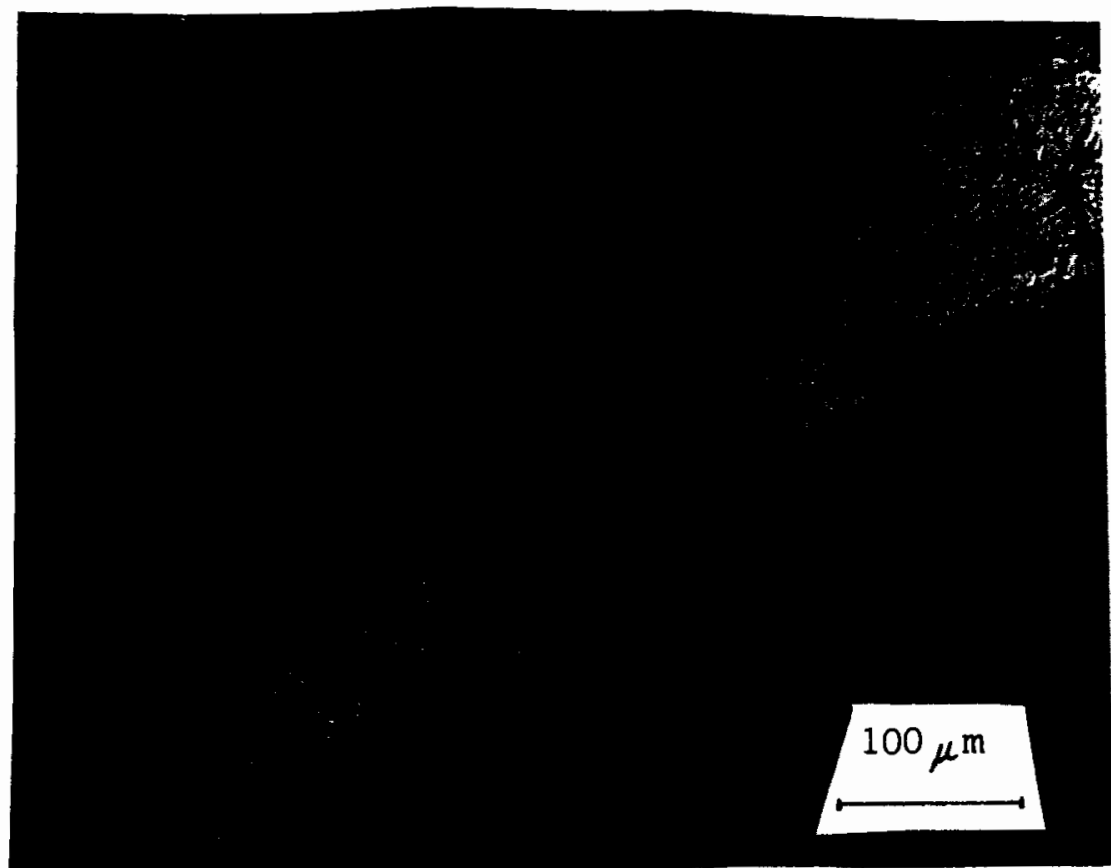

Figure 20. Iron exposed to hydrogen and argon. This is a front side view of the sample showing unusual line characteristics. This photograph is taken with a metallurgical microscope, magnified 190X (photograph \#6).

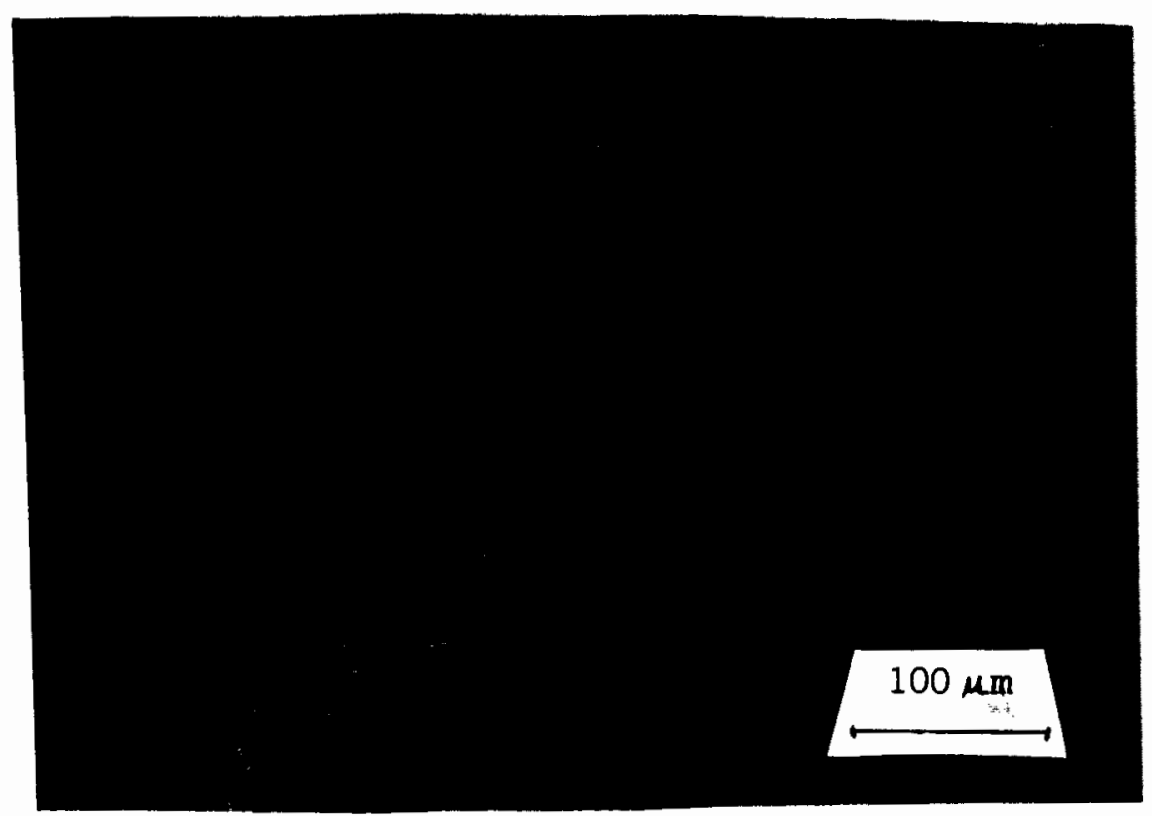

Figure 21. Iron exposed to hydrogen and argon. This is the reverse side but same location as in photograph \#6. A metallurgical microscope has also been used here (photograph \#7). 
Normally slip-bands are transverse to the direction of pull, if the sample is strained in a pulling fashion, and the continuation of this strain, shown in Figure 16, increases the number of black lines, which transform into dark patches (16). If the irregular lines of Figures 19 and 20 were slip bands or Neumann's bands, then they probably would not turn in irregular directions. The angularity of these lines indicate that the iron sample has undergone changes which were not observed in the other two samples. Figure 22 looks at the area of photograph \#6 more closely.

A second area on the sample exposed to hydrogen and argon illustrates the existence of these peculiar lines once again (Figure 23). The upper part of Figure 23 contains a sharply angled line. The other lines, other than the crystal boundaries, are roughly parallel, but vary in length, and possess a somewhat jagged appearance. The second line from the bottom gently curves into the boundary at one end, while the one above it also gently curves in the same direction, but ending abruptly.

The irregular lines of Figures 22 and 23 do not appear to have crystal boundary features. Crystal boundaries appear to meet one another at vertices forming roughly 120 degrees. The lines occur inside the boundaries themselves and they do not necessarily meet them. These lines do not necessarily meet each other or cross one another.

Figure 22 displays the flip side of the sample area seen in photograph \#6. Identical surface structures apparently penetrated from one side of the iron sample to the other. Identical markings were not found on opposite sides of the iron sample that was not exposed to hot, dense gases, but they were found for the iron sample exposed to argon alone, which will be seen in an example in this report. 


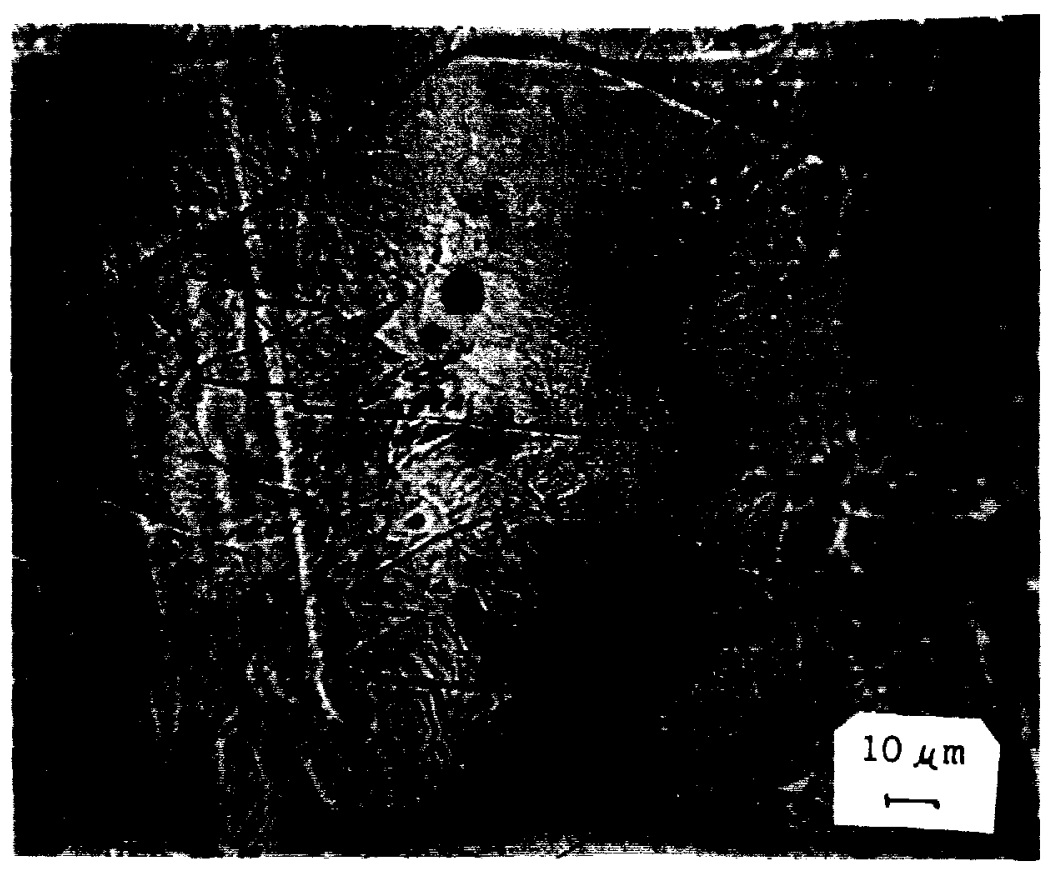

Figure 22. Iron exposed to hydrogen and argon. A closer 10ok at photograph \#6, magnified 460X, demonstrates the unusual angles that the lines seem to make. A crystal boundary is also present (photograph \#8).

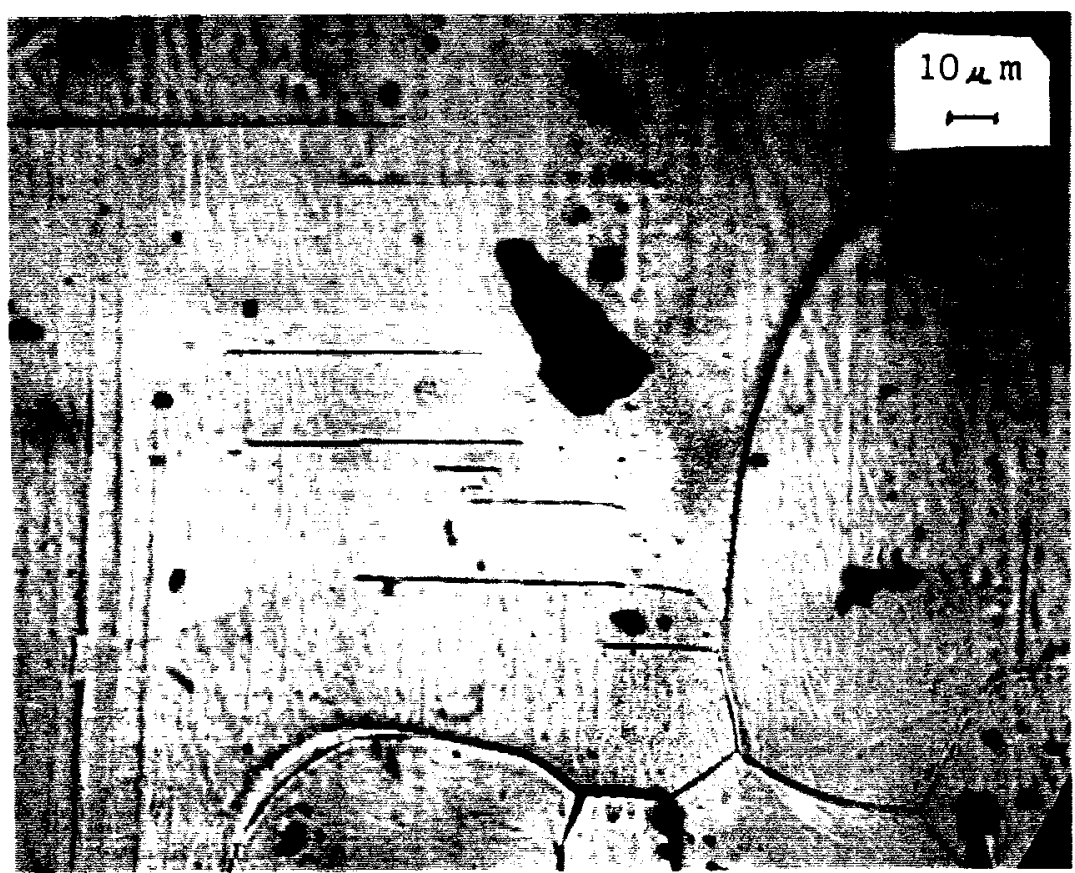

Figure 23. Iron exposed to hydrogen and argon. Another area on this sample reveals lines, one being sharply angled. This photograph is taken with a metallurgical microscope, magnified 460X (photograph \#9). 
Iron undergoes allotropic phases as it passes through a certain range of temperatures, discussed earlier. Since the temperature in the ballistic compressor reached $2000^{\circ} \mathrm{C}$ while the iron foil was being compressed by gases, the iron had undergone structural changes from one allotropic form to another. This process is reversible an the temperature cools. Iron changes from the bcc structure at about $906^{\circ} \mathrm{C}$ to the fcc structure ( $\alpha$-iron to $\gamma$-iron) and back again to the bcc structure at $1404^{\circ} \mathrm{C}(\gamma$-iron to $\delta$-iron). These changes in allotropic forms may be responsible for the identical surface structures found on opposite sides of the samples exposed to the hot, dense gases. Dash and Otte (17) have found that "identical surfaces relief effects" occurred on the opposite flat surfaces of the $\gamma$-crystal of a high purity $\mathrm{Fe}-18 \mathrm{Cr}-12 \mathrm{Ni}$ alloy. The $\tau$-crystal for this alloy means that it exists in the fcc austenitic condition. Their work included an investigation of thin films of this alloy for the purpose of understanding a transformation process, from the $\gamma$ structure through a possible path leading to the bcc martensite, or $\alpha^{\prime}$-crystal. The fcc form that the iron samples proceeds through during temperature changes is likely to be responsible for this 'identical mapping' effect found on opposite sides of each sample face.

Figures 24 and 25 show SEM photographs of the areas seen in Figures 20 and 21. Greater resolution as well as higher magnification allow more surface detail to appear. In order to actually 'see' the irregular lines and the boundaries on the iron surface, the 'spot size' must be near maximum for the SEM so that irregularities that are present can emit strongly, making them appear 'bright' or 'white' against the background. The strong emission follows the angularity of the lines, 
as well as their vertices. Figure 25 is magnified $2000 \mathrm{X}$ and the EDS is used to analyze specific positions on the iron surface. The line of this photograph is near the center one in Figure 24 . Since the irregular lines appear bright when visualizing them with a high spot size on the SEM, and since they appear dark under the metallurgical microscope (they reflect light obliquely), then they probably protrude above the iron surface.

The particles that appear on the iron matrix are impurities, debris made of silica that existed within the ballistic compressor while the iron foils were compressed. The compressor apparently had not been completely clean before its use. The debris is likely the result of a damaged window at one end of the compressor that broke during a previous compression. These particles, which are also charged when a high spot sized is used, are separate entities from the iron matrix, and should not cause any affect upon the solubility of hydrogen within its structure. Even DaSilva et al. had indicated that within the temperature range from the $\alpha / \gamma$ transformation down to about $350 \mathrm{C}$, the purity of iron does not play a significant role in affecting the hydrogen solubility of iron.

The unusual marks in Figures 26 and 27 have been observed on the iron foil exposed to hydrogen and argon, but appear completely different from those irregular lines on Figures 24 and 25. They are broad, thick, and short in appearance, almost comet-like in shape, with an oval head at one end, and a tail that tapers off at the other end. The marks appear as though a 'square-bar' screwdriver had been applied to the surface at high pressures, making niches, like a needle over a wax film. These marks do not deviate into sharp angles, nor are they uniform in 
thickness. Similar features were found for the iron foil exposed to argon alone, but not for the unexposed iron foil.

As iron changes from the fcc to the bcc structure upon cooling, it expands, causing protrusions above its surface. The cooling of iron after being subject to ballistic compression might be responsible for relief features existing on its surface.

The author of this report is, for the most part, convinced that the iron matrix exposed to hydrogen and argon can be more easily penetrated by a foreign substance than the other two iron. foil samples. This is noticed when a pin is pressed through the surface of the former sample by hand.

Figures 28 and 29 are metallurgical microscope photographs of iron surfaces exposed to argon alone. Figure 28 contains crystal boundaries and visible particles, and it also contains lenticular shaped patches (right-center and upper-center corner). These patches are likely to be slip-bands seen for the iron foil not exposed to gases. The particles are the same type as those seen for the iron foil exposed to hydrogen and argon. The flip side of this photograph is illustrated in Figure 29, which shows that the crystal boundaries made a transition from one side to the other (the positive is recopied such that it is aligned in the same direction as the one in Figure 28; this is accomplished by printing the photograph with the negative flipped on the same side in an enlarger as the previous photograph).

Figure 30 is another metallurgical microscope display of iron exposed to argon alone, magnified 460x. Crystal boundaries are present, and the 'bean-shaped' object is likely another silicon-rich particle.

Figure 31 illustrates well defined crystal boundaries for the iron 


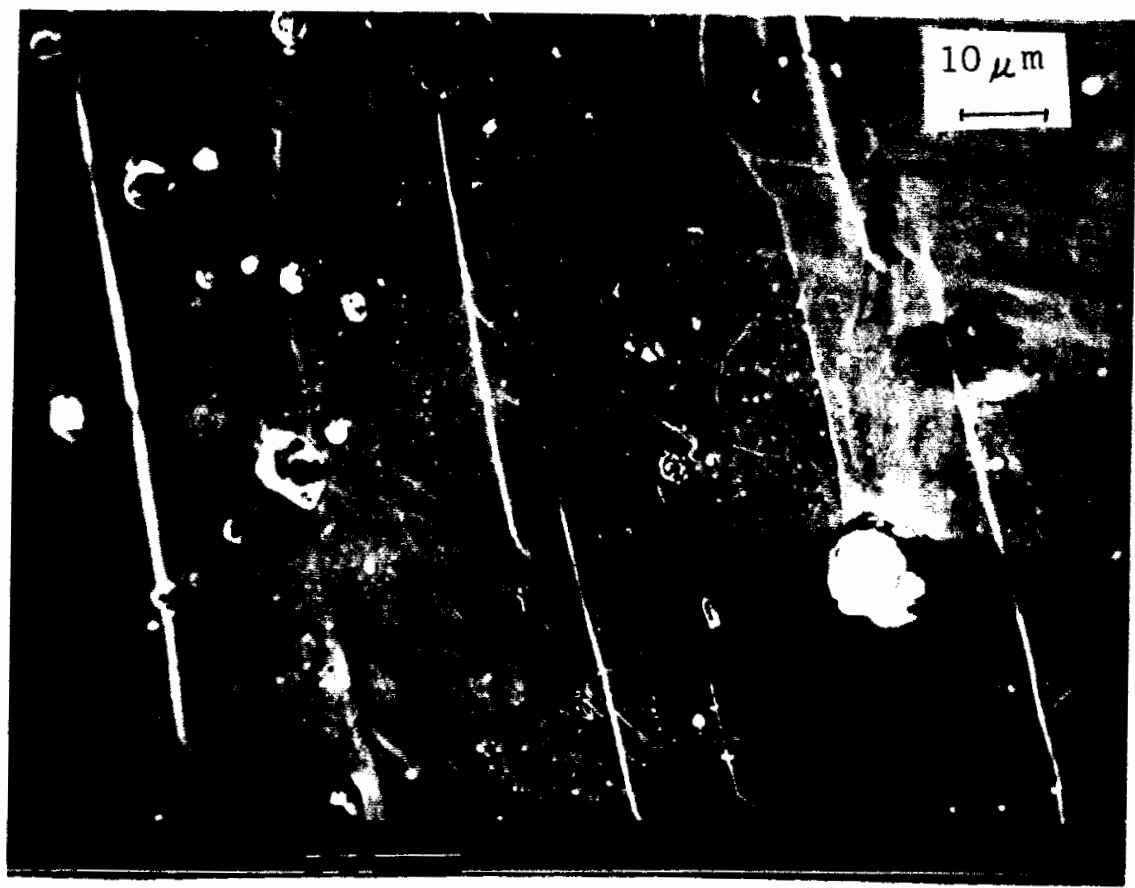

Figure 24. Iron exposed to hydrogen and argon. This photograph is from the scanning electron microscope and is the same image as that of photograph \#7 but at higher magnification $(690 \mathrm{X})$. Note irregular lines (photograph \#10).

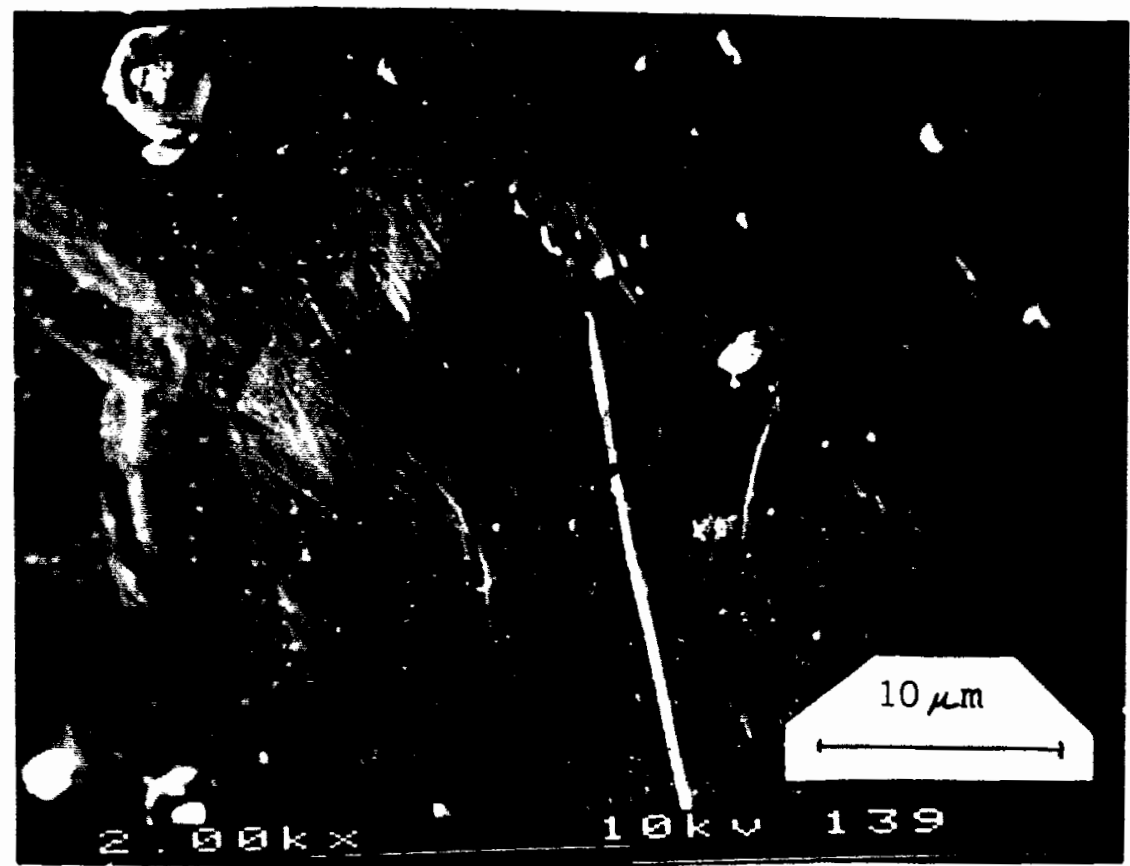

Fiqure 25. Iron exposed to hydrogen and argon. The magnification is increased in this photograph, which shows the center line in photograph \#10. This is taken by an SEM and the arrows indicate places of EDS analysis (photograph \#11). 


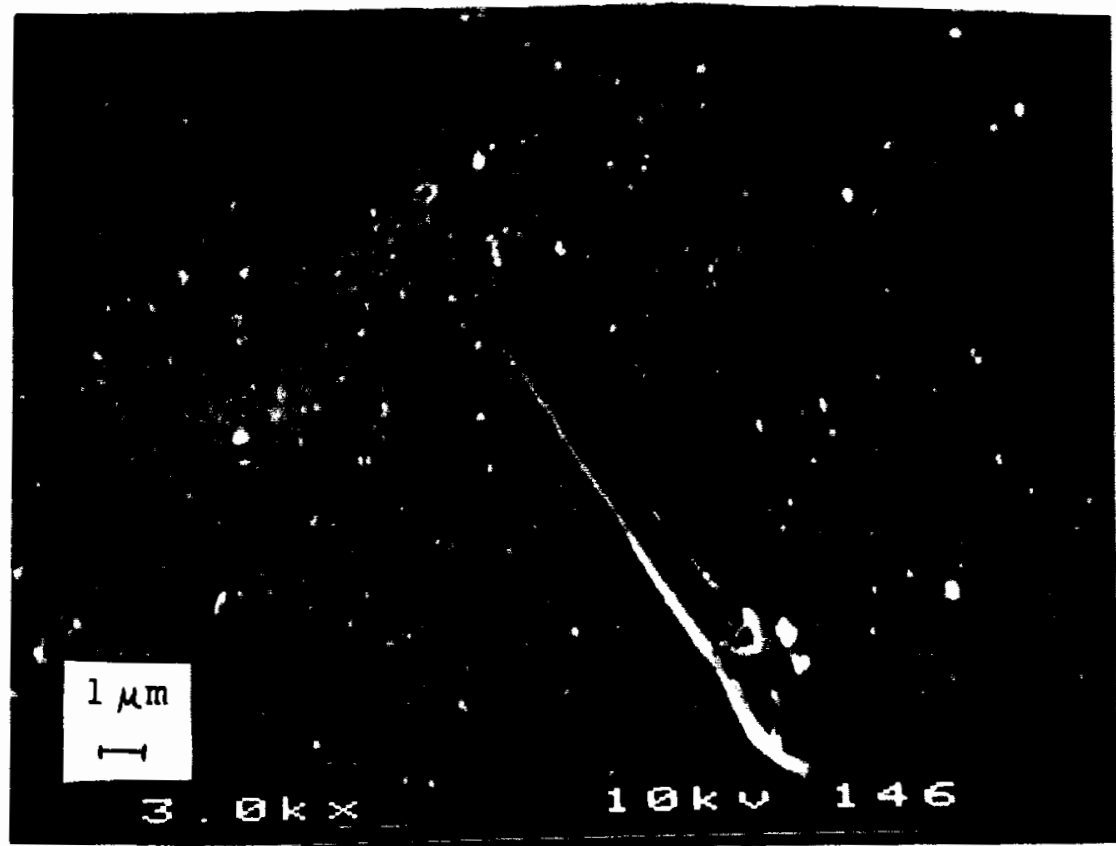

Figure 26. Iron exposed to hydrogen and argon. SEM photograph here is taken at a magnification of 3000x, showing unusual scar-like feature. EDS analysis has been created for this area (photograph \#12).

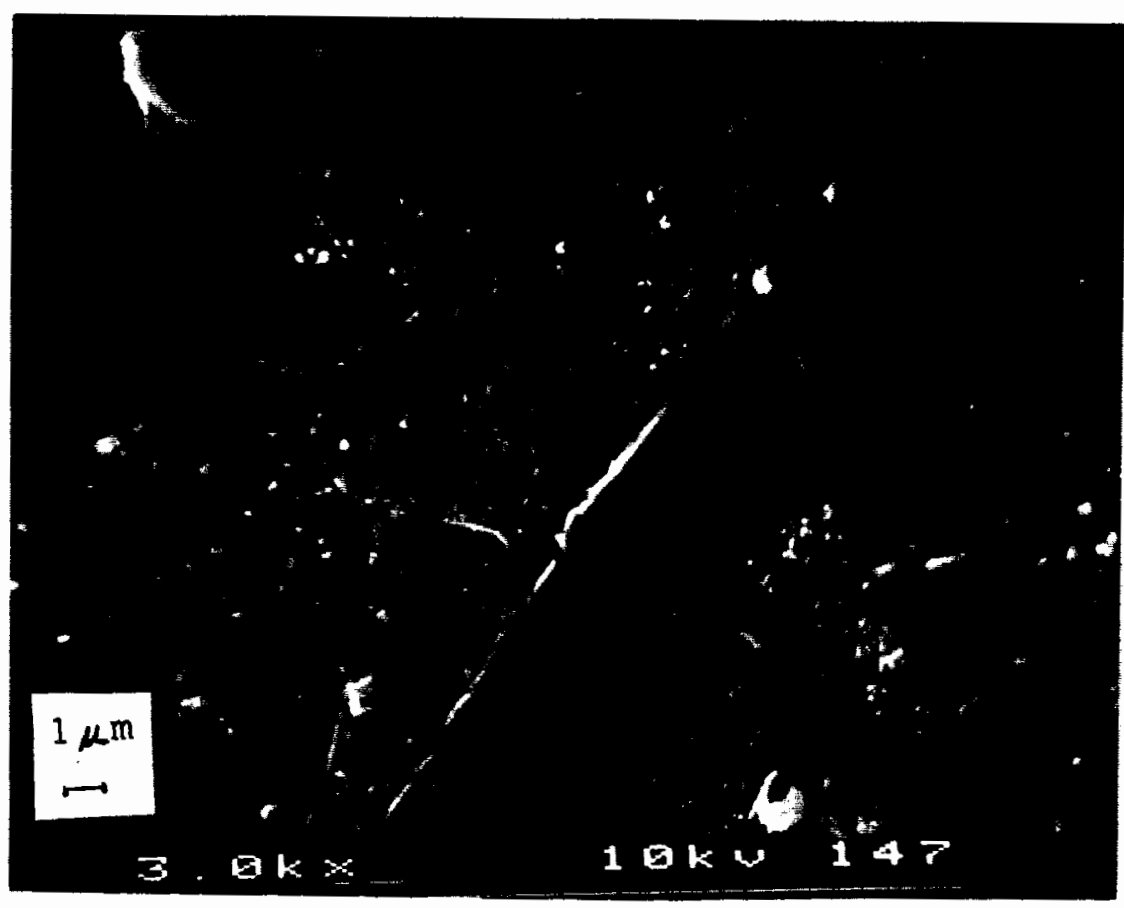

Figure 27. Iron exposed to hydrogen and argon. Unusual mark exists in this photograph also, taken at 3000X using the SEM (photograph \#13). 


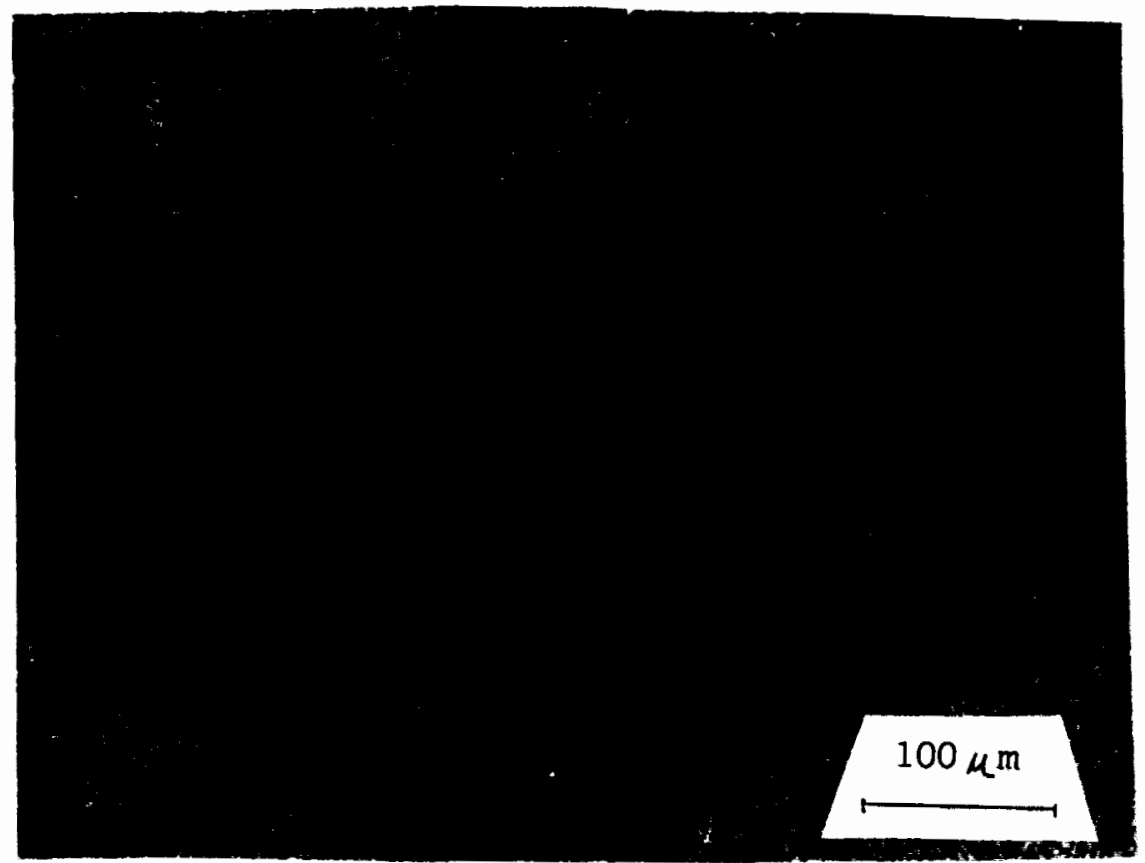

Figure 28. Iron expose to argon alone. This photograph was taken from side one of this sample, which shows crystal boundaries. This is a metallurgical microscope display, magnified 190X (photograph \#14).

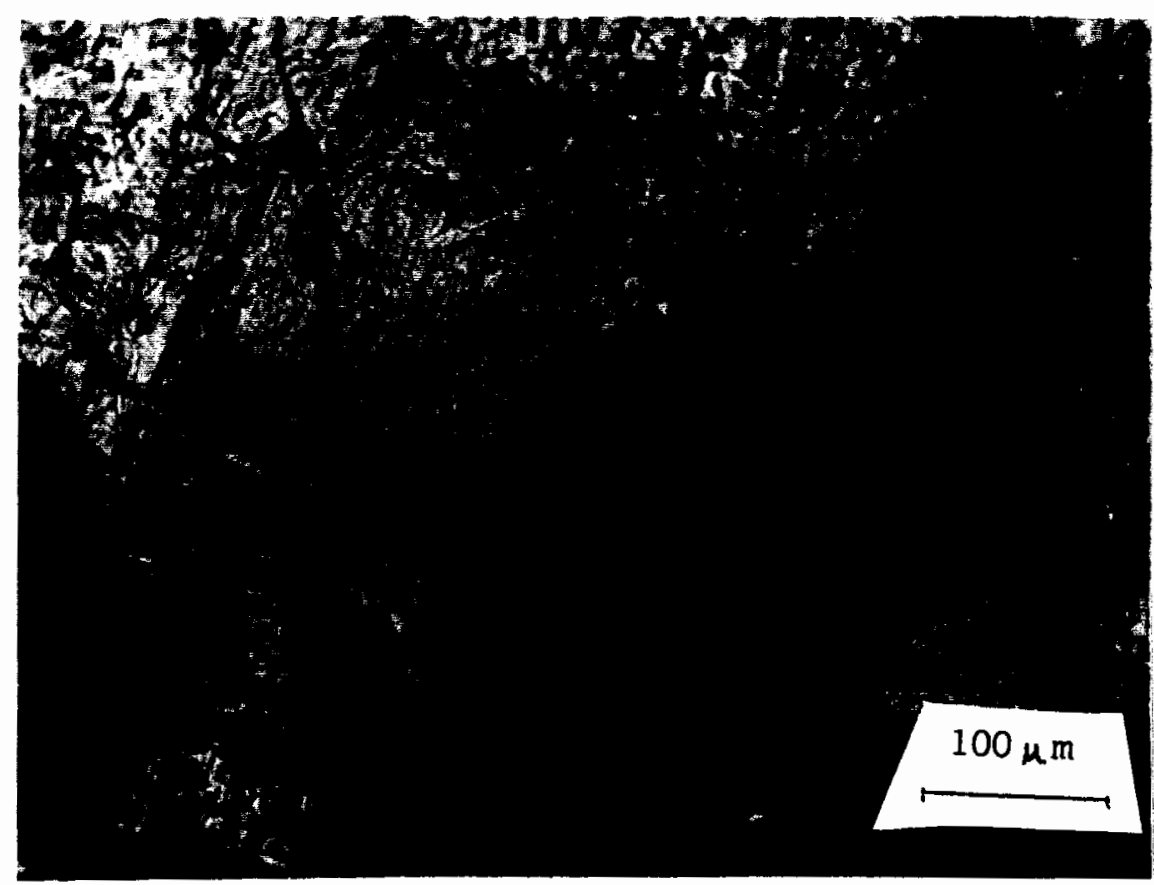

Figure 29. Iron exposed to argon alone. This metallurgical microscope photograph represents the reverse side of photograph \#14, but at the same location. Crystal boundaries mirror each other for both displays (photograph \#15). 


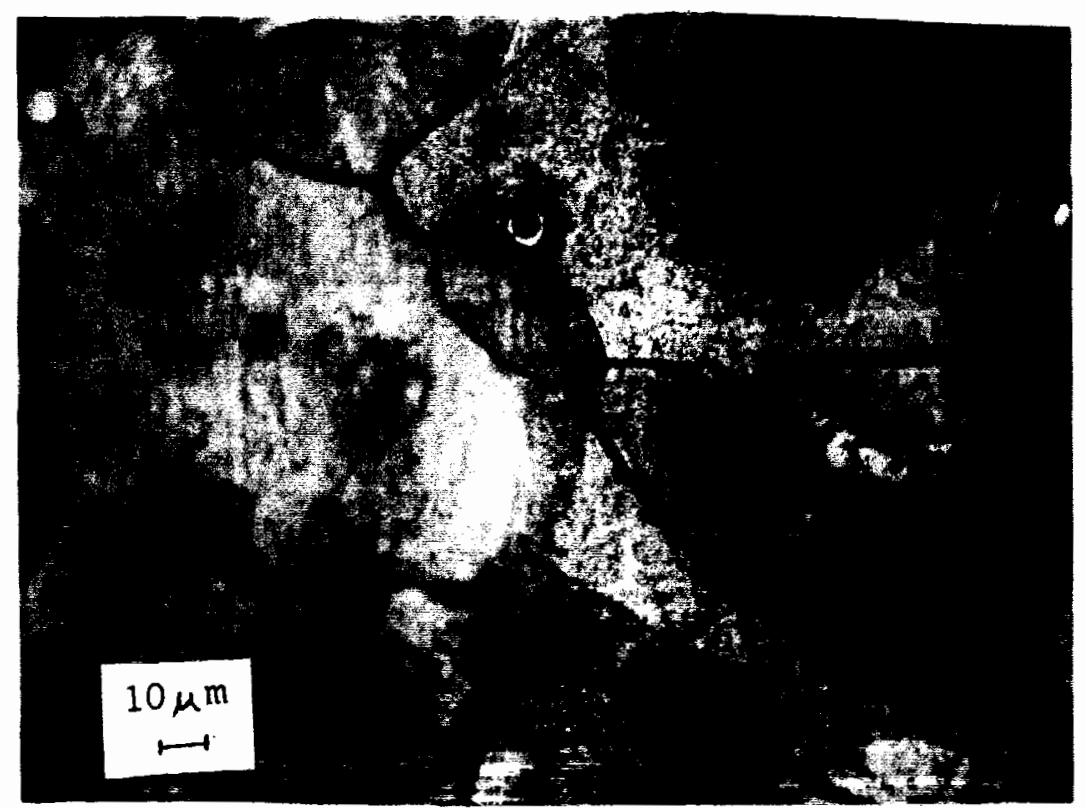

Figure 30. Iron exposed to argon alone. This is a metallurgical microscope photograph, magnified 460X. The crystal boundaries are clearly visible here (photograph \#16).

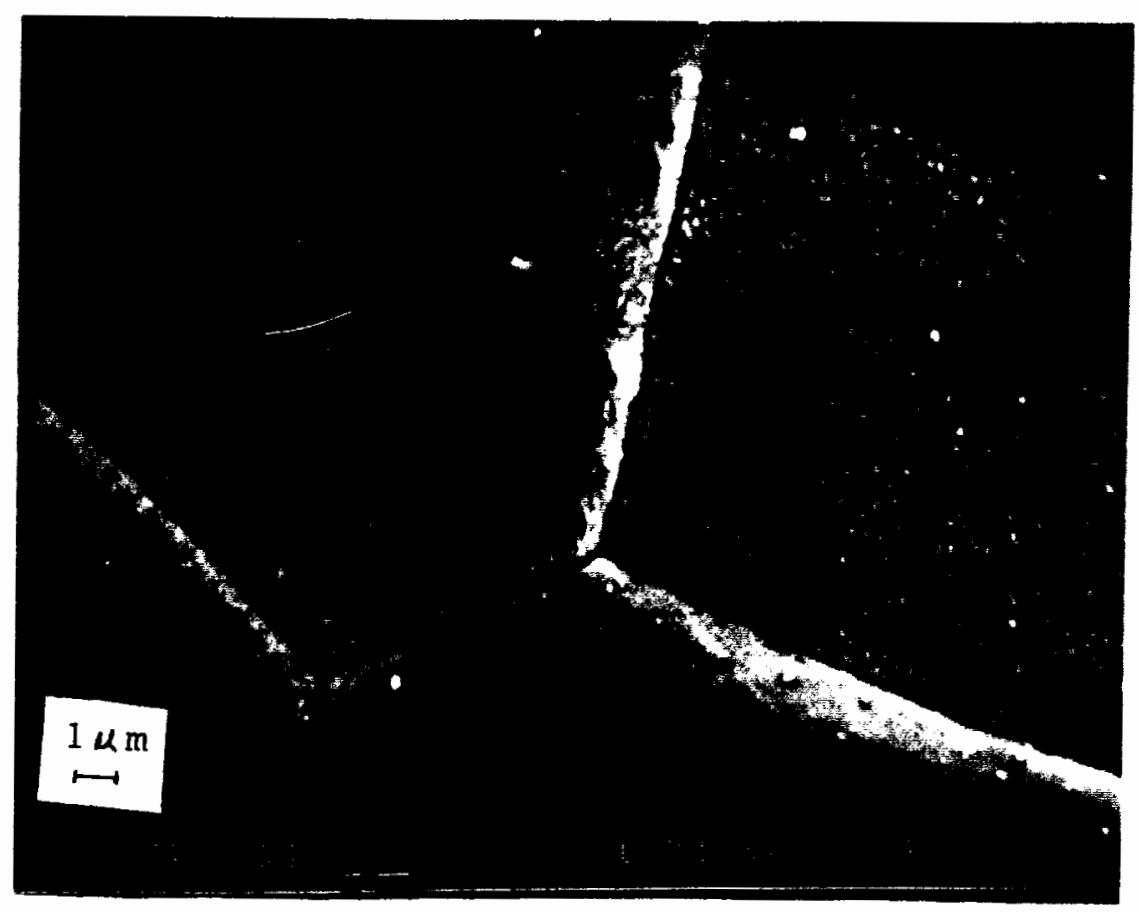

Figure 31. Iron exposed to argon alone. The SEM photograph here shows crystal boundaries magnified 3000X (photograph \#17). 
sample exposed to argon alone, using the SEM and magnified 3000X. Here boundary 1 ines meet at nearly 120 degrees. The parallel, 'brush-like' lines seen in metallurgical or SEM photographs for the iron foil unexposed to gases, but not seen here in this photograph, indicate the direction of cold-rolling. These 'brush-like lines apparantly disappear when the foil is subjected to ballistic compression, with the gases inside the compressor reaching above $2000^{\circ} \mathrm{C}$ - beyond the melting point of iron.

Although line features, such as those seen ir. Figures 20 and 21 , have not been found for the samples that were not exposed to a hydrogen gas concentration, such lines may not be necessarily the result of the presence of hydrogen gas within the ballistic compressor. These lines tens to be parallel in certain directions, and might suggest the presence of slip-bands, though the author of this report is in doubt. Compositional analysis made from the EDS show the iron foil that was exposed to both hydrogen and argon gases to have undergone change due to the presence of hydirogen. Energy spectra are provided for each iron foil sample, and differences lie below $1.28 \mathrm{keV}$. These differences involve the elements oxygen, carbon, and iron.

Figure 32 shows the full energy spectrum for the unexposed iron sample. Figure 33 concentrates on the oxygen, carbon, and Fei peaks for the whole area of Figure 15. The oxygen peak is the greatest, and a carbon peak is barely visible, registering only about 12 counts. The spectrum from another area on the same iron sample is given in Figure 34. The oxygen peak is nearly twice as high as the Fel peak, and the carbon peak, again, just barely registers, reaching only about 16 counts. 


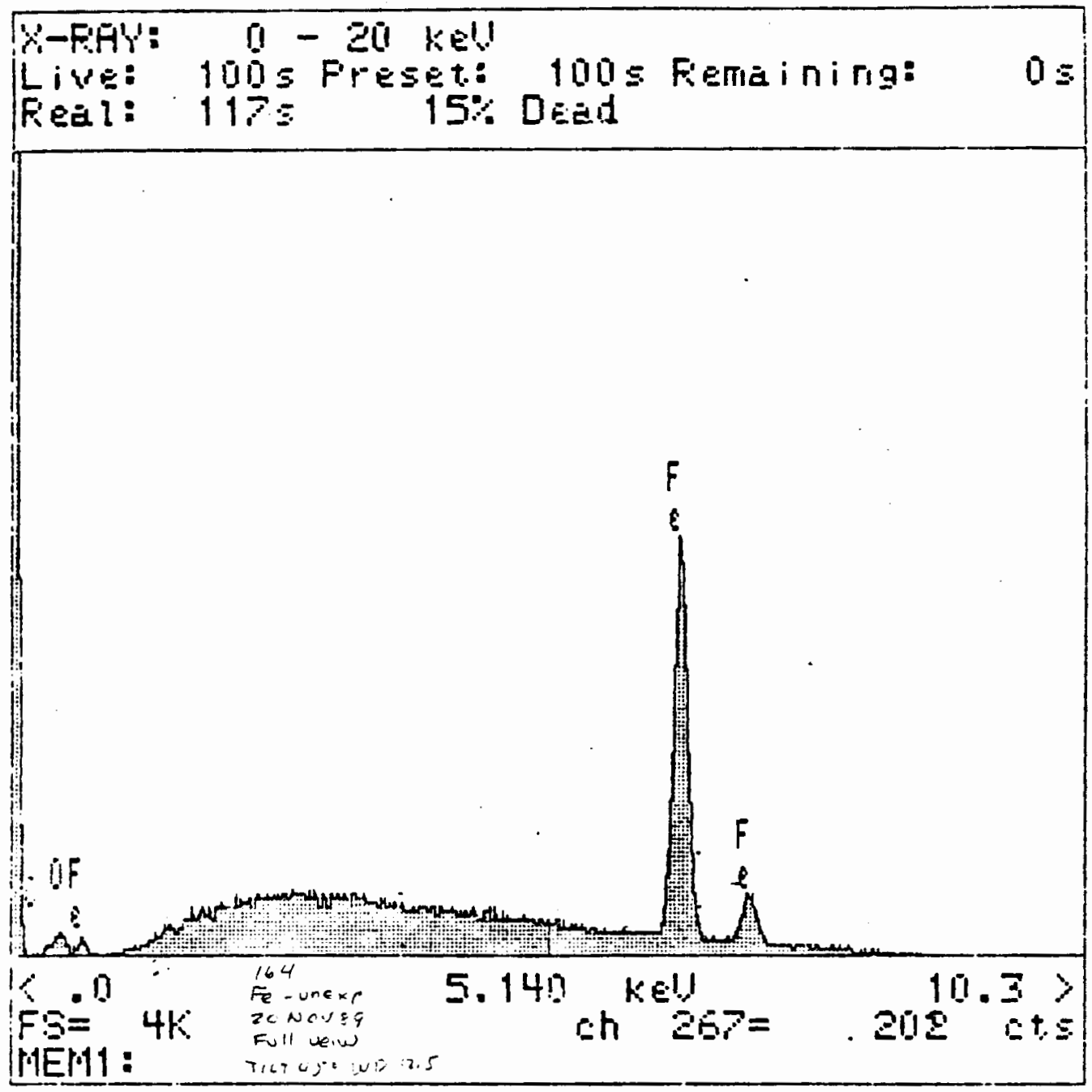

Figure 32. Spectrum of iron unexposed. Spectrum is for photograph \#4 (full view). Full scale is 4000 counts. The full spectrum is shown above. The oxygen intensity peak is greater than that of Fel while the carbon intensity peak barely exists.

Spectrum: FeKa FeK Intensity: $\begin{array}{lllll}1970 & 239 & 103 & 128 & 12\end{array}$ 
and argon gases. Figure 35 is an analysis of the bright center line of Figure 25, and Figure 35 analyzes the background portion for the same photograph (an arrow on each photograph indicates the spot for which compositional analysis was taken). These spectra consists of Fel peaks that tower over the oxygen peaks by nearly two times. The carbon peak is much more dominant for this sample than it was for the unexposed iron, rising almost as high as the oxygen peak. Other areas of this sample show the same effect. Figures 37 and 38 are of areas seen in Figure 26, one illustrating the dark line towards the bottom, and the other of the background portion. Figure 39 is made for another dark line, seen in Figure 27, which gives approximately the same results as the previous ones for this sample.

Figure 40 is a spectrum representing the iron sample that was exposed to argon gas alone. The whole area seen in Figure 31 is analyzed and yields an oxygen peak that rises above the FeL peak. The carbon peak is negligible here.

The iron sample exposed to hydrogen and argon gases consistently yield spectra with the FeL peaks rising above the oxygen peaks, and also with a strong carbon peak. The other two iron samples show a reversal of the heights of the FeL and the oxygen peak, accompanied by little or no carbon peak. Each of these samples have been handled by human hands at least several times throughout their life times, and such handling would have left finger or hand prints containing carbon. Carbon exists in greater proportion over the surface of the iron foil exposed to hydrogen and argon than it does for the other two iron foils. Apparently this sample retains the carbon better than the other two. This suggests that it may be an iron carbon alloy. Figure 41 summarizes the characteristic 


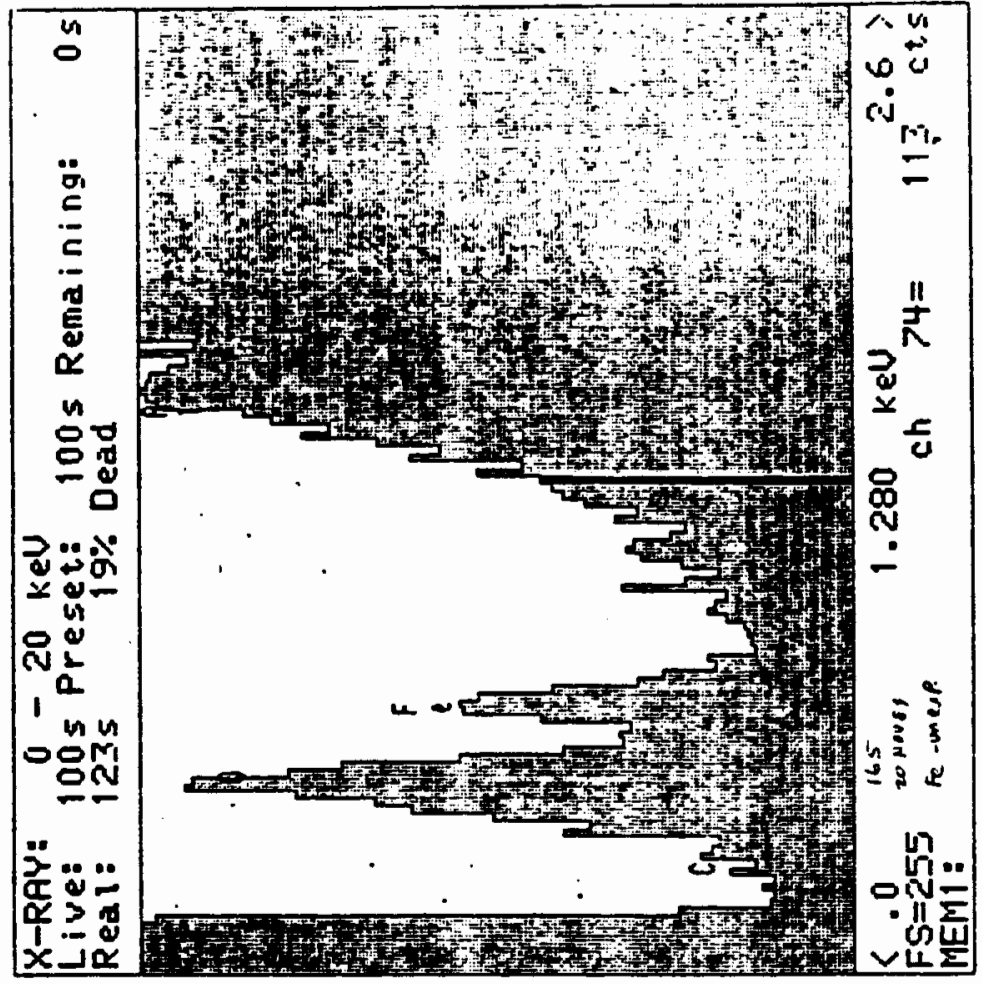

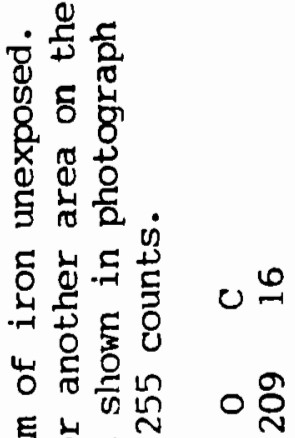

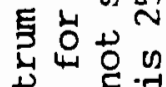

包过

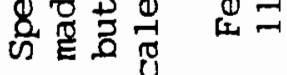

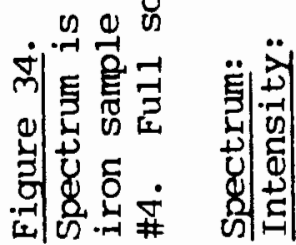

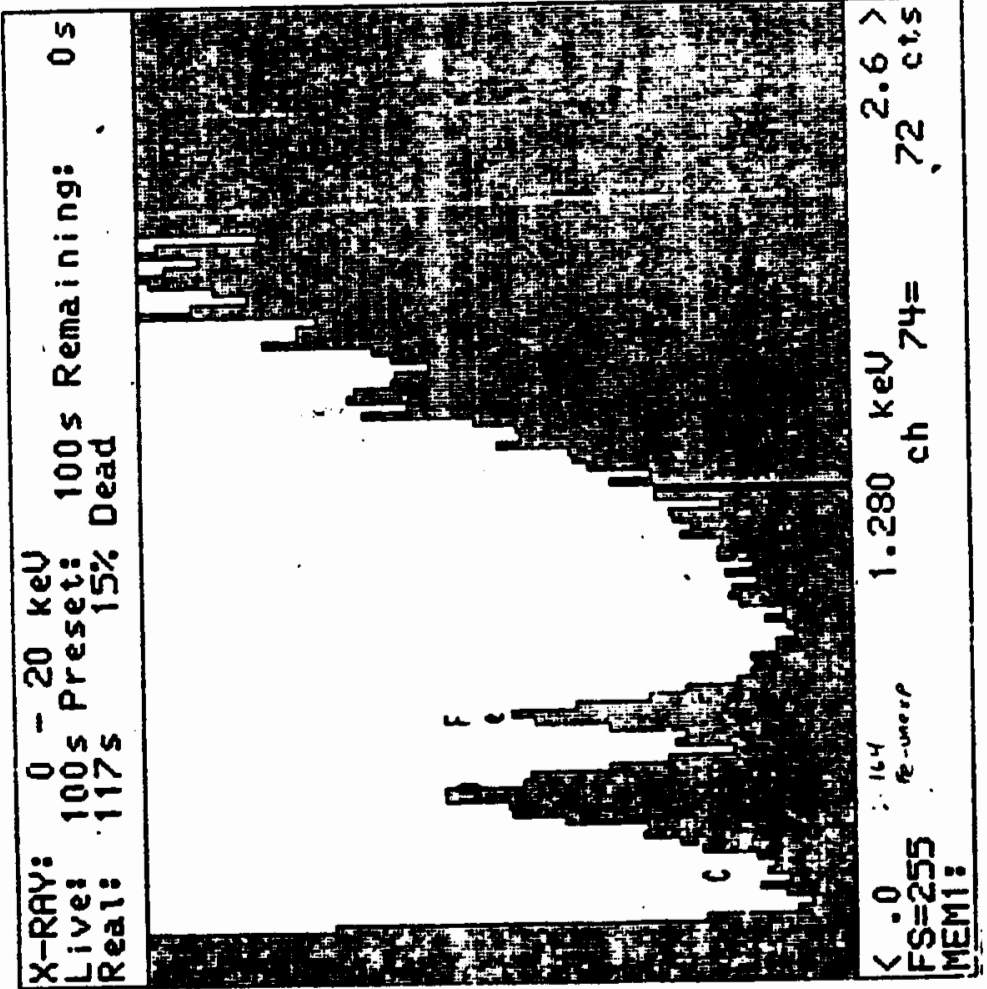

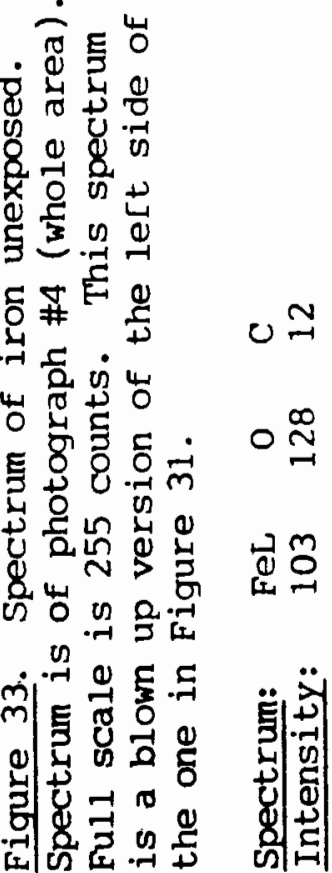




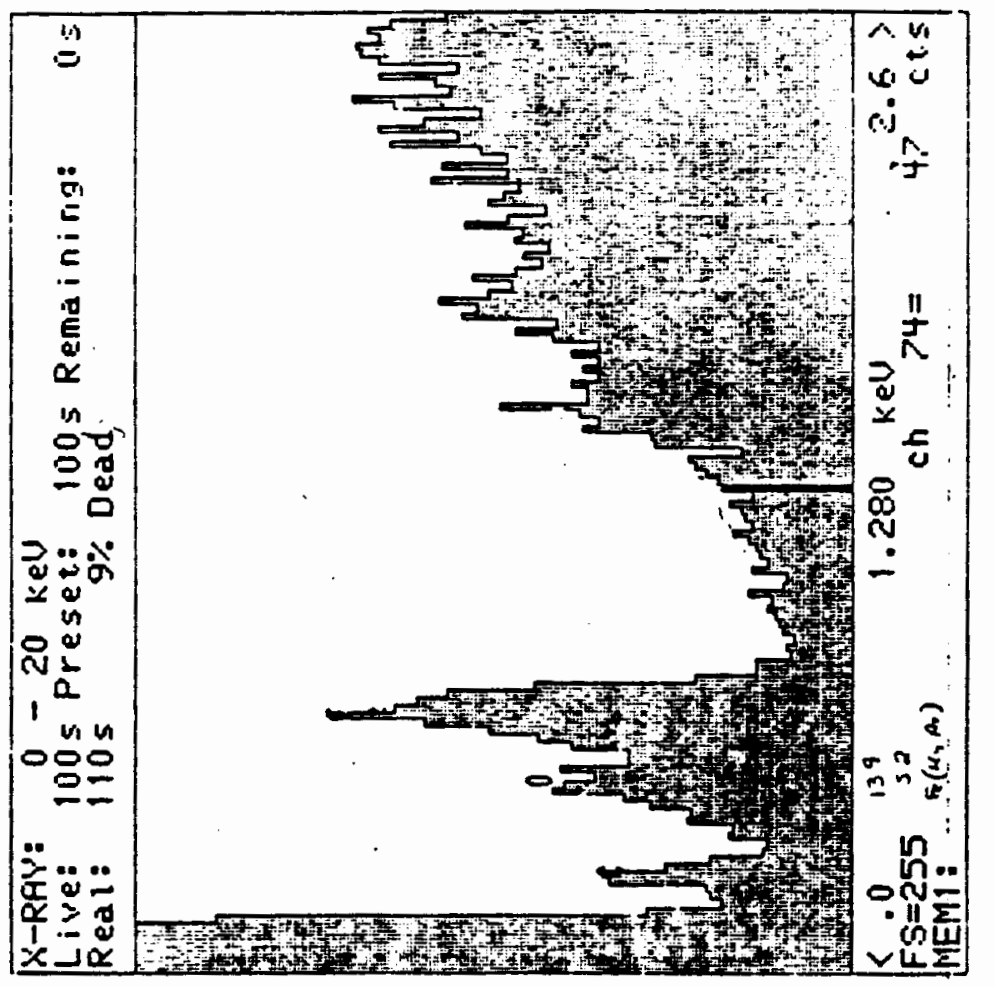

웅

跑吕

究

๘ 8

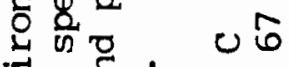

$\rightarrow$ 开

岁它岂苛

동 8

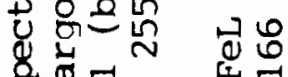

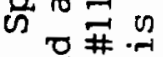

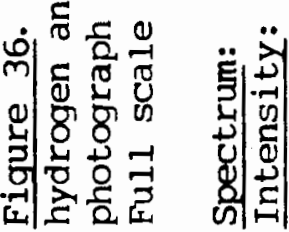

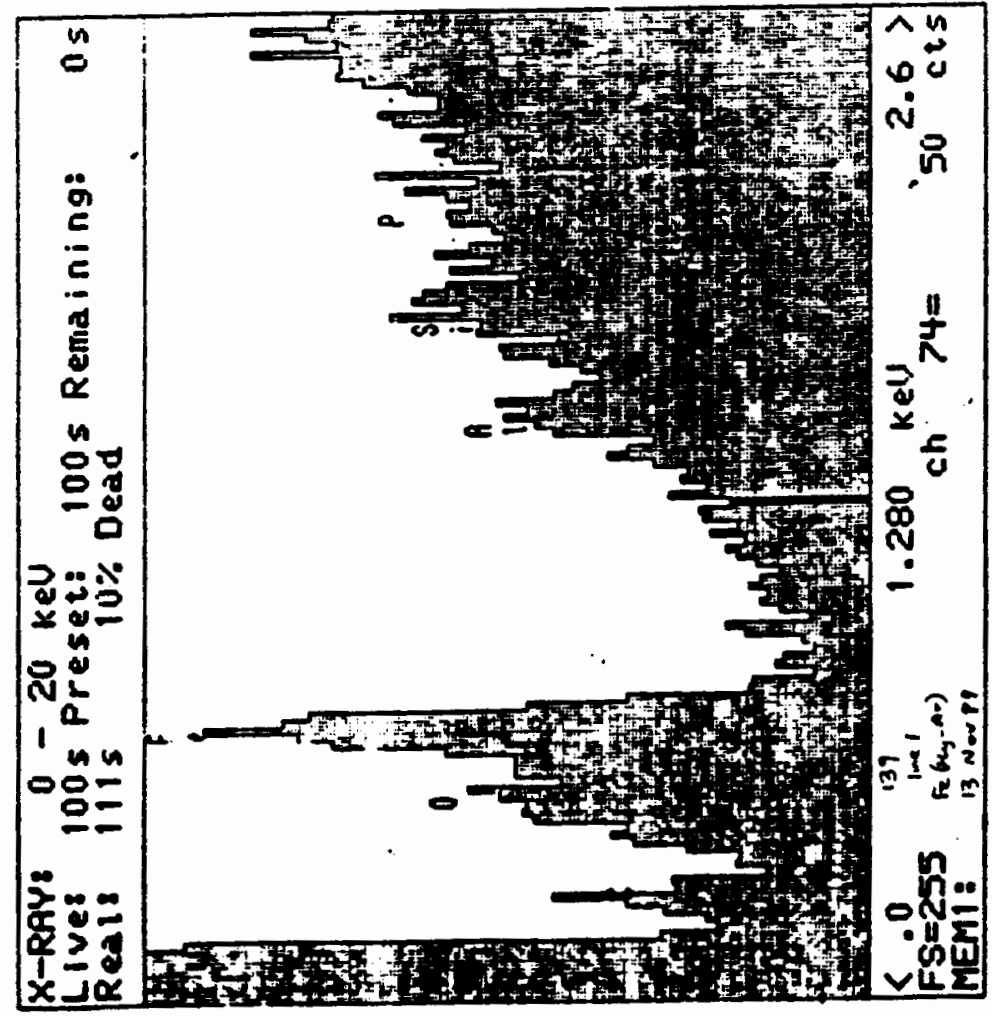

엉응 的

을

州娄

8 워

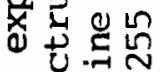

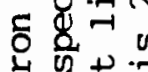

ने चैं

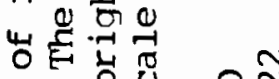

E 0 U $0 \underset{-}{N}$

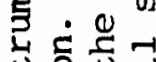

号宫

泡可

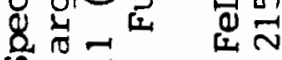

ज \#.

.

ตी| 过

․

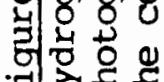

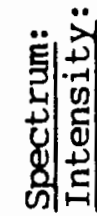




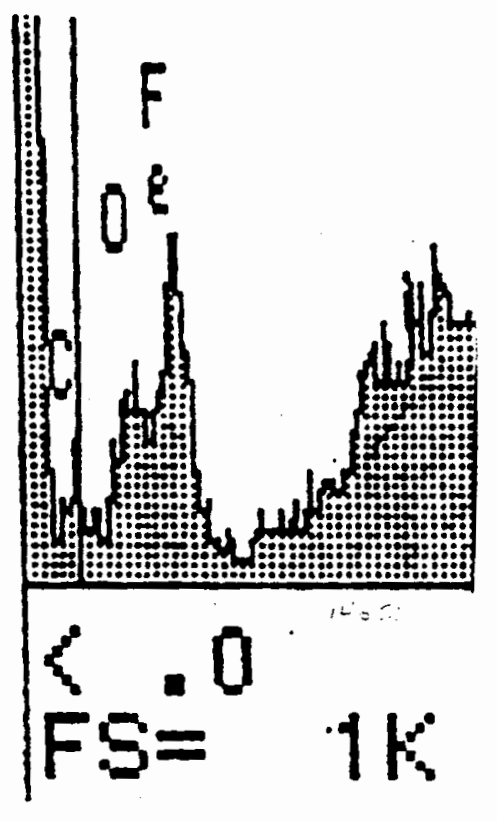

Figure 37. Spectrum of iron exposed to hydrogen and argon. Taken for photograph \#12, dark line at bottom center.

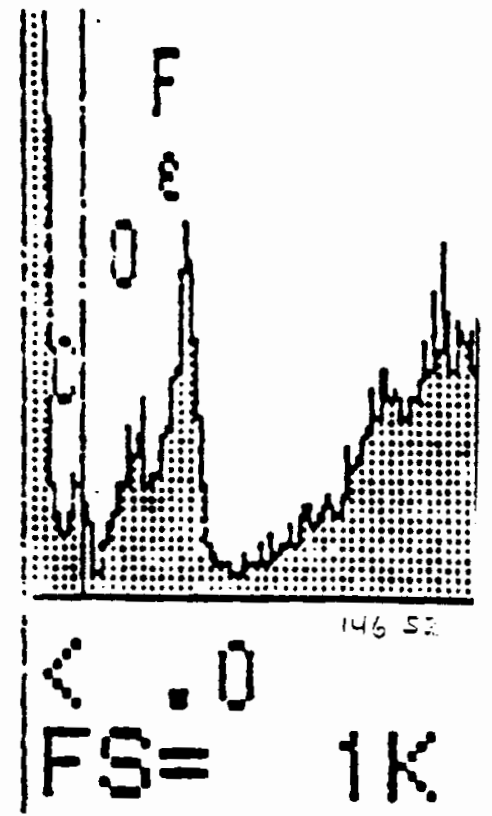

Figure 38 . Spectrum of iron exposed to hydrogen and argon. Taken for photograph \#12, background.

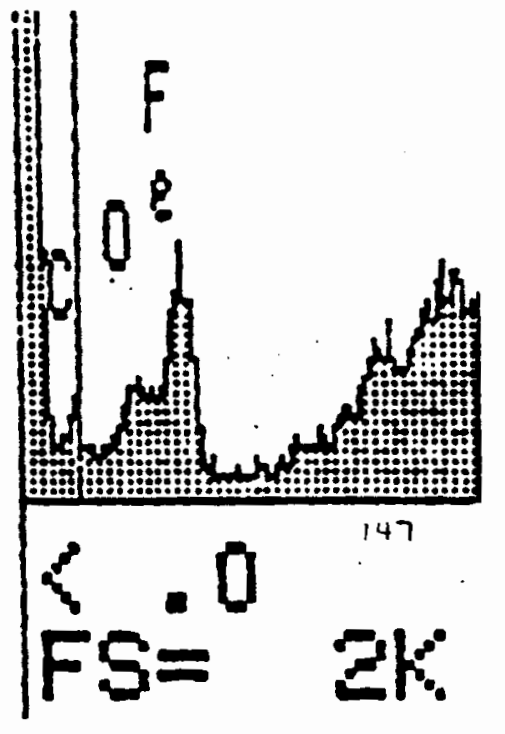

Figure 39. Spectrum of iron exposed to hydrogen and argon. Taken for photograph \#13, dark line towards the center.
For Figure 37 :

$\begin{array}{llll}\text { Spectrum: } & \text { FeL } & 0 & \text { C } \\ \text { Intensity: } & 172 & 84 & 67\end{array}$

For Figure 38 :

$\begin{array}{llll}\text { Spectrum: } & \text { FeL } & 0 & C \\ \text { Intensity: } & 175 & 86 & 49\end{array}$

For Figure 39 :

Spectrum: FeL $0 \quad C$ Intensity: $201 \quad 10490$ 


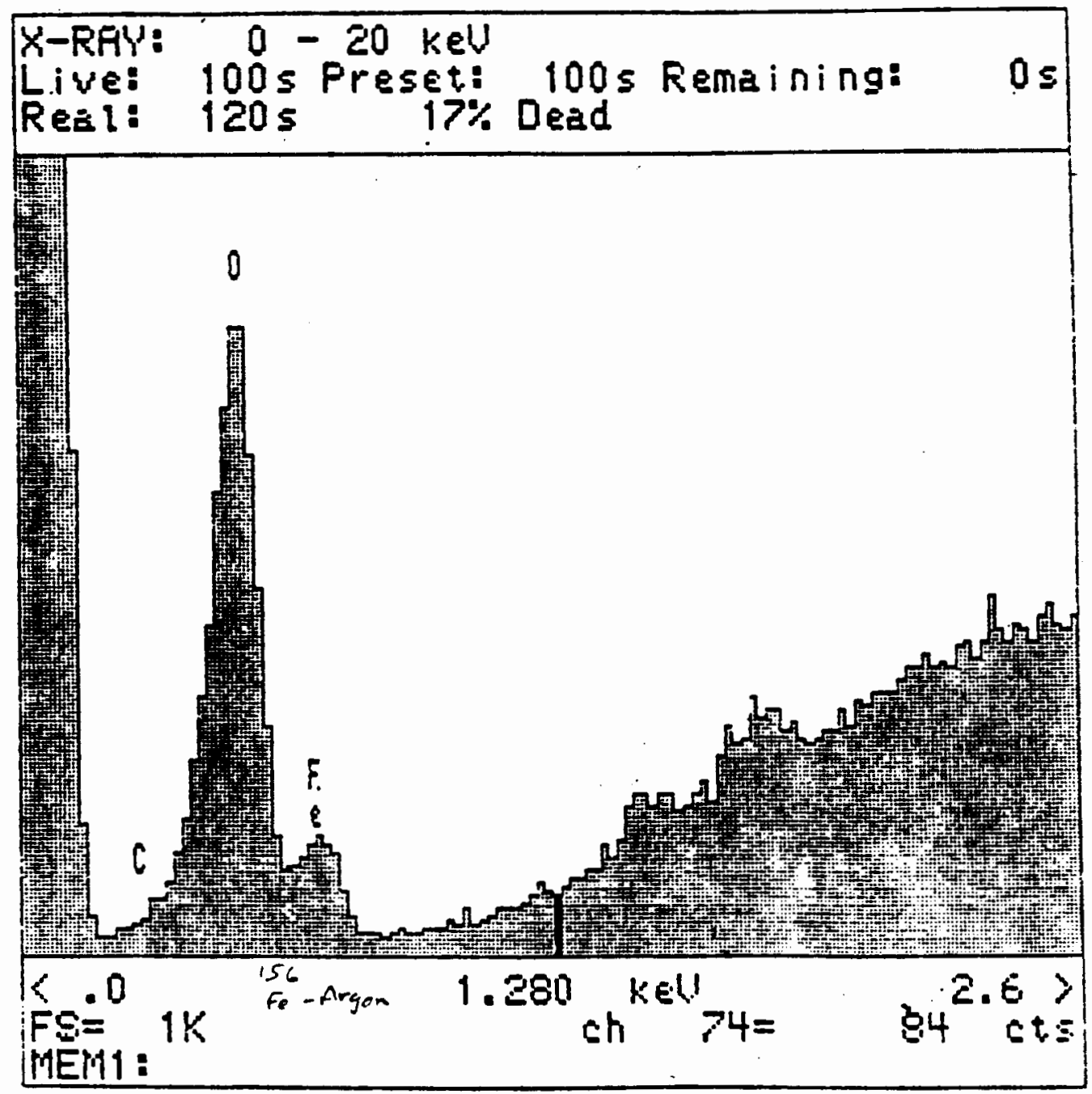

Figure 40. Spectrum of iron exposed to argon alone. Spectrum is for photograph \#17 (whole area). Full scale is 1000 counts. The oxygen intensity peak is nearly six times that of the FeL peak. A carbon peak appears non-existent here.

Spectrum: FeL $0 \quad C$ Intensity: $\quad 1277610$ 
peak strengths for each iron sample, and it also includes the Fel to oxygen ratio for each sample area investigated. The Fel to oxygen ratios for the iron sample exposed to hydrogen and argon yield values that are approximately two to one.

\begin{tabular}{|c|c|c|c|c|c|}
\hline & FeL & Oxygen & Carbon & FeL : 0 & Fe Sample \\
\hline 1 & 103 & 128 & 12 & $0.81: 1$ & \multirow{2}{*}{$\begin{array}{c}F e \\
\text { Unexposed }\end{array}$} \\
\hline 2 & 110 & 209 & 16 & $0.53: 1$ & \\
\hline 3 & 166 & 86 & 67 & $1.93: 1$ & \multirow{5}{*}{$\begin{array}{c}\text { Fe } \\
\text { Exposed } \\
\text { to } \\
\text { Hydrogen } \\
\text { and } \\
\text { Argon } \\
\text { Gases }\end{array}$} \\
\hline 4 & 215 & 122 & 91 & $1.76: 1$ & \\
\hline 5 & 172 & 84 & 67 & $2.05: 1$ & \\
\hline 6 & 175 & 86 & 49 & $2.04: 1$ & \\
\hline 7 & 201 & 104 & 90 & $1.93: 1$ & \\
\hline 8 & 127 & 761 & 0 & $0.17: 1$ & $\begin{array}{c}\mathrm{Fe}- \\
\text { Argon Gas }\end{array}$ \\
\hline
\end{tabular}

Figure 41. Characteristic peak counts. The characterpeaks for each iron sample are listed here for comparison. The Fel to oxygen ratios are included. The ratio is greater than one for the iron foil exposed to hydrogen and argon, while the other two foils yield a ratio of less than one. The carbon peak is nearly the same height as the oxygen peak for each area on the iron foil exposed to hydrogen and argon, while the other two foils have small or negligible carbon peaks. 


\section{CONCLUSION}

The physical nature of the iron foil exposed to hot, dense hydrogen and argon gases suggests that its structural and compositional properties have been altered due to the presence of hydrogen as a component of the gaseous mixture in the ballistic compressor. Visual inspection of this sample, when compared to the iron foil unexposed to gases at high pressures and temperatures, appears to contain a 'milk-like' luster to the naked eye. It seems to be less resilient, and softer, than the pure unexposed iron piece, and it is more easily penetrated by a needle than the latter. These affects are also noticeable when this sample is compared to the iron foil sample that had been exposed to argon alone in the ballistic compressor.

A shift in the position of the characteristic peaks for the 200 plane by one full degree, as demonstrated on the $\mathrm{x}$-ray powder diffractometer charts, suggests that the iron sample exposed to both the hydrogen and argon mixture is structurally different from that exposed to the argon gas alone. The unusual triple peak for the 310 plane in the hydrogen and argon sample is not seen for any other plane of the other two samples.

The metallurgical microscope and the scanning electron microscope were able to display unusual line features that contain segments connected at sharp angles to one another. This is seen only for the hydrogen and argon sample. One area, in particular, shows a serrated line shaped feature, while another yields straight lines with curvature on their ends. These lines appear to represent surface upheaval, and might possibly 
be the result of volume expansion of the iron sample itself. This volume expansion could be caused by the penetration of hydrogen gas within the iron structure, causing stress that might affect its lattice arrangement.

This report has shown that surface detail, such as depressions and reliefs, are identically composed on each side of the two samples that had undergone ballistic compression. The allotropic phase of iron that may be responsible for this is the bcc phase which forms from fcc on cooling to room temperature.

The energy dispersive $x$-ray spectrometer, which is linked to the scanning electron microscope, shows that the Fel to oxygen peak ratio for each energy spectrum chart is greater than one when the hydrogen and argon sample is analyzed, but it shows that this ratio is less than one when the other two samples are examined. Also a distinct carbon peak exists for the former sample.

The results yielded from the machines used for this report indicate that a 'change' apparently occurred for pure iron when compressed with a hot, dense mixture of hydrogen and argon gas, and this change seems to indicate that the hydrogen gas had somehow interacted with the iron structure. 


\section{SELECTED BIBLIOGRAPHY}

1. Reilly J.J. and Sandrock, Gary D. 1980. "Hydrogen Storage in Metal Hydrides," Scientific American, February 1980, 118.

2. Takeo, M., J. Dash, A.M. Kasaaian, A. Trzynka, and W.A. Lanford, "Formation of iron hydride in iron foil exposed to a hot, dense gas mixture of argon and hydrogen," Unpublished research, Portland State University.

3. V.E. Antonov, I.T. Belash,V.F. Degtyareva, E.G. Ponyatovskii, and V.I. Shiryaev 1980. 'Sov. Physics Dok1. 25, 490.

4. Schreyer, G. French, G.K. Wolf, and F.E. Wagner 1983. "Mossbauer Study of Iron Hydride Formation by Low Temperature Ion Implantation," Solid State Conmunications, 46, 647.

5. Mellor, J.W. 1953. A Comprehensive Treatise on Inorganic and Theoretical Chemistry, Vol. XII pp.775-778, 880-881.

6. A.J. Kurnick, H.H. Johnson 1974. Met. Trans. $\underline{5}, 1199$.

7. DaSilva, J.R.G. and S.W. Stafford and Rex B. McLellan 1976. "The Thermodynamics of the Hydrogen-Iron System," Journal of the Less Cormon Metals, 49,407

8. M. Takeo, Quentin A. Holmes, and Shang Yi Ch'en 1967. "Thermodynamic Conditions of the Test Gas in a Ballistic Compressor," Reprinted from Journal of Applied Physics, 38, 3544.

9. Tegart, W.J.MoG. 1959. "The Electrolytic and Chemical Polishing of Metals," Pergamon Press Inc. 96.

10. Azaroff, Leonid V. 1968. "Elements of X-Ray Crystallography," McGraw-Hill Book Company, p. 365-388.

11. Andrews, K.W. and D,J, Dyson and S.R. Keown 1971. "Interpretation of Electron Diffraction Patterns," Plenum Press, pp. 148-157.

12. Hu, Hsun 1985. "Recovery, Recrystallization, and Grain-Growth Structures," Metallography and Microstructures, V9, 692-699.

13. Cullity, B.D. 1967. "Elements of X-Ray Diffraction," Addison Wesley, pp. 96-103, 263-269. 
14. Durrant, P.J. and B. Durrant 1970. "Introduction to Advanced Inorganic Chemistry," Longman Group LTD p. 1061-1064.

15. Swanson, Howard E., Ruth K. Fuyat, and George M. Ugrinic 1959. "Standard X-ray Diffraction Powder Patterns'" NBS Circular 539, Vol. IV, 3.

16. Mellor, J.W. 1953. A Comprehensive Treatise on Inorganic and Theoretical Chemistry, Vol. XII p. 895-897.

17. Dash, J. and H.M. Otte 1962. "Thin Film Transmission Observations of a Thermal Transformation in Stainless Steel," Fifth International Congress for Electron Microscopy, $\mathrm{HH}-4$. 
APPENDIX A

ELECTRON DIFFRACTION 
APPENDIX A

ELECTRON DIFFRACTION

The atomic structure of a crystalline material consists of an orderly, periodically repeated pattern of unit cells, whereas, the amorphous material is made of atoms or molecules oriented in random positions with respect to one another. The transmission electron microscope distinguishes this difference in material structure by the scattering of its electron beam as it penetrates a specimen under investigation. Identification of various materials is possible for the orderly atomic arrangements, which cause the electron beam to scatter in well defined directions. Crystal structures and the positive identification of minerals are implemented by this orderly reflection of the electron beam.

Reflections are reinforced by successive atomic planes lying parallel to tone another in a crystal lattice as radiation, such as $\mathrm{x}$-rays or electrons, penetrates the structure under investigation. Bragg had shown this using his equation, $2 d \sin \theta=n \lambda$, where ' $d$ ' is the plane spacing. Both $x$-rays and electron waves apply to Bragg's equation.

When a beam of radiation reflects off an array of atoms lying in successive planes, and $2 d \sin \theta=n \lambda$ is satisfied, then the diffracted beam is actually deviated by an angle $2 \theta$ from the incident beam, and the diffraction spot will occur at some distance, $r$, from the undeviated path of the radiation, depending on how far the radiation travels 
before it is 'stopped' by a target, such as a photographic film. If we call the distance between our atomic planes and the target at which the radiation is stopped, ' 1 ', then the following relationship is constructed in Figure 42.

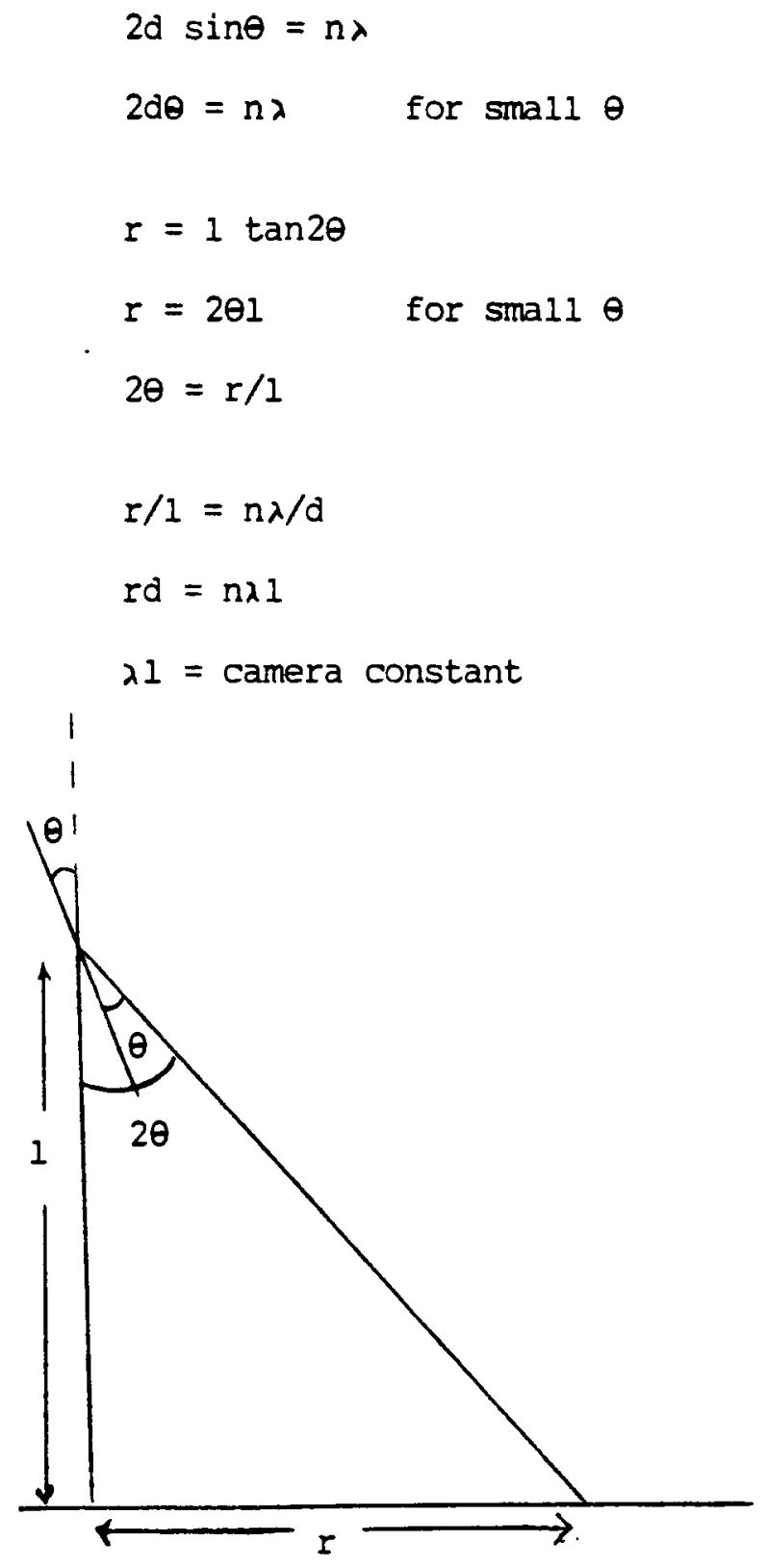

Figure 42. Scattered beam from atomic planes to target. 
APPENDIX B

THIN IRON FILM SAMPLE FRAMES 
APPENDIX B

\section{THIN IRON FILM SAMPLE FRAMES}

1) Prepare milling fixture

a) from aluminum plate, 1/8" thick, grade 2024, cut and mill 2 pieces, $1.200 "$ by $2.000^{\prime \prime}$.
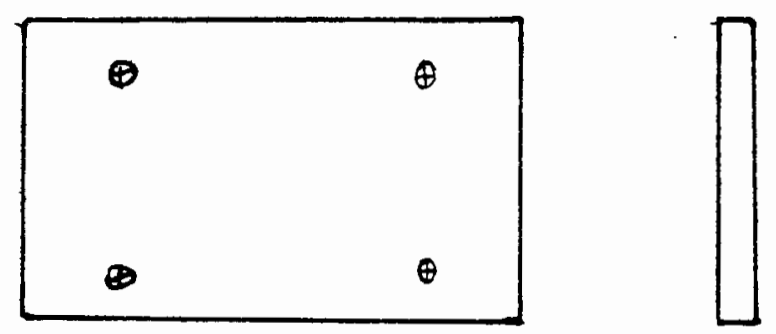

b) Drill \#34 (4) holes, as indicated, on upper plate and tap \#4-40 on lower plate.

\#34 drill through 4 places on upper plate.

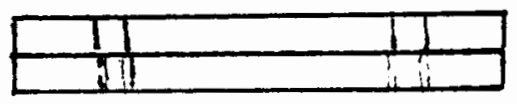

\#4-40 tap 4 places on lower plate.

c) Mill window on upper plate. Mill pocket 0.700 by 0.950 and 0.048 deep on lower plate.

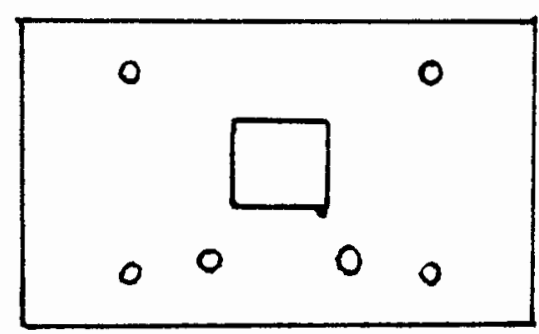

upper plate

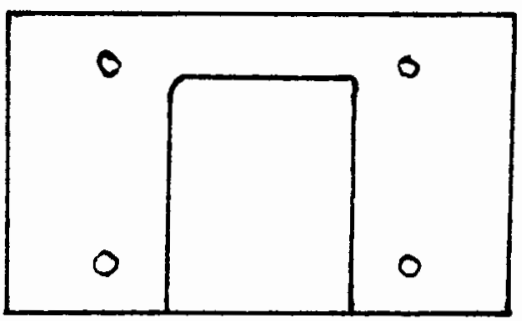

lower plate

* Bevel window on upper plate if so desired (outer edge)

d) Milling fixture now ready for milling windows in frames. Use 4 \#-40 socket head screws, 1/4 long.

Sample Frames: $1 \mathrm{~cm}^{2}, 0.005^{\prime \prime}$ stainless steel sheet metal, grade 304 
2) Prepare shimstock: $0.005^{\prime \prime}$ thick stainless steel

a) Cut rectangular pieces on a shear, 0.700 by 0.950

* For this fixture, need 10 pieces, since pocket is 0.048 deep. $0.00510=0.05$, leaves $0.003^{\prime \prime}$ for clamping.

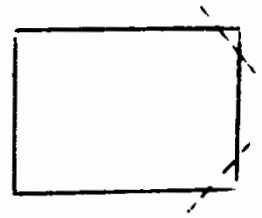

Trim corners.

b) Stack all 10 pieces and clamp (sandwich) them with the 4 screws.

C) Mill window with a sharp 1/8" diameter endmill, and drill with $1 / 8$ drill, 2 places as shown.

d) With snips or appropriate scissors, trim each piece as shown.
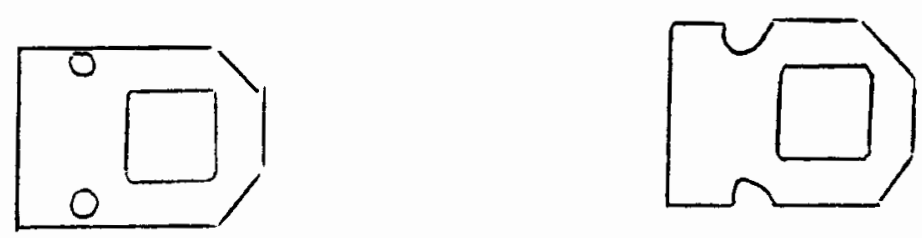

e) Now each piece is ready for bending the "frame edge" on it. Edge should be formed along dotted lines.

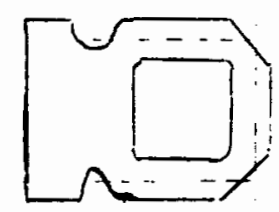

* A small aluminum block can be used for this purpose.

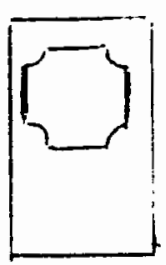

raised

section

to locate

window

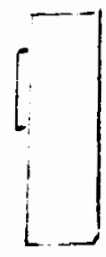

section

raised

by 0.004

The design and construction of these frames are by Garo Arakelyan; Physics Department, Portland State University. 